Soto, C. J., Napolitano, C. M., Sewell, M. N., Yoon, H. J., \& Roberts, B. W. (2022). An integrative framework for conceptualizing and assessing social, emotional, and behavioral skills: The BESSI. Journal of Personality and Social Psychology, 123, 192-222.

\title{
An Integrative Framework for Conceptualizing and Assessing Social, Emotional, and Behavioral Skills: The BESSI
}

Christopher J. Soto, ${ }^{1}$ Christopher M. Napolitano, ${ }^{2,3}$ Madison N. Sewell, ${ }^{2}$ Hee J. Yoon, ${ }^{4}$ and Brent W. Roberts ${ }^{4,5}$

\author{
${ }^{1}$ Department of Psychology, Colby College \\ ${ }^{2}$ Department of Educational Psychology, University of Illinois at Urbana-Champaign \\ ${ }^{3}$ Department of Psychology, University of Zurich \\ ${ }^{4}$ Department of Psychology, University of Illinois at Urbana-Champaign \\ ${ }^{5}$ Hector Research Institute of Education Sciences and Psychology, Tübingen University
}

\begin{abstract}
Author Note
Christopher J. Soto and Christopher M. Napolitano are co-first authors. The co-first authors and fifth author hold the copyright for the Behavioral, Emotional, and Social Skills Inventory (BESSI), which was used in the present research. Data collection for the high school student sample was supported by Character Lab, and facilitated through the Character Lab Research Network, a consortium of schools across the country working collaboratively with scientists to advance scientific insights that help kids thrive. Additional data collection was supported by faculty research grants from Colby College and the University of Illinois at Urbana-Champaign. Supporting materials for this article are available at https://osf.io/4zgyr/

Correspondence concerning this article should be addressed to Christopher J. Soto, Department of Psychology, Colby College, 5550 Mayflower Hill, Waterville, ME 04901. Email: christopher.soto@colby.edu
\end{abstract}




\begin{abstract}
People differ in their social, emotional, and behavioral (SEB) skills: their capacities to maintain social relationships, regulate emotions, and manage goal- and learning-directed behaviors. In five studies using data from seven independent samples $(N=6,309)$, we address three key questions about the nature, structure, assessment, and outcomes of SEB skills. First, how can SEB skills be defined and distinguished from other kinds of psychological constructs, such as personality traits? We propose that SEB skills represent how someone is capable of thinking, feeling, and behaving when the situation calls for it, whereas traits represent how someone tends to think, feel, and behave averaged across situations. Second, how can specific SEB skills be organized within broader domains? We find that many skill facets can be organized within five major domains representing Social Engagement, Cooperation, Self-Management, Emotional Resilience, and Innovation Skills. Third, how should SEB skills be measured? We develop and validate the Behavioral, Emotional, and Social Skills Inventory (BESSI) to measure individuals' capacity to enact specific behaviors representing 32 skill facets. We then use the BESSI to investigate the nomological network of SEB skills. We show that both skill domains and facets converge in conceptually meaningful ways with socioemotional competencies, character and developmental strengths, and personality traits, and predict consequential outcomes including academic achievement and engagement, occupational interests, social relationships, and wellbeing. We believe that this work provides the most comprehensive model currently available for conceptualizing SEB skills, as well as the most psychometrically robust tool available for assessing them.
\end{abstract}

Keywords: noncognitive skills; personality traits; psychological assessment; social and emotional learning; socioemotional skills 


\section{An Integrative Framework for Conceptualizing and Assessing Social, Emotional, and Behavioral Skills: The BESSI}

Noncognitive skills, a construct that nearly everyone can agree is important but no one can agree on how to measure. (Harden, 2021)

Success in life is multicausal. No single biological, psychological, social, or historical factor fully determines a person's life outcomes. This complexity, however, has not dissuaded researchers, practitioners, and policymakers from seeking to identify factors that influence a person's chances for success in life. In recent years, scholars across a broad swath of the social and behavioral sciences have begun to investigate the nature, structure, assessment, and outcomes of positive personal qualities such as noncognitive skills, character strengths, socioemotional learning competencies, and what we term social, emotional, and behavioral (SEB) skills: people's capacities to maintain social relationships, regulate emotions, and manage goal- and learning-directed behaviors (Soto et al., 2021) ${ }^{1}$. These constructs hold promise, due to their links with positive outcomes in important life domains, as well as their potential malleability (Casillas et al., 2015; Duckworth et al., 2007; Durlak et al., 2011; Farrington et al., 2012; Kautz et al., 2014; Nagaoka et al., 2015; National Research Council, 2012; OECD, 2015).

Despite this promise, research on skills, strengths, and competencies lacks consensus, and is fragmented by disciplinary differences and a dizzying array of terms, definitions, and measures (Abrahams et al., 2019; Berg et al., 2017; Duckworth \& Yeager, 2015). We therefore propose that the understanding and application of skill-related constructs can be advanced by

\footnotetext{
${ }^{1}$ Our use of the term "social, emotional, and behavioral skills" builds on multidisciplinary work investigating positive personal qualities. The terms' social and emotional components derive from work in developmental psychology and education, while the behavioral component derives from work in social and personality psychology, as well as behavioral economics.
} 
answering three critical questions. First, how should SEB skills be defined and distinguished from other kinds of psychological constructs? Second, how can specific SEB skills be organized within broader domains? Third, how should SEB skills be measured?

The present research addresses these questions across a series of five studies. We first propose an integrative conceptual framework for defining and organizing SEB skills. Next, we investigate the hierarchical structure of SEB skills while developing a broadband measure of skill domains and facets: the Behavioral, Emotional, and Social Skills Inventory (BESSI). Finally, we examine the utility of this framework by testing the BESSI's convergence with existing measures of socioemotional competencies, character and developmental strengths, and personality traits, as well as its ability to predict consequential outcomes such as academic achievement and engagement, occupational interests, social relationships, and well-being.

\section{What Are (and Are Not) Social, Emotional, and Behavioral Skills?}

As noted above, the literature on positive personal qualities is populated by a host of competing terms: 21 st century competencies, character strengths, noncognitive skills, social and emotional learning competencies, and soft skills, among others (Abrahams et al., 2019; Berg et al., 2017). However, these different conceptualizations tend to have certain things in common. They generally refer to qualities that are beneficial to the individual and their social partners, expressed most clearly in relevant situations, distinct from measured intelligence, and relatively stable over time, but potentially responsive to intervention (Duckworth \& Yeager, 2015). These commonalities provide a starting point for defining SEB skills, but they encompass an extremely broad conceptual space that includes skills, beliefs, attitudes, values, and personality traits. Such a broad, unwieldy space may conceal meaningful differences between related but distinguishable kinds of constructs. To further refine this space, we have defined SEB skills as people's 
capacities to maintain social relationships, regulate emotions, and manage goal- and learningdirected behaviors (Soto et al., 2021). In two key ways, this definition clarifies what SEB skills are. First, they are functional capacities: acquired abilities that can potentially be improved through training and effortful practice. Second, they include capacities related to both overt and covert forms of behavior, such as socially interacting with other people, completing tasks, setting and pursuing goals, regulating emotions, and learning from new experiences.

This definition also clarifies what SEB skills are not. They are related-but not equivalent — to personality traits. Personality traits refer to people's characteristic patterns of thinking, feeling, and behaving, or how someone tends to behave, averaged across situations (Allport, 1937; Fleeson \& Jayawickreme, 2015). In contrast, SEB skills represent functional capacities: how someone is capable of behaving, when the situation calls for it (Paulhus \& Martin, 1987; Wallace, 1966, 1967). This distinction is analogous to the difference between workers' or athletes' typical performance and maximal performance (Sackett et al., 1988). The present research applies this definition of skills as functional capacities toward investigating the structure, assessment, and outcomes of SEB skills.

\section{How Can Specific Skills Be Organized within Broader Domains? Similarities and Differences between Models of Skill-Related Constructs}

Alongside the many terms for skill-related constructs, scholars have also proposed many structural models or taxonomies designed to organize specific skill facets within overarching skill domains (Berg et al., 2017). Table 1 aligns several prominent taxonomies. These taxonomies differ in multiple ways, such as the number of domains included, as well as the domains' labels and content. However, a closer look reveals key points of convergence. One similarity is that each taxonomy includes a total of three to five domains. Second, there is 
considerable overlap between the social, emotional, and behavioral content of these domains. For example, a conceptual review by scholars in education and psychology (National Research Council, 2012) proposed three domains of 21 st century competencies: interpersonal competencies (e.g., leadership, communication), intrapersonal competencies (e.g., initiative, selfregulation), and cognitive competencies (e.g., innovation, decision making). Similarly, a partnership between researchers and educators (Park et al., 2017) developed a tripartite taxonomy of interpersonal strengths, intrapersonal strengths, and intellectual strengths.

Other models draw finer-grained distinctions by differentiating between separate types of interpersonal and intrapersonal skills. The Collaborative for Academic, Social, and Emotional Learning (CASEL, 2020) distinguishes between interpersonal skills used to maintain social relationships (relationship skills) and those used to understand people's thoughts, feelings, and perspectives (social awareness competencies). Similarly, the Five Cs model of positive youth development (Lerner et al., 2005) differentiates interpersonal skills used to establish relationships (connection skills) from those used to empathize with others (caring skills). Regarding intrapersonal skills, the CASEL framework distinguishes between those used to pursue goals (self-management competencies) and those used to understand one's attitudes, emotions, and values (self-awareness competencies). Similarly, the Five Cs taxonomy differentiates intrapersonal skills used to achieve goals in key life domains (competence skills) from those used to maintain positive attitudes and emotions (confidence skills).

\section{Using the Big Five as a Starting Point to Organize SEB Skills}

Despite the differences between these models, their key areas of overlap resemble the Big Five personality traits in terms of their social, emotional, and behavioral content (Abrahams et al., 2019; Casillas et al., 2015; Kautz et al., 2014; OECD, 2015). As shown in Table 1, many 
models include domains focused on agentic interpersonal behaviors (resembling Big Five Extraversion), communal interpersonal behaviors (resembling Agreeableness), goal-focused intrapersonal behaviors (resembling Conscientiousness), emotion-focused intrapersonal behaviors (resembling Emotional Stability vs. Neuroticism), and cognitive or intellectual behaviors oriented towards learning (resembling Openness to Experience).

There are several conceptual and practical benefits to organizing SEB skills in terms of a five-dimensional taxonomy similar to the Big Five. One benefit is breadth: the Big Five integrate a wide range of social, emotional, and behavioral characteristics. The domains of Extraversion and Agreeableness capture the key dimensions of interpersonal behavior (DeYoung et al., 2013; McCrae \& Costa, 1989), Extraversion and Emotional Stability capture the most prominent dimensions of emotional life (Diener et al., 2003), and Conscientiousness and Openness to Experience capture the behavioral traits most relevant to educational and occupational attainment (Heckman \& Kautz, 2012; Noftle \& Robins, 2007; Wilmot \& Ones, 2019).

A complementary benefit concerns depth, in the form of articulating more-specific, facetlevel constructs. Many personality psychologists have explored the structure of personality traits within each Big Five domain, thereby developing hierarchical representations of the Big Five that distinguish between many lower-level facets (e.g., Condon, 2017; McCrae \& Costa, 2010; Soto \& John, 2017; Stark et al., 2014). Many of these facet-level traits could be translated into corresponding SEB skills, yielding a detailed taxonomy of specific skills (Abrahams et al., 2019; Chernyshenko et al., 2018). For example, both the NEO-PI-3 and BFI-2 Extraversion domains include an assertiveness facet trait that could be reconceptualized as a skill: one's capacity to take charge of a social group and influence group members' behavior. 
Beyond these conceptual advantages, there are also practical reasons for starting with the Big Five. Much contemporary personality research is conducted from a Big Five perspective. This includes research examining the relevance of personality traits across the lifespan (Roberts et al., 2008; Soto \& Tackett, 2015), across cultural contexts (Saucier \& Goldberg, 2001; Schmitt et al., 2007), and across consequential life outcomes (Ozer \& Benet-Martinez, 2006; Soto, 2019, 2021). Thus, a taxonomy of SEB skills that parallels the Big Five would allow researchers to readily synthesize findings regarding skills and traits, while also investigating differences between these two kinds of constructs (e.g., in their development and outcomes).

Taken together, these conceptual and practical advantages suggest that the Big Five framework could be used to develop a comprehensive, hierarchically organized taxonomy of SEB skills that is broad in its range of content, deep in its specification of facet-level constructs, and practical in that it can be readily synthesized with the existing scientific literature. Although none of these advantages are unique to the Big Five, they are arguably more true of the Big Five than of any other existing personality model (John et al., 2008).

\section{Toward an Integrative Structural Model of SEB Skills}

Combining a five-dimensional structure with our conceptualization of SEB skills, we have proposed (Soto et al., 2021; see Table 1) that many specific skill facets can be organized within five major content domains that parallel the Big Five traits in terms of their social, emotional, and behavioral referents, but are defined in terms of people's functional capacities (i.e., skills) rather than their general tendencies (i.e., traits). We label these domains as:

1. Social Engagement Skills: capacities used to actively engage with other people;

2. Cooperation Skills: capacities used to maintain positive social relationships;

3. Self-Management Skills: capacities used to effectively pursue goals and complete tasks; 
4. Emotional Resilience Skills: capacities used to regulate emotions and moods;

5. Innovation Skills: capacities used to engage with novel ideas and experiences.

Like many taxonomies (including the Big Five), these five domains represent fuzzy classes or prototypes rather than strict, mutually exclusive categories. Some important skills blend aspects of two or more domains, and others fall outside of them. Nevertheless, we propose that these five domains can provide a useful foundation upon which to build a broadband framework for conceptualizing and assessing SEB skills. The present research investigates this possibility.

\section{How Should Social, Emotional, and Behavioral Skills Be Assessed?}

Efforts to clarify the definition and structure of skill-related constructs have been accompanied by work to develop valid assessment methods. This psychometric research has largely focused on two contrasting approaches (Abrahams et al., 2019; Duckworth \& Yeager, 2015). First, many measures of skills, strengths, and competencies adopt the questionnaire format of a standard personality inventory. Their items are adjectives, phrases, or statements that describe a pattern of behavior, and participants rate how well the item describes their typical behavior using a multi-point agreement or frequency scale. This approach has important advantages. Inventory measures can be reliable and valid indicators of behavior, are relatively easy and inexpensive to administer, and can be adapted to self-report and observer-report formats (John \& Soto, 2007; Mehl et al., 2006; Vazire, 2006). However, this approach also has a key drawback: personality inventory items are designed to measure the frequency or typicality of particular thoughts, feelings, and behaviors. They therefore assess traits more so than skills.

The second approach uses behavioral tasks that present standardized situations or stimuli designed to elicit specific skills. For example, the Torrance Tests of Creative Thinking present a series of verbal and nonverbal tasks, and then score the number, diversity, originality, and detail 
of individuals' responses (TTCT; Torrance, 1966). Similarly, the Mayer-Salovey-Caruso Emotional Intelligence Test scores individuals' responses to tasks requiring them to recognize specific emotions, match them to relevant situations, and distinguish between regulatory strategies (MSCEIT; Mayer et al., 2003; see also Mayer et al., 2012). Task-based measures have an advantage over personality inventories in that they directly assess individuals' skills, rather than their typical or trait-like patterns of behavior. However, behavioral tasks also have disadvantages. For example, behavioral tasks with strong psychometric properties (such as the TTCT and MSCEIT) are time and resource intensive to administer, whereas brief behavioral tasks often produce less reliable scores with weak relations to real-world behaviors, and to each other (Eisenberg et al., 2019; Enkavi et al., 2019; Von Gunten et al., 2020).

A possible solution to these tradeoffs is offered by skills inventories: questionnaire measures in which each item represents a specific social, emotional, or behavioral skill, and respondents rate their own capacity (or the capacity of a target individual) to perform that skill when called upon to do so (Wallace, 1966, 1967). For example, skills inventories have been developed to assess people's capacities to perform prosocial and antisocial interpersonal behaviors (Paulhus \& Martin, 1987), behaviors related to emotional intelligence (Petrides, 2009), and the CASEL competencies (Davidson et al., 2018). Because skills inventories can potentially combine the skill focus of behavioral tasks with the reliability, validity, efficiency, and flexibility

of questionnaire measures, the present research adopts a skills inventory approach to develop and validate the Behavioral, Emotional, and Social Skills Inventory (BESSI).

\section{Overview of the Present Research}

In sum, previous scholarship highlights three critical but unresolved questions regarding social, emotional, and behavioral skills. First, how should SEB skills be defined and 
distinguished from other kinds of psychological constructs, such as personality traits? We propose that many SEB skills can be identified by conceptualizing them as functional capacities: how someone is capable of thinking, feeling, or behaving when the situation calls for it . Second, how can specific SEB skills be organized within broader domains? We propose that hierarchical representations of the Big Five can be used to identify and organize many skill facets in terms of five domains reflecting Social Engagement, Cooperation, Self-Management, Emotional Resilience, and Innovation Skills. Third, how should SEB skills be measured? We propose that a skills inventory approach—in which respondents rate how well they can enact a variety of specific behaviors — can provide reliable, valid, efficient, and flexible assessment.

To investigate these questions and proposals, we first apply our definition of skills-ascapacities to hierarchical representations of the Big Five, in order to identify an inclusive set of SEB skill facets and develop a preliminary item pool (Study 1). We then analyze seven independent samples of adolescents' and adults' self-reports and observer-reports to refine our conceptual and measurement framework at both the facet and domain levels (Studies 2 and 3), thereby developing the Behavioral, Emotional, and Social Skills Inventory (BESSI). Next, we examine SEB skills' relations with existing measures of strengths and competencies, as well as their ability to provide incremental information beyond personality traits (Study 4). Finally, we test whether SEB skills predict important outcomes including academic achievement and engagement, occupational interests, social relationships, and well-being (Study 5).

\section{Study 1: Identifying an Inclusive Set of SEB Skill Facets}

Study 1 investigated whether our conceptualization of SEB skills could be used to translate hierarchical representations of the Big Five into an inclusive set of SEB skill facets. Specifically, we identified several existing, hierarchically structured Big Five models and 
measures. We then reviewed these frameworks' facet-level constructs, and applied our definition of SEB skills as capacities used to maintain social relationships, regulate emotions, and manage goal-and learning-directed behaviors to identify candidate skill facets. Finally, we drafted a preliminary pool of inventory items to assess these skill facets. We generally expected that our conceptual review would identify a large number of skill facets relevant to the domains of Social Engagement, Cooperation, Self-Management, Emotional Resilience, and Innovation Skills that could be readily translated into a preliminary item pool for the BESSI.

\section{Developing a Hierarchical Taxonomy of SEB Skills}

To identify an inclusive set of facet-level constructs, the first and fifth authors reviewed a selection of hierarchically structured Big Five models and measures: the NEO-PI-3, BFI-2, Tailored Adaptive Personality Assessment System (TAPAS; Stark et al., 2014), Synthetic Aperture Personality Assessment Personality Inventory (SAPA-PI; Condon, 2017), and OECD framework for social and emotional skills (Chernyshenko et al., 2018). Collectively, these models and measures include 113 facet-level constructs derived using different strategies (e.g., literature reviews, empirical analyses) and intended for different contexts (e.g., basic research, applied assessment). Adopting a researcher-driven approach, we reviewed each model or measure's facet-level constructs and identified as many non-redundant facets as possible that could be conceptualized as SEB skills, rather than only as personality traits. We also generated a few candidate facets that seemed oriented toward the low pole of a Big Five domain, and may therefore have been excluded from previous models (e.g., the capacity to argue as a skill associated with low Agreeableness).

This review yielded a total of 33 candidate skill facets, which are listed and defined in Table 2. Table 3 shows how these facets align with the hierarchical Big Five models and 
measures included in our review. These tables illustrate that many Big Five facets can indeed be reconceptualized as specific SEB skills related to the broader domains of Social Engagement, Cooperation, Self-Management, Emotional Resilience, and Innovation Skills.

\section{Developing a Preliminary Item Pool (BESSI v0.1)}

To operationalize the 33 candidate SEB skill facets, the research team drafted items assessing each of the skill facets listed in Table 2. Each item was phrased as describing a specific behavior that someone could be more or less skilled at enacting (e.g., "Introduce myself to strangers," “Get started on tasks," “Calm down when I'm feeling angry”). To provide adequate content validity and measurement precision, while also allowing space to subsequently refine the item pool, we drafted approximately 10 items per facet. This approach yielded a total of 312 items, with 8 to 13 items per skill facet. These items, available at [https://osf.io/4zgyr/], constitute version 0.1 of the BESSI (BESSI v0.1).

\section{Study 2: Conceptually and Empirically Refining SEB Skill Facets}

The overarching goal of Study 2 was to refine the conceptual taxonomy and preliminary item pool generated by Study 1. More specifically, we aimed to (a) merge facets that could not be sufficiently distinguished from each other, (b) split facets that were not sufficiently coherent, and (c) refine the BESSI item pool so that each facet could be efficiently measured using a psychometrically sound scale. We generally expected that an iterative rational-empirical approach would produce a coherent, differentiated, and robust framework for conceptualizing and assessing SEB skills at the facet level. 


\section{Method}

\section{Participants and Procedure}

We refined our facet-level framework through an iterative process that spanned four independent samples of participants. All participants were visitors to PersonalityLab.org, a noncommercial website that allows its users to complete online surveys in exchange for free, automatically generated feedback. For Study 2, participants completed the BESSI items as part of a survey titled Find Your Hogwarts House. This survey provided feedback framed in terms of compatibility with the four residential houses of Hogwarts School of Witcheraft and Wizardry featured in the Harry Potter book series (Rowling, 1997). Participants were recruited passively, and could find the survey through search engines, links from other websites, and word of mouth. The study was approved by the Colby College Institutional Review Board. All materials and data for Study 2 are available at [https://osf.io/4zgyr/].

Internet Samples A and B. Internet samples A and B each included 2,000 participants randomly assigned to complete one of five BESSI item subsets. Each subset focused on a specific skill domain: Social Engagement, Cooperation, Self-Management, Emotional Resilience, or Innovation Skills. The subsets ranged in length from 45 to 79 items for sample A, and 98 to 102 items for sample B. All participants also completed the BFI-2, which was used to generate the survey feedback. Demographic information for these samples is presented in Supplemental Table S1. Both samples were balanced in terms of gender and diverse in terms of ethnicity and nationality.

Respondents were excluded from analysis if they (a) answered fewer than $90 \%$ of the survey questions, (b) did not report their gender, (c) did not report their age, or reported an age of less than 10 or greater than 80 years old, (d) reported that they did not speak English fluently, (e) 
reported inconsistent information about their nationality, (f) had a within-person standard deviation of less than 0.50 across the BFI-2 items, or (g) completed the survey multiple times. These exclusion criteria were designed to help ensure data quality, at the cost of excluding some respondents who had difficulty completing the survey. After applying these criteria, missing item responses were replaced with the item mean, rounded to the nearest possible response. The final samples were then randomly selected to balance for both gender and the BESSI item subsets.

Internet Samples C and D. Internet samples C and D included 400 and 600 participants, respectively, who each completed a version of the BESSI with 200 (sample C) or 192 (sample D) items. As shown in Supplemental Table S1, these samples were balanced in terms of gender, and diverse in terms of age, ethnicity, and nationality. Data screening procedures were identical to Internet samples A and B, except that participants were not excluded on the basis of withinperson standard deviations (because the BFI-2 was not administered).

Statistical power. For two-tailed tests at the $\alpha=.05$ significance level, a sample size of 400 or 600 participants provides adequate (i.e., $80 \%$ ) power to detect true effects of at least $\rho=$ .14 or .11 , respectively, and high (i.e., 95\%) power to detect true effects of at least $\rho=.18$ or .15 , respectively. These sample sizes exceed the recommended minimum of approximately 250 observations for obtaining stable estimates of correlations (Schönbrodt \& Perugini, 2013).

\section{Measures}

Behavioral, Emotional, and Social Skills Inventory, versions 0.1 to 1.0. The Behavioral, Emotional, and Social Skills Inventory (BESSI) is a questionnaire measure designed to assess individuals' capacities to maintain social relationships, regulate emotions, and manage goal- and learning-directed behaviors. As described in Study 1, the BESSI items are short phrases that each describe a specific behavior. Respondents are instructed to rate how capable 
they are of enacting the thought, feeling, or behavior described by each BESSI item, rather than how well each item describes their typical behavior.

The BESSI items and instructions were gradually refined across Study 2. BESSI v0.1, administered in subsets to Internet sample A, included a total of 312 items. It instructed participants to rate how easy or hard it was for them to perform each behavior well, on a 5-point difficulty scale ranging from $1=$ very hard to 5 = very easy. BESSI v0.2, administered in subsets to Internet sample B, included a total of 274 items rated using the same 5-point difficulty scale. BESSI v0.3, administered in full to Internet sample C, included 200 items. Its instructions asked participants to rate how well they could perform each behavior, reflecting their current level of expertise, on a scale ranging from $1=$ not at all well (beginner) to $5=$ extremely well (expert). This "how-well" rating scale focuses more directly on skill level (rather than effort), and seems more appropriate for adapting the BESSI to an observer-report format (see Study 3 ). ${ }^{2}$ Finally, BESSI v1.0, administered in full to Internet sample D, included 192 items. These items were rated on a simplified version of the 5-point how-well scale that ranged from $1=$ not at all well to $5=$ extremely well $^{3}$ The surveys used to administer each version of the BESSI, a Supplemental Appendix showing the items included in each version, and self-report and observer-report forms for administering the BESSI v1.0 are available at [https://osf.io/4zgyr/].

\footnotetext{
${ }^{2}$ Separate samples were administered the BESSI v0.3 using either the 5-point difficulty scale from Internet samples A and B or a modified version of this scale that instructed respondents to rate half of the items in terms of easiness, and the other half in terms of difficulty. Because results were very similar, only results from the how-well condition are reported here.

${ }^{3}$ Separate samples were administered the BESSI v1.0 using either the 5-point how-well scale with expertise labels from Internet sample $\mathrm{C}$ or a 3-point how-well scale without expertise labels. Because results were very similar, only results from the 5-point how-well condition without expertise labels are reported here.
} 
Big Five Inventory-2. The BFI-2 is a 60-item questionnaire that measures the Big Five personality domains - Extraversion, Agreeableness, Conscientiousness, Negative Emotionality (vs. Emotional Stability), and Open-Mindedness (or Openness to Experience) — as well as 15 more-specific facet traits (Soto \& John, 2017). Its items are short, descriptive phrases that participants rated on a 5-point agreement scale. Cronbach's alpha reliabilities for the domain scales ranged from .80 to .90 in Internet sample A $(M=.85)$, and from .79 to .90 in Internet sample B $(M=.85)$. Alphas for the facet scales ranged from .64 to .84 in Internet sample A $(M=$ $.74)$, and .63 to .85 in Internet sample $\mathrm{B}(M=.74)$.

\section{Results and Discussion}

\section{BESSI v0.1 Facet Scales (Internet Sample A)}

Table 4 presents the number of items and alpha reliability for each BESSI v0.1 skill facet in Internet sample A. These facet scales ranged in length from 8 to 13 items $(M=9.45)$, with alpha reliabilities ranging from .83 to $.94(M=.88)$.

These results indicate high internal consistency for all facets, but suggest that many could be shortened with little cost to reliability. Moreover, examination of item characteristics suggested that some items would be better assigned to a different facet. Therefore, based on corrected item-total correlations, correlations with other facets, and conceptual judgments of item content, we reassigned 23 items to a different facet. After repeating the item-level analyses using the new item assignments, we trimmed each facet to approximately 8 items based on their empirical characteristics and conceptual content, revised some items to clarify their meaning or reduce redundancy, and drafted new items to supplement facets with fewer than eight remaining items. In total, we deleted 55 items, revised 22 items, and drafted 13 new items. 


\section{BESSI v0.2 Facet Scales (Internet Sample B)}

As shown in Table 4, the BESSI v0.2 facet scales ranged in length from 8 to 10 items ( $M$ $=8.56)$, with alpha reliabilities ranging from .82 to $.94(M=.89)$, indicating high internal consistency. However, psychometric analyses suggested that further refinements were possible. First, based on their high intercorrelations and overlapping item content, we merged the Capacity for Social Warmth and Friendliness facets, as well as the Anger Management and Emotional Control facets. Second, based on corrected item-total correlations, correlations with other facets, and judgments of item content, we reassigned some items to different facets and trimmed each facet to approximately 6 items. Third, we drafted new items to test whether a Time Management facet could be differentiated from Organizational Skill and Task Management. In total, we reassigned 8 items, deleted 84 items, revised 1 item, and drafted 10 new items.

\section{BESSI v0.3 Facet Scales (Internet Sample C)}

As shown in Table 4, the BESSI v0.3 facet scales ranged in length from 6 to 8 items ( $M=$ 6.45), with alpha reliabilities ranging from .83 to $.93(M=.88)$. Because correlations of the preliminary Time Management scale with Organizational Skill and Task Management were comparable to several other interfacet correlations, we retained all three facets. We then used corrected item-total correlations, correlations with other facets, and judgments of item content to trim each facet to a final set of six items.

\section{BESSI v1.0 Facet Scales (Internet Sample D)}

As shown in the right-most columns of Table 4 , each of the 32 BESSI v1.0 facets included 6 items, with alpha reliabilities ranging from .80 to $.93(M=.87)$. Item and scale-level analyses did not suggest any further changes to the BESSI facets. We therefore concluded our iterative process and adopted a 32-facet framework for the BESSI. 


\section{Testing the Facet-Level Structure of SEB Skills}

To formally test the robustness of this proposed facet-level framework, we conducted a series of confirmatory factor analyses (CFAs). Specifically, in Internet samples C and D, we compared a 32-facet model to a baseline, single-factor model. For both models, the 192 BESSI v1.0 items were aggregated into two-item parcels using simple rotation within each facet (i.e., the first and fourth items, second and fifth items, and third and sixth items). In the single-factor model, all item parcels loaded on a single, general factor. In the 32-facet model, each parcel loaded on a factor representing its intended skill facet, and the 32 facet factors were allowed to intercorrelate. In both models, all factor variances were set to 1, all parcels were defined as ordinal indicators, and the models were fit using the weighted least squares mean and variance adjusted (WLSMV) estimator in Mplus 8.4 (Muthén \& Muthén, 2017).

Model fit statistics are presented in Table 5, and McDonald's omega reliabilities for the facet factors are reported in Table 4. These results illustrate two key patterns. First, differentiating between the 32 facet factors dramatically improved model fit, as compared with the single-factor model $(\Delta \mathrm{CFI} \geq .602 ; \Delta \mathrm{TLI} \geq .607 ; \Delta \mathrm{RMSEA}=-.085 ; \Delta \mathrm{SRMR} \leq-.108)$. Second, judged against conventional standards (Hooper et al., 2008) for adequate fit (CFI and $\mathrm{TLI} \geq .90 ; \mathrm{RMSEA}$ and SRMR $\leq .08)$ and good fit $(\mathrm{CFI}$ and TLI $\geq .95 ; \mathrm{RMSEA}$ and $\mathrm{SRMR} \leq$ $.05)$, the 32-facet model provided adequate to good fit in both samples (CFI $\geq .936$; TLI $\geq .926$; RMSEA $\leq .041 ;$ SRMR $\leq .042)$, with uniformly high standardized loadings $(M=.86$ in each sample; for complete standardized estimates, see Supplemental Table S2) and omega reliabilities $(M=.90$ in each sample), as well as generally moderate correlations between facets ( $M$ absolute $r=.32$ and .31 , respectively). These results support the BESSI's proposed facet-level structure. 


\section{Conclusion}

The results of Study 2 indicate that our iterative rational-empirical approach produced a coherent, differentiated, and robust framework for conceptualizing and assessing SEB skills at the facet level. They further indicate that (a) many specific SEB skill facets can be identified by defining skills as functional capacities, and (b) a skills inventory, such as the BESSI, in which respondents rate how well they can enact a variety of specific thoughts, feelings, and behaviors, can provide psychometrically sound assessment of these skills.

\section{Study 3: Examining the Domain-Level Organization of SEB Skills}

Study 3 had two main goals. First, we tested whether the facet-level framework for SEB skills developed in Study 2 could be replicated in samples representing multiple developmental periods (adolescence, adulthood) and assessment perspectives (self-reports, observer-reports). Second, we investigated the domain-level structure of SEB skills. We generally expected that most specific skill facets could be organized within five broad domains: Social Engagement, Cooperation, Self-Management, Emotional Resilience, and Innovation Skills.

\section{Method}

In Study 3, we conducted further analyses of Internet samples C and D, described above (see Study 2). We also analyzed data from three new samples: a sample of college students' selfreports, a sample of high school students' self-reports, and a sample of adults' observer-reports. All materials and data for Study 3 are available at [https://osf.io/4zgyr/].

\section{Participants and Procedure}

College student sample. This sample included 322 students enrolled in psychology courses at Colby College, a private college in the Northeastern United States, who participated in exchange for partial fulfillment of a course requirement. The sample included more women than 
men (69.6\% female, $29.8 \%$ male, $0.6 \%$ another gender), and almost all (99.1\%) were 18 to 22 years old $(M=19.38, S D=1.13)$. The sample was reasonably diverse in terms of seniority (40.4\% first-years, $27.6 \%$ sophomores, $21.4 \%$ juniors, $10.6 \%$ seniors) and ethnicity $(74.5 \%$ White/Caucasian, 20.2\% Asian/Asian American, 8.7\% Hispanic/Latino, 6.5\% Black/African American, 2.2\% another ethnicity, with $11.8 \%$ reporting multiple ethnicities). Potential participants were excluded if they answered fewer than $90 \%$ of the BESSI items, failed either of two attention-check items, completed the survey battery in less than 10 minutes (approximately one third of the median time), or submitted the survey multiple times. Data collection was approved by the Colby College Institutional Review Board.

High school student sample. This sample included 499 students from large suburban and urban high schools in the United States. They completed an online survey as part of the Character Lab Research Network, a consortium of schools across the country working collaboratively with scientists to advance scientific insights that help kids thrive (Duckworth, 2019). The sample was approximately balanced in terms of gender $(52.7 \%$ female, $45.1 \%$ male, $1.2 \%$ another gender, $1.0 \%$ not reported), and most participants $(91.6 \%)$ were 14 to 17 years old $(M=15.62, S D=1.17)$. The sample was diverse in terms of grade level $(30.9 \% 9$ th grade, $33.5 \%$ 10th grade, $20.0 \% 11$ th grade, $14.6 \% 12$ th grade, $1.0 \%$ not reported) and ethnicity $(42.1 \%$ White/Caucasian, 34.1\% Black/African American, 18.4\% Hispanic/Latino, 3.0\% Asian/Asian American, $0.6 \%$ another ethnicity, 4.4\% multiple ethnicities, $4.2 \%$ not reported). Potential participants were excluded if they answered fewer than $90 \%$ of the BESSI items, failed either of two attention-check items, or completed the survey in less than one third of the median time. Data collection was approved by the Advarra Institutional Review Board. 
Observer sample. This sample included 488 adults who completed an observer-report version of the BESSI to describe someone they know well. They were recruited using the Qualtrics Online Sample service, and paid approximately \$3 USD for participating. The sample was closely balanced in terms of gender ( $51.6 \%$ female, $48.0 \%$ male, $0.4 \%$ another gender $)$ and diverse in terms of age (range $=18$ to $87, M=49.26, S D=16.32$ ), but relatively homogenous in terms of ethnicity (84.2\% White/Caucasian, 6.1\% Black/African American, 4.7\% Asian/Asian American, 3.1\% Hispanic/Latino, 1.8\% another ethnicity).

Most observers chose to rate a spouse or romantic partner $(41.2 \%)$, friend $(27.0 \%)$, or family member $(22.5 \%)$, with smaller numbers rating a coworker $(4.9 \%)$ or other acquaintance (4.3\%). Most participants reported that they knew the target extremely well $(65.4 \%)$ or very well (22.5\%), and strongly liked the target (79.9\%). The mean length of acquaintance was 24.37 years $(M d n=20, S D=17.86)$. Potential participants were excluded if they answered fewer than $90 \%$ of the BESSI items, failed either of two attention-check items, failed to answer either of two open-ended comprehension items, completed the survey in less than one third of the median time, reported inconsistent demographic information, or reported that they did not answer the survey items honestly. Data collection was approved by the University of Illinois at UrbanaChampaign Office for the Protection of Research Subjects.

Statistical power. For two-tailed tests at the $\alpha=.05$ significance level, a sample size of 322 or 490 participants provides adequate power to detect true effects of at least $\rho=.15$ or .13 , respectively, and high power to detect true effects of at least $\rho=.20$ or .16 , respectively.

\section{Measures}

All participants completed an online version of the BESSI via the Qualtrics survey platform. Participants in the college and high school student samples completed the 192-item 
BESSI v1.0. Participants in the observer sample completed the superset of 284 BESSI v0.2 and v0.3 items, from which we extracted the 192 BESSI v1.0 items for analysis. Participants in the college student sample also completed the BFI-2, as well as a battery of convergent validity measures (described further in Study 4). Those in the high school student sample completed a battery of external validity measures (described further in Study 5). In all samples, missing item responses were imputed using the same procedure as in Study 2.

\section{Results and Discussion}

\section{Replicating the Facet-Level Structure of SEB Skills}

We first conducted CFAs to test the facet-level framework derived in Study 2. We therefore fit the single-factor and 32-facet models developed in Study 2 to the high school student, college student, and observer samples. As shown in Table 5, the BESSI's facet-level structure was clearly recovered in these samples. In each sample, a single-factor model did not provide acceptable fit $(\mathrm{CFI} \leq .788$; TLI $\leq .783$; RMSEA $\geq .096$; SRMR $\geq .086)$, whereas a 32facet model provided adequate to good fit $(\mathrm{CFI} \geq .950 ; \mathrm{TLI} \geq .943 ; \mathrm{RMSEA} \leq .041 ; \mathrm{SRMR} \leq$ $.042)$. Moreover, the 32 -facet model yielded uniformly high standardized loadings $(M=.87, .85$, and .91 in the three samples, respectively) and omega reliabilities $(M=.89,91$, and .94 , respectively; for complete standardized estimates, see Supplemental Table S3). These results further support the robustness of the BESSI's facet-level structure.

\section{Investigating the Domain-Level Structure of SEB Skills}

Our next goal was to investigate the domain-level structure of SEB skills. To do this, we conducted exploratory factor analyses (EFAs) of the BESSI facets, and also examined their correlations with the Big Five personality traits. 
Exploratory factor analyses. We submitted observed scores on the 32 BESSI facet scales to a series of EFAs in Internet sample C, the college students sample, the high school student sample, and the observer sample (thereby reserving Internet sample D for subsequent, confirmatory analyses). In each sample, we extracted and rotated one to seven factors to examine whether these structures would replicate consistently across samples and correspond with the proposed skill domains of Social Engagement, Cooperation, Self-Management, Emotional Resilience, and Innovation Skills. These analyses were conducted using robust maximum likelihood (MLR) estimation and oblique, direct oblimin rotation (with $\Delta=0$ ) in Mplus 8.4.

Supplemental Tables S4-S10 present the standardized factor loadings, interfactor correlations, and Tucker's congruence coefficients for these analyses in each sample; results for the five-factor solution, averaged across the four samples, are presented in Table 6 . These results indicate several noteworthy findings. First, only the one-, two-, and five-factor structures replicated consistently across samples, with mean factor congruence coefficients of $.99, .95$, and .93, respectively; all other solutions included at least one factor with mean congruence of .76 or lower, which falls below conventional standards for factor replication (congruence $\geq .85$; Lorenzo-Seva \& ten Berge, 2006). Second, the five-factor structure corresponds closely with the five proposed skill domains. Third, in this five-factor structure, many skill facets were clearly linked with a single higher-order domain, with the Self-Management domain showing the largest number of linked facets. Fourth, some skill facets loaded substantially on two domain factors, while others showed more modest loadings distributed across multiple domains (e.g., Adaptability loaded on all domains except Self-Management). ${ }^{4}$

\footnotetext{
${ }^{4}$ To further check the robustness of this five-factor structure, we also conducted EFAs of the 192 BESSI items in each sample. Convergent correlations between factor scores derived from the 32 facets vs. 192 items averaged .99 in Internet sample $\mathrm{C}$ and the college student sample, .98 in the
} 
Correlations with personality traits. Table 7 presents correlations between the BESSI skill facets and Big Five personality traits in the college student sample. These correlations indicate that SEB skill facets are moderately to strongly linked with the Big Five. Each BESSI facet had at least one absolute correlation of .30 or stronger with a Big Five trait, and most had at least one correlation of .50 or stronger. Consistent with the EFA results, these correlations also show that some BESSI facets were clearly associated with a single Big Five trait, while others were about equally associated with multiple traits.

A proposed domain-level framework for SEB skills. Taken together, these EFA and correlational results provide preliminary support for the proposal that many specific SEB skills can be organized in terms of five broad skill domains representing Social Engagement, Cooperation, Self-Management, Emotional Resilience, and Innovation Skills.

To formalize this domain-level framework for SEB skills, we reviewed each BESSI skill facet in terms of its social, emotional, and behavioral content; pattern of EFA loadings; and correlations with the Big Five traits. We then designated each skill facet as either a singledomain facet, an interstitial facet, or a compound facet. The 25 resulting single-domain facets were those that showed a clear and distinctive association with a particular social, emotional, or behavioral domain. The 4 interstitial facets combined aspects of two particular domains, whereas the 3 compound facets showed links with three or more domains.

Figure 1 presents a schematic representation of this domain-level structure, and illustrates two noteworthy findings. First, Self-Management was the most prominent domain of SEB skills

observer sample, and .91 in the high school student sample. Only 1 of the 20 convergent correlations was below $.90(r=.78$ for the Cooperation Skills factor in the high school student sample). Overall, these results indicate strong convergence between the five-factor structures derived from the facets vs. items. 
as measured by the BESSI: about twice as many skill facets showed distinctive associations with Self-Management as with each of the other four domains. Second, SEB skills did not neatly cohere into a simple domain-level structure. Although most skill facets were strongly linked with a single domain, several showed more-complex links. For example, the Adaptability facet involves the capacity to regulate emotions (Emotional Resilience) when experiencing new ideas and activities (Innovation), as well as new social situations (Social Engagement). Including these facets reduces the parsimony of our structural model. However, in our view this cost is outweighed by a corresponding gain in comprehensiveness.

\section{Testing the Proposed Domain-Level Structure}

The proposed structure illustrated in Figure 1 is necessarily a simplification that cannot fully represent all of the meaningful links between SEB skills. However, it may serve as a useful template for capturing the overall pattern of relations. To test this possibility, we specified two latent variable models that included both facet-level and domain-level factors. As in our previous analyses, these models were fit to the 96 BESSI item parcels. Both models were fit to each of our five samples, including Internet sample D, which had been held out of previous EFAs and correlational analyses to allow for independent replication of the proposed domain-level structure. Fit statistics for these models are reported in Table 8, and complete standardized model estimates are provided in Supplemental Tables S11 and S12.

The first model was a hierarchical five-domain CFA model, which nested the 32 BESSI facets within 5 correlated domain-level factors. In this model, each item parcel was allowed to load on its facet factor, and each facet factor was allowed to load on one or more domain factors following the domain-level structure illustrated in Figure 1. Specifically, each single-domain facet was allowed to load on only one domain factor. Interstitial facets were each allowed to load 
on two domain factors, and compound facets were allowed to load on all five domains.

Supplemental Figure S1 presents a partial illustration of this model.

As shown in Supplemental Table S11, the BESSI item parcels loaded substantially onto their facet factors $(M$ standardized loading $=.87)$, and all single-domain and interstitial facets loaded substantially onto their assigned domain factors $(M=.72)$ in all five samples. Moreover, this model provided adequate fit in the high school student and observer samples $(\mathrm{CFI}=.910$ to $.930, \mathrm{TLI}=.907$ to $.927, \mathrm{RMSEA}=.052$ to $.060, \mathrm{SRMR}=.049$ to .075$)$, as well as borderline to adequate fit in the college sample $(\mathrm{CFI}=.894, \mathrm{TLI}=.891, \mathrm{RMSEA}=.056, \mathrm{SRMR}=.076)$. However, it showed inadequate fit in the two Internet samples $(\mathrm{CFI}=.822$ to $.841, \mathrm{TLI}=.815$ to $.835, \mathrm{RMSEA}=.060$ to $.065, \mathrm{SRMR}=.086$ to .088$)$. These findings suggest that, in some populations, the BESSI's domain-level structure can be captured by a purely confirmatory, hierarchical model. However, in some cases a more complex model may be needed.

We therefore specified a second model, the bifactor five-domain ESEM, to represent the domain-level structure illustrated in Figure 1 while also allowing a more-complex organization of skill facets. In general, exploratory structural equation models (ESEMs) combine aspects of CFA and EFA, and bifactor models allow observed indicators to load directly onto multiple factors specified at different levels of abstraction. Thus, the bifactor five-domain ESEM included 32 confirmatory facet-level factors and 5 exploratory domain-level factors. It allowed each BESSI item parcel to load onto its assigned facet factor, as well as the five domain factors. To ensure that the domain factors would approximate our proposed domain-level structure, they were rotated toward a target matrix in which all loadings on the domain factors were targeted at zero, except for those implied by Figure 1. Thus, for facets assigned to a single domain in Figure 1, their item parcels' loadings on the remaining four domains were targeted at zero. Similarly, for 
interstitial facets assigned to two domains in Figure 1, their parcels' loadings on the other three domains were targeted at zero. The five domain factors were allowed to intercorrelate; however, the 32 facet factors were constrained to be independent from each other and from the domain factors. ${ }^{5}$ Thus, the bifactor five-domain ESEM retains a strict, confirmatory approach to the BESSI's facet-level structure, while allowing a more-complex domain-level structure.

Supplemental Figure S2 presents a partial illustration of this model.

As shown in Table 8, in all five samples the bifactor five-domain ESEM substantially improved model fit over the hierarchical five-domain CFA model $(\Delta \mathrm{CFI}=.041$ to $.117, \Delta \mathrm{TLI}=$ .040 to $.115, \Delta \mathrm{RMSEA}=-.017$ to $-.025, \Delta \mathrm{SRMR}=-.027$ to -.052$)$, and provided adequate to good overall fit $(\mathrm{CFI}=.939$ to $.971, \mathrm{TLI}=.930$ to $.967, \mathrm{RMSEA}=.035$ to $.041, \mathrm{SRMR}=.022$ to .038). Moreover, as shown in Supplemental Table S12, the item parcels consistently loaded onto their intended domain factors $(M$ standardized loading $=.57)$ and designated facet factors $(M=$ .46). ${ }^{6}$ These results indicate that the SEB skill facets assessed by the BESSI can be organized in terms of five domain-level factors that allow for a complex pattern of facet-domain relations.

\section{Conclusion}

Taken together, the findings of Study 3 support three key conclusions. First, the facetlevel framework developed in Study 2 can be recovered in samples representing different developmental periods and assessment perspectives. Second, many specific SEB skills can be

\footnotetext{
${ }^{5}$ In some samples, the bifactor five-domain ESEM produced negative residual variances for some item parcels, indicating that observed scores on these parcels were fully explained by the domain and facet factors. This issue can be addressed by constraining each problematic parcel to have a facet loading equal to its two other same-facet parcels.

${ }^{6}$ Note that the generally smaller loadings for the bifactor ESEM, as compared with the hierarchical CFA model, reflect the fact that the bifactor model allowed each item parcel to load separately on the domain and facet factors, whereas the hierarchical models only allowed the parcels to load directly on the facet factors.
} 
organized in terms of five broad domains: Social Engagement, Cooperation, Self-Management, Emotional Resilience, and Innovation Skills. These domains resemble the Big Five personality traits in terms of their social, emotional, and behavioral referents, but are conceptualized and assessed as related sets of functional capacities rather than traits. Third, the relations between SEB skill facets and domains are complex: many SEB skill facets are clearly linked with a single broad domain, but some show a more complex pattern of domain-level associations.

\section{Study 4: Testing the Convergent, Discriminant, and Incremental Validity of SEB Skills}

Studies 1 to 3 developed a structural model of SEB skills, as well as a skills inventorythe BESSI-to assess these skills as functional capacities. Building on this work, Study 4 pursued two main goals. First, we investigated the nomological network of SEB skills (Cronbach \& Meehl, 1955; John \& Soto, 2007) by examining their relations with measures of socioemotional competencies, character and developmental strengths, and personality traits. Second, we investigated the incremental validity of SEB skills by testing whether they capture unique information beyond what is represented by personality traits. We generally expected that SEB skills would relate meaningfully with other social, emotional, and behavioral constructs, and would also provide unique information beyond the Big Five traits.

\section{Method}

\section{Participants and Procedure}

Study 4 analyzed additional data from 313 members of the college student sample described above (see Study 3). After completing an online version of the BESSI, these participants also completed a battery of convergent validity measures as part of the same Qualtrics survey. All of these participants completed measures of the Big Five personality traits (the BFI-2, described above) and developmental strengths (the Positive Youth Development- 
Short Form). A subsample of 249 participants also completed assessments of character strengths (the Tripartite Taxonomy of Character) and socioemotional competencies (the Social and Emotional Competency Assessment, and Social-Emotional Learning Surveys). ${ }^{7}$

Participants were excluded from analysis in Study 4 if they answered fewer than $90 \%$ of a convergent measure's items or failed either of two attention-check items embedded within the battery of convergent measures. Missing item responses were imputed using the same procedure as in Studies 2 and 3. All materials and data for Study 4 are available at [https://osf.io/4zgyr/].

\section{Measures}

Developmental Strengths. The Positive Youth Development-Short Form (PYD-SF; Geldhof, Bowers, et al., 2014) uses 34 items to assess the "Five Cs" of positive youth development: Competence, Confidence, Character, Caring, and Connection. Twenty-six of its items are pairs of contrasting statements that participants rated on a 5-point semantic differential scale. The remaining eight items are individual statements or activities that participants rated on a 5-point scale reflecting their degree of agreement, importance, or descriptiveness. In the present sample, alpha reliabilities were .68 for Competence, .84 for Confidence, .65 for Character, .83 for Caring, and .82 for Connection.

Character Strengths. The Tripartite Taxonomy of Character (TTC; Park et al., 2017) uses 24 items to assess Interpersonal Strengths (including the facets of Social Intelligence, Interpersonal Control, and Gratitude), Intrapersonal Strengths (including Grit and Academic Control), and Intellectual Strengths (including Curiosity and Zest). The items are statements that participants rated on a 7-point frequency scale to describe their behavior during the past 30 days.

\footnotetext{
${ }^{7}$ These sample sizes reflect the fact that different measures were added to the survey at different times during data collection.
} 
Alpha reliabilities were .82 for Interpersonal Strengths, .86 for Intrapersonal Strengths, and .86 for Intellectual Strengths. Alphas for the facet scales ranged from .59 to .82 , with a mean of .71.

Socioemotional Competencies. The Social and Emotional Competency Assessment (SECA; Davidson et al., 2018) uses 40 items to assess five domains of socioemotional competencies identified by CASEL: Self-Awareness (including the facets of Self-Concept and Emotion Knowledge), Self-Management (including Goal Management, Emotion Regulation, and School Work), Social Awareness, Relationship Skills, and Responsible Decision-Making. Its items are phrases describing specific competencies that participants rated on a 4-point scale to describe how easy or difficult it was for them to enact that competency. Alpha reliabilities were .78 for Self-Awareness, .60 for Social Awareness, .89 for Self-Management, .52 for Relationship Skills, and .55 for Responsible Decision-Making. Alphas for the five facet scales ranged from .51 to .84 , with a mean of .69 .

Socioemotional Learning. The CORE Districts' Social-Emotional Learning Surveys (SELS; West et al., 2018) use 18 items to assess four socioemotional competencies: SelfManagement, Social Awareness, Self-Efficacy, and Growth Mindset. The five Self-Management items are statements that participants rated on a 5-point frequency scale to describe their behavior during the previous 30 days. The four Social Awareness items are questions that participants answered on item-specific 5-point scales to describe their behavior during the previous 30 days. The four Self-Efficacy items are outcome statements that participants rated on a 5-point scale to indicate their degree of confidence about attaining each outcome. Finally, the four Growth Mindset items are belief statements that participants rated on a 5-point agreement scale. Alpha reliabilities were .70 for Self-Management, .61 for Social Awareness, .89 for SelfEfficacy, and .80 for Growth Mindset. 


\section{Computing Observed Scores for the BESSI Domains and Facets}

As an alternative to latent variable models, in Study 4 we computed BESSI domain and facet scores through simple aggregation of observed item responses. Each of the 32 BESSI facets was scored as the average of its six constituent items. Each of the five skill domains was then scored as the average of its constituent facets, as illustrated in Figure 1. When computing the domain scores, single-domain facets (e.g., Leadership Skill) were given full weight toward their assigned domain (Social Engagement), interstitial facets (e.g., Energy Regulation) were given half weight toward each of their two domains (Social Engagement and Self-Management), and interstitial facets (e.g., Adaptability) were not scored on any domains.

Self-report and observer-report versions of the BESSI, as well as SPSS syntax, R syntax, and an Excel template for computing domain and facet scores, are available at [https://osf.io/4zgyr/]. Descriptive statistics and interscale correlations for the BESSI domain and facet scales in the college student sample are presented in Supplemental Table S13. Alpha reliabilities for the BESSI domain scales were .98 for Self-Management Skills, .94 for Social Engagement Skills, .94 for Cooperation Skills, .95 for Emotional Resilience Skills, and .94 for Innovation Skills. Alphas for the 32 facets ranged from .80 to .94 , with a mean of .88 . Correlations between these observed scale scores and domain factor scores obtained from the hierarchical five-domain CFA model specified in Study 3 were .99 for Self-Management, .97 for Social Engagement, .96 for Cooperation, .98 for Emotional Resilience, and .96 for Innovation. Scale-factor correlations for the 32 BESSI facets ranged from .96 to 1.00 , with a mean of .98 . These results indicate that observed scale scores can serve as reasonably accurate proxies for latent factor scores at both the domain and facet levels. 


\section{Results and Discussion}

\section{Convergent and Discriminant Validity of SEB Skills}

Domain-level correlations and regressions. The BESSI skill domains' correlations with the domain-level measures of socioemotional competencies, character and developmental strengths, and personality traits are presented in Table 9, and the full correlation matrix is presented in Supplemental Table S13. Table 10 presents standardized coefficients from regressing each convergent measure on the set of five BESSI domains. Hypotheses regarding convergent and discriminant validity can be derived from the mapping presented in Table 1. For example, Table 1 implies that Social Engagement Skills should correlate substantially with TTC Interpersonal Strengths, PYD Connection, SECA Relationship Skills, and BFI-2 Extraversion.

The 22 convergent correlations hypothesized in Table 1 averaged .57, whereas the remaining 68 discriminant correlations averaged only .33. In regression analyses, the standardized coefficients for the hypothesized convergent associations averaged .49 , whereas the discriminant associations averaged -.04. Moreover, $82 \%$ of the convergent associations, but only $13 \%$ of the discriminant associations, remained positive and statistically significant $(p<.05)$ across these analyses. Particularly strong convergent associations included Self-Management Skills with BFI-2 Conscientiousness, TTC Intrapersonal Skills, and SECA and SELS SelfManagement; Social Engagement Skills with BFI-2 Extraversion; Cooperation Skills with BFI-2 Agreeableness, PYD Caring, TTC Interpersonal Skills, and SECA Social Awareness; Emotional Resilience Skills with BFI-2 Emotional Stability, PYD Confidence, and SECA Self-Awareness; and Innovation Skills with BFI-2 Open-Mindedness (all $r \mathrm{~s}$ and $\beta \mathrm{s} \geq .51$ ).

Facet-level correlations. Next, we examined the convergent and discriminant validity of SEB skills at the facet level. The BESSI skill facets' correlations with the facet-level measures of 
socioemotional competencies, character and developmental strengths, and personality traits, as well as domain-level convergent measures that do not subsume any facet-level subscales, are presented in Table 11, and the full correlation matrix is presented in Supplemental Table S13. Inspection of Table 11 reveals two general patterns. First, some SEB skill facets converged quite strongly with specific competencies, strengths, and traits. For example, the BESSI Task Management facet correlated strongly with BFI-2 Productiveness, SECA School Work, and TTC Academic Self-Control ( $r \mathrm{~s} \geq .73$ ). Second, some competencies, strengths, and traits showed differential relations with specific BESSI facets located within the same skill domain. For example, TTC Interpersonal Self-Control correlated more strongly with BESSI Anger Management $(r=.59)$ than with any other Emotional Resilience skill facet $(r s \leq .40)$.

Facet-level regressions. To further test convergent and discriminant validity at the facet level, we conducted a series of forward stepwise regressions to predict each of the 22 domainlevel convergent measures from the 32 BESSI facets. To prevent undue capitalization on chance, only predictors significant at the $p<.001$ level were permitted to enter the regressions, and each regression was limited to a maximum of five predictors.

Table 12 presents the standardized regression coefficients for these analyses. As this table shows, each competency, strength, and trait was predicted by a distinct set of skill facets. In one case, a convergent measure (PYD Confidence) was uniquely predicted by a lone skill facet (BESSI Confidence Regulation). Several other convergent measures were predicted by a combination of two skill facets. For example, TTC Intrapersonal Strengths were predicted by BESSI Task Management and Responsibility Management. Finally, some convergent measures were predicted by a profile of three or more skill facets. For example, SELS Social Awareness was predicted by BESSI Capacity for Social Warmth, Expressive Skill, and Anger Management. 


\section{Incremental Validity of SEB Skills}

The results reported above indicate that, as expected, several SEB skills converged strongly with the Big Five personality traits. Thus, our final set of analyses in Study 4 investigated whether SEB skills capture any unique information beyond the Big Five traits. To do this, we first regressed each domain-level measure of socioemotional competencies, character strengths, and developmental strengths on the Big Five. In a second step, we added the five BESSI skill domains as an incremental set of predictors. We then reversed this procedure by first regressing each convergent measure on the BESSI domains, and then adding the Big Five.

Table 13 presents the proportion of variance accounted for by each set of predictors. These results show that the Big Five traits accounted for 32\% of the variance in strengths and competencies, on average. Adding the BESSI skill domains as predictors increased this average by $10 \%$, with a statistically significant increment in 15 of 17 cases $(p s<.05)$. By comparison, the BESSI skill domains alone accounted for an average of $38 \%$ of the variance. Adding the Big Five traits increased this average by $4 \%$, with a significant increment in 13 of 17 cases.

Interestingly, the BESSI domains provided especially large increments when predicting the socioemotional competencies assessed by the SELS and SECA. These results indicate that, despite substantial correlations between SEB skills and the Big Five traits, the five BESSI skill domains capture some unique information reflecting socioemotional competencies.

\section{Conclusion}

Taken together, the results of Study 4 support two key conclusions about SEB skills' nomological network. First, SEB skill domains and facets relate meaningfully with other social, emotional, and behavioral constructs including socioemotional competencies, character and developmental strengths, and personality traits. Second, although SEB skills converge 
substantially with personality traits, they also capture unique information. This information likely reflects SEB skills' focus on functional capacities, rather than typical behavior. These findings support the convergent, discriminant, and incremental validity of SEB skills.

\section{Study 5: Testing SEB Skills' Relations with Student Outcomes}

Study 5 aimed to further extend the nomological network of SEB skills by using a longitudinal, multi-method design to test preregistered hypotheses about the capacity of SEB skills to concurrently and prospectively predict student outcomes. We generally expected that SEB skill domains and facets would relate meaningfully with high school students' academic achievement and engagement, occupational interests, social relationships, and well-being.

\section{Method}

\section{Participants and Procedure}

Participants were 492 members of the high school student sample described above (see Study 3) for whom information about one or more student outcomes was available. After completing an online version of the BESSI, these participants also completed a battery of outcome measures as part of the same Qualtrics survey. This battery included measures of academic engagement, occupational interests, peer acceptance, friendship quality, romantic relationship satisfaction, family relationship satisfaction, volunteerism, physical exercise, and life satisfaction. (Due to time constraints, participants could not also complete measures of personality traits, strengths, and competencies.) Beyond these self-reported outcomes, schoolreported course grades were also available for a subset of 474 participants.

Participants were excluded from analysis in Study 5 if they answered fewer than $90 \%$ of an outcome measure's items or failed either of two attention-check items embedded within the 
battery of outcome measures. Missing item responses were imputed using the same procedure as in Studies 2, 3, and 4. All materials and data for Study 5 are available at [https://osf.io/4zgyr/].

\section{Measures}

BESSI skill domains and facets. Observed scale scores for the BESSI domains and facets were computed using the same procedure as in Study 4. Descriptive statistics and interscale correlations for the BESSI domain and facet scales in the high school student sample are presented in Supplemental Table S14. Alpha reliabilities for the BESSI domain scales were .98 for Self-Management Skills, .94 for Social Engagement Skills, .94 for Cooperation Skills, .96 for Emotional Resilience Skills, and .93 for Innovation Skills. Alphas for the 32 facets ranged from .76 to .92 , with a mean of .86 . Correlations between these observed scale scores and factor scores obtained from the hierarchical five-domain CFA model specified in Study 3 were .99 for Self-Management, .97 for Social Engagement, .95 for Cooperation, .98 for Emotional Resilience, and .95 for Innovation. Scale-factor correlations for the 32 BESSI facets ranged from .94 to .99, with a mean of .97 .

Academic Engagement. Academic engagement was assessed using an abbreviated version of the Engagement versus Disaffection with Learning measure (EDL; Skinner et al., 2008). The 20 EDL items are statements assessing behavioral and emotional engagement vs. disaffection that respondents rate on a 4-point agreement scale. Participants rated three items selected from each EDL subscale, producing an index of overall academic engagement with alpha reliability of .80 .

Occupational Interests. Occupational interests were assessed using the O*Net Mini Interest Profiler (Rounds et al., 2016). Its 30 items are tasks associated with realistic, investigative, artistic, social, enterprising, or conventional occupations as conceptualized in the 
RIASEC theory of interest types (Holland, 1997). Respondents rated each item using a 5-point enjoyment scale. Alpha reliabilities were .83 for realistic, .81 for investigative, .81 for artistic, .70 for social, .78 for enterprising, and .76 for conventional interests.

Peer Acceptance. Peer acceptance was assessed using an item from the Behavior Report Form (Paunonen, 2003) and an item adapted from a previous study of social status (Anderson et al., 2001). The first item asked respondents to rate their level of popularity among their peers on a 9-point scale. Similarly, the second item asked respondents to rate their level of status (defined as prominence, respect, and influence) within their social group on a 9-point scale. These two items were averaged to form a composite index of peer acceptance with alpha reliability of .74.

Friendship Quality. Friendship quality was assessed using an abbreviated version of the Friendship Qualities Scale (FQS; Bukowski et al., 1994). The 23 FQS items are statements assessing the companionship, conflict, help, security, and closeness of the respondent's relationship with their best friend who is not their romantic partner. Participants rated three items selected from each FQS subscale using a 5-point agreement scale. Because the conflict subscale did not converge with the other subscales $(r=.11)$, the items from the four remaining subscales were averaged to form an index of overall friendship quality with alpha reliability of .89 .

Romantic Relationship Quality. Participants currently involved with a romantic partner for at least one month completed two items adapted from the Dyadic Adjustment Scale (Spanier, 1976). The first item asked them to rate their overall degree of happiness in the relationship on a 9-point scale. The second asked them to select one of six statements to best describe their feelings about the future of their relationship. These two items were standardized and averaged to form an index of overall romantic relationship quality with alpha reliability of .56. 
Parental Relationship Quality. The quality of participants' relationships with their parents was assessed using six items adapted from the Dunedin Study of lifespan development (see Belsky et al., 2001). These items were questions asking participants to rate the degree of affectional solidarity that they felt with their mother and father using item-specific 5 or 6-point rating scales. These items were standardized and averaged to form separate three-item indexes of relationship quality with the participant's mother (alpha reliability $=.83$ ) and father (alpha $=$ 72).

Volunteerism. Volunteering behavior was assessed using four items adapted from a previous study (Carlo et al., 2005). The first three asked participants to report whether they had ever volunteered, were currently volunteering, and planned to volunteer during the next two months, respectively. The final item asked participants to rate the likelihood that they would volunteer in a community service program if asked, using a 5-point probability scale. Following the original study, these items were submitted to a principal components analysis, and scores on the first unrotated component were saved as an overall index of volunteer behavior with approximate alpha reliability of .62 .

Physical Exercise. Exercise behavior was assessed using the Godin Leisure Time Exercise Questionnaire (Godin \& Shephard, 1985). Its three items ask respondents to report the number of days in a typical week that they engage in strenuous, moderate, and mild physical exercise, respectively. An overall index of exercise behavior is computed as a weighted composite of the three items, with alpha reliability of .53 in the present sample.

Life Satisfaction. Life satisfaction was assessed using the Satisfaction With Life Scale (Diener et al., 1985). Its five items are statements that respondents rate on a 7-point agreement scale. Alpha reliability was .85 . 
Academic Achievement. Participants' course grades during the winter 2020 and spring 2020 quarters were reported by their schools, transformed onto a 0-100 scale, and aggregated into an overall grade point average (GPA) for each term. Because participants completed the BESSI at the beginning of the winter 2020 quarter, their winter and spring course grades can be used to test the predictive associations of SEB skills with academic achievement. Moreover, the winter quarter was completed prior to widespread disruption of the US educational system by the Covid-19 pandemic, whereas the spring quarter was completed in the midst of the pandemic. Therefore, course grades during these two terms reflect students' academic achievement under relatively normal (winter 2020) and highly unusual (spring 2020) circumstances.

\section{Preregistration}

Hypotheses and planned analyses for Study 5 were preregistered with the Character Lab Research Network prior to data collection. The complete preregistration protocol is available at [https://osf.io/f4kjw].

\section{Results and Discussion}

\section{Links between SEB Skill Domains and Student Outcomes}

Domain-level correlations and regressions. Our first set of analyses examined the BESSI skill domains' concurrent and prospective associations with student outcomes. Preregistered predictions for 19 of these associations are shown in Supplemental Table S15. Table 14 presents zero-order domain-outcome correlations, as well as partial correlations controlling for gender and grade level. Table 15 presents standardized coefficients from regressing each outcome on the set of five skill domains, as well as gender and grade level. As these tables show, 18 of the 19 hypothesized domain-outcome associations showed statistically significant $(p<.05)$ correlations in the expected direction (Mean $r=.32$ ). All 18 of these effects 
remained significant after controlling for gender and grade level (Mean partial $r=.32$ ), and 11 still remained significant after also controlling for the other four skill domains (Mean $\beta=.37$ ).

A total of 19 domain-outcome associations remained statistically significant in the same direction across all of the correlation and regression analyses. This included 11 associations hypothesized in Table S2: Self-Management Skills predicted winter and spring course grades, as well as academic engagement; Social Engagement Skills predicted enterprising occupational interests, peer acceptance, friendship quality, exercise, and life satisfaction; Emotional Resilience Skills predicted life satisfaction; and Innovation Skills predicted investigative and artistic interests. The results also included eight non-hypothesized but readily interpretable associations: Self-Management Skills predicted mother and father relationship quality, as well as life satisfaction; Cooperation Skills predicted social interests and friendship quality; and Emotional Resilience Skills predicted academic engagement, realistic interests, and peer acceptance.

\section{Links between the BESSI Facets and Student Outcomes}

Facet-level correlations. We also conducted exploratory analyses to investigate the BESSI skill facets' links with student outcomes. Table 16 presents the zero-order correlations, as well as partial correlations controlling for gender and grade level. These results indicate that some skill-outcome associations generalized across multiple same-domain facets, but other facets also showed distinctive associations with student outcomes. For example, winter course grades were predicted by each of the nine Self-Management facets, but also by the Leadership Skill facet of Social Engagement, the Teamwork Skill facet of Cooperation, the Abstract Thinking Skill facet of Innovation, and the Information Processing Skill interstitial facet.

Facet-level regressions. Our final set of analyses used forward regressions to identify the most distinctive facet-outcome links by regressing each student outcome on the set of 32 BESSI 
facets. As in Study 4, only predictors significant at the $p<.001$ level were permitted to enter, and each regression was limited to a maximum of five predictors.

The standardized regression coefficients for these analyses are presented in Table 17. These results show that each of the 17 student outcomes, aside from romantic relationship quality, was significantly predicted by a distinctive set of skill facets. Some outcomes were uniquely predicted by a single facet. For example, artistic occupational interests were predicted by Creative Skill, and exercise behavior by Energy Regulation. Other outcomes were positively predicted by a combination of facets. For example, spring GPA was positively predicted by the combination of Leadership Skill and Task Management, whereas peer acceptance was predicted by Confidence Regulation and Conversational Skill.

\section{Conclusion}

The findings of Study 5 extend the nomological network of SEB skills by showing that skill domains and facets concurrently and prospectively predict student outcomes. Specifically, the BESSI domains and facets showed conceptually meaningful and empirically robust associations with high school students' academic achievement (i.e., course grades) and engagement, occupational interests, social relationships, and well-being.

\section{General Discussion}

The present research addressed three key questions about the conceptualization and assessment of social, emotional, and behavioral skills. First, how should SEB skills be defined and distinguished from other kinds of psychological constructs? We defined SEB skills as people's capacities to maintain social relationships, regulate emotions, and manage goal- and learning-directed behaviors. Furthermore, we proposed that SEB skills can be distinguished from personality traits in that skills represent how someone is capable of thinking, feeling, and 
behaving when the situation calls for it, whereas traits represent how someone tends to think, feel, and behave when averaged across situations. Supporting this proposal, we used our definition to translate facet-level personality constructs into an inclusive list of candidate skills (Study 1). We then refined this list into a final set of 32 conceptually coherent and empirically distinguishable SEB skill facets (Study 2).

Second, how can specific SEB skills be organized within broader domains? Based on prominent points of overlap between previous taxonomies, we proposed that most skill facets can be organized within five major domains_-Social Engagement Skills, Cooperation Skills, SelfManagement Skills, Emotional Resilience Skills, and Innovation Skills - that resemble the Big Five in terms of their social, emotional, and behavioral referents, but represent sets of related functional capacities rather than traits. Supporting this proposal, results from five samples indicated that many skill facets are clearly linked with one of the five proposed domains, but that some interstitial and compound facets combine aspects of multiple domains (Study 3).

Third, how should SEB skills be measured? We proposed that a skills inventory approach could provide reliable, valid, efficient, and flexible assessment. In this approach, each inventory item assesses a specific behavior, and respondents rate their own (or a target individual's) capacity to successfully enact that behavior. We implemented this proposal by developing and validating the Behavioral, Emotional, and Social Skills Inventory (BESSI). We found that the BESSI domains and facets have a robust multidimensional structure (Studies 2 and 3), converge with competencies, strengths, and personality traits while still providing unique information (Study 4), and predict consequential outcomes such as academic achievement and engagement, occupational interests, social relationships, and well-being (Study 5). 


\section{Broader Implications}

By investigating these questions and proposals, the present research makes two emergent contributions to the skills literature. The first is a framework that integrates a conceptualization of SEB skills as functional capacities with a structural model of domains and facets that is both inclusive and differentiated. The second is a measure — the BESSI — that is arguably the most comprehensive and psychometrically sound measure of SEB skills currently available.

These contributions advance our understanding of skill-related constructs, and offer new opportunities for applying this knowledge. For example, our definition of SEB skills as functional capacities draws on previous scholarship concerning trait vs. ability conceptualizations of personality (Paulhus \& Martin, 1987; Wallace, 1966, 1967), typical vs. maximal performance (Sackett et al., 1988; Turner, 1978), and socioemotional strengths and competencies (Abrahams et al., 2019; Duckworth \& Yeager, 2015). We extend this scholarship by conceptualizing and assessing SEB skills within a broadband framework that spans thoughts, feelings, and behaviors ranging from leadership and teamwork to time management and creativity. Moreover, we provide new evidence regarding the degree of relation vs. differentiation between SEB skills and personality traits. Extending previous studies (Paulhus \& Martin, 1987; Turner, 1978), we found positive correlations between the Big Five personality traits and the five skill domains assessed by the BESSI. These correlations were substantial in size, but SEB skills provided unique information even after controlling for personality traits. We suspect that the positive relations between personality traits and SEB skills reflect reciprocal influences: someone who is good at performing a particular behavior (high skill) will likely enact it more frequently (high trait), and conversely someone who frequently enacts a behavior will 
tend to become better at performing it. However, additional research using longitudinal or experimental designs is needed to directly test for such reciprocal influences.

Our conceptual framework also offers new insights regarding the structure of individual differences in thoughts, feelings, and behavior. Personality traits are typically conceptualized and measured as relatively independent dimensions (Goldberg, 1990; John et al., 2008). In contrast, we found that the structure of SEB skills is a positive—-but still differentiated — manifold (see also Paulhus \& Martin, 1987). This positive manifold likely reflects, at least in part, measurement artifacts (e.g., evaluative bias, response style, use of unipolar scales; Anusic et al., 2009; Goldberg, 1992; Rammstedt et al., 2013). However, it may also partly reflect a substantive individual difference (e.g., in people's overall levels of functioning; Musek, 2007). Future research can test these possibilities.

A related insight concerns the relative prominence of specific forms of thinking, feeling, and behaving within trait vs. skill conceptualizations. The Big Five traits are traditionally ordered (I) Extraversion, (II) Agreeableness, (III) Conscientiousness, (IV) Emotional Stability vs. Neuroticism, and (V) Openness to Experience (Goldberg, 1990; John et al., 2008). This ordering reflects the fact that natural language includes many words to describe interpersonal traits, somewhat fewer to describe task and goal-focused traits, and fewer still to describe emotional and cognitive traits (De Raad et al., 2010). In contrast, the present research yielded a conceptual and empirical framework in which Self-Management subsumed about twice as many facets as any other skill domain. This outcome is consistent with the considerable attention paid to self-management constructs (e.g., grit, self-control, self-regulation) in the skills literature (CASEL, 2020; Casillas et al., 2015; Duckworth, Peterson, Matthews, \& Kelly, 2007; Kautz et al., 2014; OECD, 2015). It suggests that many task-focused and motivational constructs can be 
readily conceptualized as skills, and that reconceptualizing some social and emotional traits as skills may shift them toward the self-management domain.

Our work to develop and validate the BESSI also has broader implications. Previous scholarship has noted that skill assessment approaches have different strengths and weaknesses, and suggested that skills inventories can combine the strong psychometrics of questionnaire measures with the focus on functional capacities embodied by behavioral tasks (Abrahams et al., 2019; Davidson et al., 2018; Duckworth \& Yeager, 2015; Soto et al., 2021). The present research provides further evidence for the promise of skills inventories, as well as a new tool that assesses 32 specific skill facets across five broad domains. Our findings indicate that the BESSI domains and facets are reliable and valid, with a robust multidimensional structure. The inventory can be flexibly adapted to both self-report and observer-report formats, and is efficient in terms of assessment time and cost. We therefore believe that the BESSI will prove useful for researchers who wish to further investigate SEB skills, as well as practitioners and policymakers who aim to assess and promote skill development in real-world contexts.

\section{Limitations and Future Directions}

The present research had important strengths, including its examination of multiple samples, developmental periods, rating perspectives, convergent constructs, and life outcomes. However, it also had limitations that highlight promising directions for future research.

\section{Calibrating the BESSI for Varied Research and Applied Contexts}

One could argue that the BESSI is both too long and too short. It is too long in the sense that a 192-item inventory, which takes approximately 15 minutes to administer, is unsuitable for some research and applied contexts with strict constraints on assessment time (e.g., Summerfield et al., 2015; Taylor et al., 2010; Wagner, Frick, \& Schupp, 2007). One potential strategy for 
abbreviating the BESSI would be to reduce the number of items used to assess each skill. An alternative strategy would be to assess only a subset of facets within each domain; for example, one could select the specific facets that seem most relevant for a particular project. However, reducing the length or breadth of a behavioral measure generally entails costs to reliability and validity (Soto \& John, 2019). Therefore, future research is needed to develop,validate, and compare short forms of the BESSI.

In contrast, the BESSI is arguably too short in that it may not assess every important SEB skill, nor does it assess other factors important for success in life, such as content knowledge and opportunity. We aimed to make the BESSI inclusive by reviewing a number of existing measures and identifying as many candidate SEB skill facets as possible. However, these existing measures focused on the Big Five personality domains, which limited our ability to identify skills beyond these domains. It may therefore be possible to define further important facets within each skill domain, further interstitial and compound facets that blend aspects of multiple domains, and potentially skills that fall entirely outside of these domains. In fact, one possible future for the BESSI is an increasingly expansive, publicly available menu of skill constructs and scales from which researchers and practitioners can sample as needed (cf. Goldberg et al., 2006).

Another measurement-related future direction concerns methods for scoring and modeling SEB skills. The present research has shown that the BESSI's factor structure can be effectively modeled using CFA and ESEM, and that observed scale scores can serve as a reasonable proxy for latent factor scores. The high internal consistency of the BESSI facet scales suggests that, in future work, Item Response Theory (IRT) approaches could also be used to estimate skill scores and further investigate their multidimensional structure. 


\section{Investigating Relations and Distinctions between Individual Difference Constructs}

The present research examined the SEB skills' convergence with a broad array of constructs and outcomes. However, all outcomes other than academic achievement were selfreported. Thus, further research is needed to test SEB skills' relations with observer-reported and objectively recorded outcomes. Moreover, the list of constructs used to investigate convergent and discriminant validity had at least one notable omission: intelligence, including cognitive ability as well as emotional and personal intelligence (Mayer et al., 2003, 2012). We expect that some SEB skills within the Innovation domain will relate with cognitive ability due to their emphasis on learning-related capacities, while some Cooperation and Emotional Resilience skills may relate with emotional and personal intelligence due to their emphasis on understanding emotions. However, future research is needed to test these hypotheses.

A broader point concerns the usefulness of distinguishing SEB skills from other kinds of individual difference constructs. Here and elsewhere, we have argued that SEB skills can be conceptually distinguished from personality traits and intelligence, as well as beliefs, attitudes, and values (Napolitano et al., 2021; Soto et al., 2021). But should they be? We believe so. One reason concerns their potential predictive power. Skills may be especially potent predictors of outcomes that require individuals to call on specific skills in high-stakes situations, whereas traits may better predict outcomes that rely on sustained behavior over long periods of time. A second reason concerns responsiveness to intervention. Conceptualizing SEB skills as functional capacities suggests that they can be learned and improved through training and effortful practice (Ambrose et al., 2010). In contrast, changing traits, beliefs, attitudes, and values may require different approaches, such as persuasion or habit formation (Hudson et al., 2019; Magidson et al., 2014). However, we did not directly compare the relations of skills, traits, strengths, and 
competencies with life outcomes, nor did we compare these constructs' developmental trajectories. Thus, future research is needed to further investigate these possibilities.

\section{The Accuracy of SEB Skill Self-Reports and Observer-Reports}

The present findings provide encouraging evidence regarding the reliability and validity of the BESSI as a self-report and observer-report measure of SEB skills. However, it also raises questions about the limits of ability self-reports and observer-reports. Previous research on cognitive ability has observed only moderate correlations between self-reported and objectively measured intelligence, with most people overestimating their cognitive ability (Freund \& Kasten, 2012; Gignac \& Zajenkowski, 2019). However, perceived ability can still predict achievement outcomes, even after controlling for objective measures (Chamorro-Premuzic et al., 2010; Guay et al., 2003). Thus, further research is needed to investigate accuracy and bias in self-reports and observer-reports of SEB skills.

\section{The Cultural Generalizability vs. Specificity of SEB Skills}

The present research analyzed data from seven independent samples. However, three of these samples recruited participants from only the United States; the others included a large number of countries, but a relatively small number of participants per country. These data provide some evidence for the generalizability of our findings, but did not allow us to directly test for cultural variation in the structure of SEB skills, in the BESSI's psychometric properties, or in links between skills and outcomes. Testing for cross-cultural generalizability is an important next step for SEB skills research, as there is considerable momentum towards developing skills interventions for youth in low- and middle-income countries (Outes-León et al., 2020). However, previous research provides only mixed evidence for the cross-cultural generalizability of other individual difference constructs, such as personality traits (e.g., De Raad 
et al., 2010; Laajaj et al., 2019; Schmitt et al., 2007; Thalmayer \& Saucier, 2014). In future work, we encourage researchers to investigate cross-cultural variation in the structure and correlates of SEB skills, thereby informing culture-specific assessments, applications, and interventions.

\section{Unpacking the Bidirectional Dynamics Between Person and Context in SEB Skills}

SEB skills reflect maximum capacities: how well a person can perform a particular behavior when a situation calls for it. Skills therefore represent a dynamic relation between a person and their context (Lerner et al., 2012; Mischel \& Shoda, 1995; Overton, 2015), in that specific situations (e.g., an impending deadline) afford a person with opportunities to use specific SEB skills (e.g., task management, stress regulation) to achieve their goals. However, future research is needed to further investigate person-situation dynamics as they relate to SEB skills. We suspect that motivation plays a key role in determining whether or not people exert their maximum skills in response to a particular situation, leading to responses such as "I'll try my very best" or "I could if I wanted to" (Duckworth et al., 2011).

\section{How Malleable are SEB skills?}

One aspect of SEB skills that has intrigued researchers, practitioners, and policymakers alike is their potential plasticity, whether through normative developmental changes or targeted interventions (Duckworth \& Yeager, 2015; Kautz et al., 2014; OECD, 2015). Although the present research assessed SEB skills in samples spanning from adolescence through middle age, it did not assess changes in SEB skills. Thus, future research can examine the longitudinal development and intervention-based plasticity of SEB skills.

For example, previous work has concluded that the lifespan development of personality traits is characterized by the cumulative continuity principle, which holds that traits' rank-order stability gradually increases across the life span, the maturity principle, which holds that most 
people become more agreeable, conscientious, and emotionally stable as they age, and the disruption hypothesis, which notes that these positive developmental trends are temporarily interrupted during early adolescence (Roberts \& DelVecchio, 2000; Roberts et al., 2006; Soto \& Tackett, 2015). These principles may or may not characterize the development of SEB skills.

Future research can also investigate the malleability of SEB skills through interventions and policy efforts. Previous work provides encouraging but preliminary evidence for the effectiveness of programs designed to promote skill development (Durlak et al., 2010, 2011; Sánchez Puerta et al., 2016). However, this work is characterized by wide variation in the constructs assessed, the populations targeted, and the design and implementation of interventions and other programs (Kautz et al., 2014; Ura et al., in press). Our integrative framework for SEB skills provides a comprehensive, flexible, and psychometrically sound approach for assessing the effectiveness and outcomes of skill-focused interventions.

\section{Conclusion}

The present research developed and validated a framework for conceptualizing and assessing social, emotional, and behavioral skills. Our findings indicate that SEB skills can be (a) conceptualized as people's capacities to maintain social relationships, regulate emotions, and manage goal- and learning-directed behaviors, (b) organized within five major domains that resemble the Big Five personality traits but are defined by sets of functional capacities rather than typical patterns of behavior, and (c) reliably, validly, efficiently, and flexibly assessed using the Behavioral, Emotional, and Social Skills Inventory (BESSI). We hope that this work will bring our passionate, multidisciplinary community of researchers and practitioners closer to consensus regarding what SEB skills are, how they can be organized within an overarching framework, and how they can be reliably and validly assessed. 


\section{References}

Abrahams, L., Pancorbo, G., Primi, R., Santos, D., Kyllonen, P., John, O. P., \& De Fruyt, F. (2019). Social-emotional skill assessment in children and adolescents: Advances and challenges in personality, clinical, and educational contexts. Psychological Assessment, 31(4), 460-473. https://doi.org/10.1037/pas0000591

Allport, G. W. (1937). Personality: A psychological interpretation. Holt.

Ambrose, S. A., Bridges, M. W., DiPietro, M., Lovett, M. C., \& Norman, M. K. (2010). How learning works: Seven research-based principles for smart teaching. Jossey-Bass.

Anderson, C., John, O. P., Keltner, D., \& Kring, A. M. (2001). Who attains social status? Effects of personality and physical attractiveness in social groups. Journal of Personality and Social Psychology, 81(1), 116-132. https://doi.org/10.1037/0022-3514.81.1.116

Anusic, I., Schimmack, U., Pinkus, R. T., \& Lockwood, P. (2009). The nature and structure of correlations among Big Five ratings: The halo-alpha-beta model. Journal of Personality and Social Psychology, 97(6), 1142-1156. https://doi.org/10.1037/a0017159

Belsky, J., Jaffee, S., Hsieh, K.-H., \& Silva, P. A. (2001). Child-rearing antecedents of intergenerational relations in young adulthood: A prospective study. Developmental Psychology, 37(6), 801-813. https://doi.org/10.1037/0012-1649.37.6.801

Berg, J., Osher, D., Same, M. R., Nolan, E., Benson, D., \& Jacobs, N. (2017). Identifying, defining, and measuring social and emotional competencies. American Institutes for Research.

Bukowski, W. M., Hoza, B., \& Boivin, M. (1994). Measuring friendship quality during pre- and early adolescence: The Development and psychometric properties of the friendship 
qualities scale. Journal of Social and Personal Relationships, 11(3), 471-484. https://doi.org/10.1177/0265407594113011

Carlo, G., Okun, M. A., Knight, G. P., \& de Guzman, M. R. T. (2005). The interplay of traits and motives on volunteering: Agreeableness, extraversion and prosocial value motivation. Personality and Individual Differences, 38(6), 1293-1305. https://doi.org/10.1016/j.paid.2004.08.012

Collaborative for Academic, Social, and Emotional Learning [CASEL]. (2020). SEL: What are the core competence areas and where are they promoted? https://casel.org/sel$\underline{\text { framework/ }}$

Casillas, A., Way, J., Burrus, J. (2015). Behavioral skills. In Camara, W., O’Connor, R., Mattern, K., Hanson, M. A. (Eds.), Beyond academics: A holistic framework for enhancing education and workplace success (pp. 25-38). ACT.

Chamorro-Premuzic, T., Harlaar, N., Greven, C. U., \& Plomin, R. (2010). More than just IQ: A longitudinal examination of self-perceived abilities as predictors of academic performance in a large sample of UK twins. Intelligence, 38, 385-392.

Chernyshenko, O. S., Kankaraš, M., \& Drasgow, F. (2018). Social and emotional skills for student success and well-being: Conceptual framework for the OECD study on social and emotional skills. https://doi.org/10.1787/db1d8e59-en

Condon, D. M. (2017). The SAPA Personality Inventory: An empirically-derived, hierarchicallyorganized self-report personality assessment model. PsyArXiv. https://doi.org/10.31234/osf.io/sc4p9

Cronbach, L. J., \& Meehl, P. E. (1955). Construct validity in psychological tests. Psychological Bulletin, 52(4), 281-302. https://doi.org/10.1037/h0040957 
Davidson, L. A., Crowder, M. K., Gordon, R. A., Domitrovich, C. E., Brown, R. D., \& Hayes, B. I. (2018). A continuous improvement approach to social and emotional competency measurement. Journal of Applied Developmental Psychology, 55, 93-106. https://doi.org/10.1016/j.appdev.2017.03.002

De Raad, B., Barelds, D. P. H., Levert, E., Ostendorf, F., Mlačić, B., Blas, L. D., Hřebíčková, M., Szirmák, Z., Szarota, P., Perugini, M., Church, A. T., \& Katigbak, M. S. (2010). Only three factors of personality description are fully replicable across languages: A comparison of 14 trait taxonomies. Journal of Personality and Social Psychology, 98(1), 160-173. https://doi.org/10.1037/a0017184

DeYoung, C. G. (2006). Higher-order factors of the Big Five in a multi-informant sample. Journal of Personality and Social Psychology, 91(6), 1138-1151. https://doi.org/10.1037/0022-3514.91.6.1138

DeYoung, C. G., Weisberg, Y. J., Quilty, L. C., \& Peterson, J. B. (2013). Unifying the aspects of the Big Five, the interpersonal circumplex, and trait affiliation. Journal of Personality, 81(5), 465-475. https://doi.org/10.1111/jopy.12020

Diener, E., Emmons, R. A., Larsen, R. J., \& Griffin, S. (1985). The Satisfaction With Life Scale. Journal of Personality Assessment, 49(1), 71-75. https://doi.org/10.1207/s15327752jpa4901_13

Diener, E., Oishi, S., \& Lucas, R. E. (2003). Personality, culture, and subjective well-being: Emotional and cognitive evaluations of life. Annual Review of Psychology, 54(1), 403425. https://doi.org/10.1146/annurev.psych.54.101601.145056

Duckworth, A. L. (2019). Using psychological science to help children thrive. Perspectives on Psychological Science, 14(1), 34-36. https://doi.org/10.1177/1745691618804194 
Duckworth, A. L., Peterson, C., Matthews, M. D., \& Kelly, D. R. (2007). Grit:

Perseverance and passion for long-term goals. Journal of Personality and Social Psychology, 92(6), 1087-1101. https://doi.org/10.1037/0022-3514.92.6.1087

Duckworth, A. L., Quinn, P. D., Lynam, D. R., Loeber, R., \& Stouthamer-Loeber, M. (2011). Role of test motivation in intelligence testing. Proceedings of the National Academy of Sciences, 108, 7716-7720. https://doi.org/10.1073/pnas.1018601108

Duckworth, A. L., Yeager, D. S. (2015). Measurement matters: Assessing personal qualities other than cognitive ability for educational purposes. Educational Researcher, 44, $237-$ 251. https://doi.org/10.3102/0013189X15584327

Durlak, J. A., Weissberg, R. P., Dymnicki, A. B., Taylor, R. D., \& Schellinger, K. B. (2011). The impact of enhancing students' social and emotional learning: A meta-analysis of schoolbased universal interventions. Child Development, 82(1), 405-432. https://doi.org/10.1111/j.1467-8624.2010.01564.x

Durlak, J. A., Weissberg, R. P., Pachan, M. (2010). A meta-analysis of after-school programs that seek to promote personal and social skills in children and adolescents. American Journal of Community Psychology, 45, 249-309. https://doi.org/10.1007/s10464-010$\underline{9300-6}$

Eisenberg, I. W., Bissett, P. G., Zeynep Enkavi, A., Li, J., MacKinnon, D. P., Marsch, L. A., \& Poldrack, R. A. (2019). Uncovering the structure of self-regulation through data-driven ontology discovery. Nature Communications, 10(1), 2319. https://doi.org/10.1038/s41467-019-10301-1

Enkavi, A. Z., Eisenberg, I. W., Bissett, P. G., Mazza, G. L., MacKinnon, D. P., Marsch, L. A., \& Poldrack, R. A. (2019). Large-scale analysis of test-retest reliabilities of self- 
regulation measures. Proceedings of the National Academy of Sciences, 116(12), 54725477. https://doi.org/10.1073/pnas.1818430116

Farrington, C. A., Roderick, M., Allensworth, E., Nagaoka, J., Keyes, T. S., Johnson, D. W., \& Beechum, N. O. (2012). Teaching adolescents to become learners: The role of noncognitive factors in shaping school performance-A critical literature review. Consortium on Chicago School Research. https://eric.ed.gov/?id=ED542543

Fleeson, W. \& Jayawickreme, E. (2015). Whole Trait Theory. Journal of Research in Personality, 56(6), 82-92. https://doi.org/10.1016/j.jrp.2014.10.009

Freund, A. M., Napolitano, C. M., \& Rutt, J. L. (2019). Personality development in adulthood: A goal perspective. In D. P. McAdams, R. L. Shiner, \& J. L. Tackett (Eds.), Handbook of personality development (pp. 313-327). Guilford Press.

Freund, P. A., \& Kasten, N. (2012). How smart do you think you are? A meta-analysis on the validity of self-estimates of cognitive ability. Psychological Bulletin, 138, 296-321.

Geldhof, G. J., Bowers, E. P., Boyd, M. J., Mueller, M. K., Napolitano, C. M., Schmid, K. L., Lerner, J. V., \& Lerner, R. M. (2014). Creation of short and very short measures of the Five Cs of positive youth development. Journal of Research on Adolescence, 24(1), 163 176. https://doi.org/10.1111/jora.12039

Geldhof, G. J., Porter, T., Weiner, M. B., Malin, H., Bronk, K. C., Agans, J. P., Mueller, M., Damon, W., \& Lerner, R. M. (2014). Fostering youth entrepreneurship: Preliminary findings from the young entrepreneurs study. Journal of Research on Adolescence, 24(3), 431-446. https://doi.org/10.1111/jora.12086

Gignac, G. E., \& Zajenkowski, M. (2019). People tend to overestimate their romantic partner's intelligence even more than their own. Intelligence, 73, 41-51. 
Godin, G., \& Shephard, R. J. (1985). A simple method to assess exercise behavior in the community. Canadian Journal of Applied Sport Sciences, 10(3), 141-146.

Goldberg, L. R. (1990). An alternative "description of personality": The Big-Five factor structure. Journal of Personality and Social Psychology, 59(6), 1216-1229. https://doi.org/10.1037/0022-3514.59.6.1216

Goldberg, L. R. (1992). The development of markers for the Big-Five factor structure. Psychological Assessment, 4, 26-42. https://doi.org/10.1037/1040-3590.4.1.26

Goldberg, L. R., Johnson, J. A., Eber, H. W., Hogan, R., Ashton, M. C., Cloninger, C. R., \& Gough, H. G. (2006). The International Personality Item Pool and the future of publicdomain personality measures. Journal of Research in Personality, 40(1), 84-96. https://doi.org/10.1016/j.jrp.2005.08.007

Guay, F., Marsh, H. W., \& Boivin, M. (2003). Academic self-concept and academic achievement: Developmental perspectives on their causal ordering. Journal of Educational Psychology, 95, 124-136.

Harden, K. P.[@kph3k]. (2021, January 11). ICYMI, we had a new paper come out in @NatureGenet last week: a GWAS of "noncognitive skills," a construct that nearly everyone can agree is important, but no one can agree on how to measure [Tweet]. Twitter. https://twitter.com/kph3k/status/1348714898243678210

Heckman, J. J., \& Kautz, T. (2012). Hard evidence on soft skills. Labour Economics, 19(4), 451464. https://doi.org/10.1016/j.labeco.2012.05.014

Holland, J. L. (1997). Making vocational choices: A theory of vocational personalities and work environments (3rd ed.). Psychological Assessment Resources. 
Hooper, D., Coughlan, J., \& Mullen, M. (2008, June). Evaluating model fit: A synthesis of the structural equation modelling literature. In A. Brown (Ed.), Proceedings of the 7th European Conference on Research Methodology for Business and Management Studies (pp. 195-200).

Hudson, N. W., Briley, D. A., Chopik, W. J., \& Derringer, J. (2019). You have to follow through: Attaining behavioral change goals predicts volitional personality change. Journal of Personality and Social Psychology, 117(4), 839-857. https://doi.org/10.1037/pspp0000221

John, O. P., Naumann, L. P., \& Soto, C. J. (2008). Paradigm shift to the integrative Big Five trait taxonomy: History, measurement, and conceptual issues. In Handbook of personality: Theory and research, 3rd ed (pp. 114-158). The Guilford Press.

John, O. P., \& Soto, C. J. (2007). The importance of being valid: Reliability and the process of construct validation. In Handbook of research methods in personality psychology (pp. 461-494). The Guilford Press.

Kautz, T., Heckman, J. J., Diris, R., Weel, B. ter, \& Borghans, L. (2014). Fostering and Measuring Skills: Improving Cognitive and Non-Cognitive Skills to Promote Lifetime Success (No. w20749). National Bureau of Economic Research. https://doi.org/10.3386/w20749

Laajaj, R., Macours, K., Pinzon Hernandez, D. A., Arias, O., Gosling, S. D., Potter, J., RubioCodina, M., \& Vakis, R. (2019). Challenges to capture the Big Five personality traits in non-WEIRD populations. Science Advances, 5(7), eaaw5226. https://doi.org/10.1126/sciadv.aaw5226 
Lerner, J. V., Bowers, E. P., Minor, K., Boyd, M. J., Mueller, M. K., Schmid, K. L., Napolitano, C. M., Lewin-Bizan, S., \& Lerner, R. M. (2013). Positive youth development: Processes, philosophies, and programs. In R. M. Lerner, M. A. Easterbrooks, J. Mistry, \& I. B. Weiner (Eds.), Handbook of psychology: Developmental psychology (pp. 365-392). Wiley.

Lerner, R. M., Lerner, J. V., Almerigi, J. B., Theokas, C., Phelps, E., Gestsdottir, S., Naudeau, S., Jelicic, H., Alberts, A., Ma, L., Smith, L. M., Bobek, D. L., Richman-Raphael, D., Simpson, I., Christiansen, E. D., \& von Eye, A. (2005). Positive youth development, participation in community youth development programs, and community contributions of fifth-grade adolescents: Findings from the first wave of the 4-H study of positive youth development. The Journal of Early Adolescence, 25(1), 17-71. https://doi.org/10.1177/0272431604272461

Lorenzo-Seva, U., \& ten Berge, J. M. F. (2006). Tucker's congruence coefficient as a meaningful index of factor similarity. Methodology, 2(2), 57-64. https://doi.org/10.1027/1614$\underline{2241.2 .2 .57}$

Magidson, J. F., Roberts, B. W., Collado-Rodriguez, A., \& Lejuez, C. W. (2014). Theory-driven intervention for changing personality: Expectancy value theory, behavioral activation, and conscientiousness. Developmental Psychology, 50(5), 1442-1450. https://doi.org/10.1037/a0030583

Mayer, J. D., Panter, A. T., \& Caruso, D. R. (2012). Does personal intelligence exist? Evidence from a new ability-based measure. Journal of Personality Assessment, 94, 124-140. https://doi.org/10.1080/00223891.2011.646108 
Mayer, J. D., Salovey, P., Caruso, D. R., \& Sitarenios, G. (2003). Measuring emotional intelligence with the MSCEIT V2.0. Emotion, 3(1), 97-105. https://doi.org/10.1037/1528-3542.3.1.97

McCrae, R. R., \& Costa, P. T. (1989). The structure of interpersonal traits: Wiggins's circumplex and the Five-Factor Model. Journal of Personality and Social Psychology, 56(4), 586595. https://doi.org/10.1037/0022-3514.56.4.586

McCrae, R. R., \& Costa, P. T., Jr. (2010). NEO Inventories Professional Manual. Psychological Assessment Resources.

Mehl, M. R., Gosling, S. D., \& Pennebaker, J. W. (2006). Personality in its natural habitat: Manifestations and implicit folk theories of personality in daily life. Journal of Personality and Social Psychology, 90(5), 862-877. https://doi.org/10.1037/0022$\underline{3514.90 .5 .862}$

Mischel, W., \& Shoda, Y. (1995). A cognitive-affective system theory of personality: Reconceptualizing situations, dispositions, dynamics, and invariance in personality structure. Psychological Review, 102, 246-268. https://doi.org/10.1037/0033295X.102.2.246

Musek, J. (2007). A general factor of personality: Evidence for the Big One in the Five-Factor Model. Journal of Research in Personality, 41(6), 1213-1233. https://doi.org/10.1016/j.jrp.2007.02.003

Muthén, L. K. and Muthén, B. O. (2017). Mplus User's Guide (8th ed.). Muthén \& Muthén. Nagaoka, J., Farrington, C. A., Ehrlich, S. B., \& Heath, R. D. (2015). Foundations for young adult success: A developmental framework. University of Chicago Consortium on Chicago School Research. https://eric.ed.gov/?id=ED559970 
National Research Council. (2012). Education for life and work: Developing transferable knowledge and skills in the 21st century. The National Academies Press.

Napolitano, C. M., Sewell, M. N., Yoon, H. J., Soto, C. J., \& Roberts, B. W. (2021). Social, emotional, and behavioral skills: An integrative model of the skills associated with success during adolescence and across the life span. Frontiers in Education, 6, 679561. https://doi.org/10.3389/feduc.2021.679561

Noftle, E. E., \& Robins, R. W. (2007). Personality predictors of academic outcomes: Big Five correlates of GPA and SAT scores. Journal of Personality and Social Psychology, 93(1), 116-130. https://doi.org/10.1037/0022-3514.93.1.116

Organisation for Economic Co-operation and Development [OECD] (2015). Skills for social progress: The power of social and emotional skills. http://www.oecd.org/education/skillsfor-social-progress-9789264226159-en.htm

Outes-Leon, I., Sánchez, A., \& Vakis, R. (2020). The power of believing you can get smarter: The impact of a growth-mindset intervention on academic achievement in Peru. The World Bank. https://doi.org/10.1596/1813-9450-9141

Overton, W. F. (2015). Processes, relations, and relational-developmental-systems. In W. F. Overton, P. C. M. Molenaar, \& R. M. Lerner (Eds.), Handbook of child psychology and developmental science: Theory and method (pp. 9-62). Wiley. https://doi.org/10.1002/9781118963418.childpsy102

Ozer, D. J., \& Benet-Martinez, V. (2006). Personality and the prediction of consequential outcomes. Annual Review of Psychology, 57, 401-421. https://doi.org/10.1146/annurev.psych.57.102904.190127 
Park, D., Tsukayama, E., Goodwin, G. P., Patrick, S., \& Duckworth, A. L. (2017). A tripartite taxonomy of character: Evidence for intrapersonal, interpersonal, and intellectual competencies in children. Contemporary Educational Psychology, 48, 16-27. https://doi.org/10.1016/j.cedpsych.2016.08.001

Paulhus, D. L., \& Martin, C. L. (1987). The structure of personality capabilities. Journal of Personality and Social Psychology, 52(2), 354-365. https://doi.org/10.1037/0022$\underline{3514.52 .2 .354}$

Paunonen, S. V. (2003). Big Five factors of personality and replicated predictions of behavior. Journal of Personality and Social Psychology, 84(2), 411-424. https://doi.org/10.1037/0022-3514.84.2.411

Petrides, K. V. (2009). Psychometric properties of the Trait Emotional Intelligence Questionnaire (TEIQue). In C. Stough, D. H. Saklofske, \& J. D. A. Parker (Eds.), Assessing emotional intelligence: Theory, research, and applications (pp. 85-101). Springer.

Primi, R., Santos, D., John, O. P., \& Fruyt, F. D. (2016). Development of an inventory assessing social and emotional skills in Brazilian youth. European Journal of Psychological Assessment, 32(1), 5-16. https://doi.org/10.1027/1015-5759/a000343

Rammstedt, B., Kemper, C. J., \& Borg, I. (2013). Correcting Big Five personality measurements for acquiescence: An 18-country cross-cultural study. European Journal of Personality, 27(1), 71-81. https://doi.org/10.1002/per.1894

Roberts, B. W., \& DelVecchio, W. F. (2000). The rank-order consistency of personality traits from childhood to old age: A quantitative review of longitudinal studies. Psychological Bulletin, 126(1), 3-25. https://doi.org/10.1037/0033-2909.126.1.3 
Roberts, B. W., Walton, K. E., \& Viechtbauer, W. (2006). Patterns of mean-level change in personality traits across the life course: A meta-analysis of longitudinal studies. Psychological Bulletin, 132(1), 1-25. https://doi.org/10.1037/0033-2909.132.1.1

Roberts, B. W., Wood, D., \& Caspi, A. (2008). The development of personality traits in adulthood. In O. P. John, R. W. Robins, \& L. A. Pervin (Eds.), Handbook of personality: Theory and research (pp. 375-398). Guilford.

Rounds, J., Ming, C. W. J., Cao, M., Song, C., \& Lewis, P. (2016). Development of an $O * N E T$ Mini Interest Profiler (Mini-IP) for mobile devices: Psychometric characteristics. Department of Labor O* NET Resource Center.

Rowling, J. K. (1997). Harry Potter and the philosopher's stone. Bloomsbury.

Sackett, P. R., Zedeck, S., \& Fogli, L. (1988). Relations between measures of typical and maximum job performance. Journal of Applied Psychology, 73(3), 482-486. https://doi.org/10.1037/0021-9010.73.3.482

Sánchez Puerta, M. L., Valerio, A., \& Bernal, M. G. (2016). Taking stock of programs to develop socioemotional skills: A systematic review of program evidence. The World Bank. https://doi.org/10.1596/978-1-4648-0872-2

Saucier, G., \& Goldberg, L. R. (2001). Lexical studies of indigenous personality factors: Premises, products, and prospects. Journal of Personality, 69(6), 847-879. https://doi.org/10.1111/1467-6494.696167

Schmitt, D. P., Allik, J., McCrae, R. R., \& Benet-Martínez, V. (2007). The geographic distribution of Big Five personality traits: Patterns and profiles of human self-description across 56 nations. Journal of Cross-Cultural Psychology, 38(2), 173-212. https://doi.org/10.1177/0022022106297299 
Schönbrodt, F. D., \& Perugini, M. (2013). At what sample size do correlations stabilize? Journal of Research in Personality, 47(5), 609-612. https://doi.org/10.1016/j.jrp.2013.05.009

Skinner, E., Furrer, C., Marchand, G., \& Kindermann, T. (2008). Engagement and disaffection in the classroom: Part of a larger motivational dynamic? Journal of Educational Psychology, 100(4), 765-781. https://doi.org/10.1037/a0012840

Soto, C. J. (2019). How replicable are links between personality traits and consequential life outcomes? The Life Outcomes of Personality Replication Project. Psychological Science, 30, 711-727. https://doi.org/10.1177/0956797619831612

Soto, C. J. (2021). Do links between personality and life outcomes generalize? Testing the robustness of trait-outcome associations across gender, age, ethnicity, and analytic approaches. Social Psychological and Personality Science, 12, 118-130. https://doi.org/10.1177/1948550619900572

Soto, C. J., \& John, O. P. (2017). The next Big Five Inventory (BFI-2): Developing and assessing a hierarchical model with 15 facets to enhance bandwidth, fidelity, and predictive power. Journal of Personality and Social Psychology, 113(1), 117-143. https://doi.org/10.1037/pspp0000096

Soto, C. J., \& John, O. P. (2019). Optimizing the length, width, and balance of a personality scale: How do internal characteristics affect external validity? Psychological Assessment, 31(4), 444-459. https://doi.org/10.1037/pas0000586

Soto, C. J., John, O. P., Gosling, S. D., \& Potter, J. (2008). The developmental psychometrics of Big Five self-reports: Acquiescence, factor structure, coherence, and differentiation from ages 10 to 20. Journal of Personality and Social Psychology, 94(4), 718-737. https://doi.org/10.1037/0022-3514.94.4.718 
Soto, C. J., Napolitano, C. M., \& Roberts, B. W. (2021). Taking skills seriously: Toward an integrative model and agenda for social, emotional, and behavioral skills. Current Directions in Psychological Science, 30(1), 26-33. https://doi.org/10.1177/0963721420978613

Soto, C. J., \& Tackett, J. L. (2015). Personality traits in childhood and adolescence: Structure, development, and outcomes. Current Directions in Psychological Science, 24, 358-362. https://doi.org/10.1177/0963721415589345

Spanier, G. B. (1976). Measuring dyadic adjustment: New scales for assessing the quality of marriage and similar dyads. Journal of Marriage and Family, 38(1), 15-28. https://doi.org/10.2307/350547

Stark, S., Chernyshenko, O. S., Drasgow, F., Nye, C. D., White, L. A., Heffner, T., \& Farmer, W. L. (2014). From ABLE to TAPAS: A new generation of personality tests to support military selection and classification decisions. Military Psychology, 26(3), 153-164. https://doi.org/10.1037/mil0000044

Summerfield, M., Freidin, S., Hahn, M., Li, N., Macalalad, N., Mundy, L., Watson, N., Wilkins, R., \& Wooden, M. (2015). HILDA user manual: Release 14. Melbourne Institute of Applied Economic and Social Research, University of Melbourne.

Taylor, M. F., Brice, J., Buck, N., \& Prentice-Lane, E. (2010). British Household Panel Survey user manual: Volume A. ISER.

Taylor, R. D., Oberle, E., Durlak, J. A., \& Weissberg, R. P. (2017). Promoting positive youth development through school-based social and emotional learning interventions: A metaanalysis of follow-up effects. Child Development, 88(4), 1156-1171. https://doi.org/10.1111/cdev.12864 
Thalmayer, A. G., \& Saucier, G. (2014). The Questionnaire Big Six in 26 nations: Developing cross-culturally applicable big six, big five and big two inventories. European Journal of Personality, 28, 482-496. https://doi.org/10.1002/per.1969

Torrance, E. P. (1966). The Torrance Tests of Creative Thinking: Technical manual. Personnel Press.

Turner, R. G. (1978). Consistency, self-consciousness, and the predictive validity of typical and maximal personality measures. Journal of Research in Personality, 12, 117-132. https://doi.org/10.1016/0092-6566(78)90088-0

Ura, S. K., Castro-Olivo, S. M., d'Abreu, A. (2020). Outcome measurement of school-based SEL intervention follow-up studies. Assessment for Effective Intervention, 46(1), 76-81. https://doi.org/10.1177/1534508419862619

Vazire, S. (2006). Informant reports: A cheap, fast, and easy method for personality assessment. Journal of Research in Personality, 40(5), 472-481. https://doi.org/10.1016/j.jrp.2005.03.003

Von Gunten, C. D., Bartholow, B. D., \& Martins, J. S. (20201). Inhibition tasks are not associated with a variety of behaviours in college students. European Journal of Personality, 34, 412-430.

Wagner, G. G., Frick, J. R., \& Schupp, J. (2007). The German Socio-Economic Panel Study (SOEP): Scope, Evolution and Enhancements (Working Paper No. 1). SOEPpapers on Multidisciplinary Panel Data Research. https://www.econstor.eu/handle/10419/150550 Wallace, J. (1966). An abilities conception of personality: Some implications for personality measurement. American Psychologist, 21, 132-138. https://doi.org/10.1037/h0023298 
Wallace, J. (1967). What units shall we employ? Allport's question revisited. Journal of Consulting Psychology, 31(1), 56-64. https://doi.org/10.1037/h0024208

West, M. R., Buckley, K., Krachman, S. B., \& Bookman, N. (2018). Development and implementation of student social-emotional surveys in the CORE Districts. Journal of Applied Developmental Psychology, 55, 119-129. https://doi.org/10.1016/j.appdev.2017.06.001

Wilmot, M. P., \& Ones, D. S. (2019). A century of research on conscientiousness at work. Proceedings of the National Academy of Sciences, 116(46), 23004-23010. https://doi.org/10.1073/pnas.1908430116 
Table 1

Aligning Prominent Taxonomies of Traits, Competencies, and Skills

\begin{tabular}{|c|c|c|c|c|c|}
\hline BESSI domains & $\begin{array}{l}\text { Social Engagement } \\
\text { Skills }\end{array}$ & $\begin{array}{l}\text { Cooperation } \\
\text { Skills }\end{array}$ & $\begin{array}{l}\text { Self-Management } \\
\text { Skills }\end{array}$ & $\begin{array}{c}\text { Emotional } \\
\text { Resilience Skills }\end{array}$ & $\begin{array}{l}\text { Innovation } \\
\text { Skills }\end{array}$ \\
\hline $\begin{array}{l}21 \text { st century } \\
\text { competencies }\end{array}$ & \multicolumn{2}{|c|}{ Interpersonal competencies } & \multicolumn{2}{|c|}{ Intrapersonal competencies } & Cognitive competencies \\
\hline $\begin{array}{l}\text { Tripartite taxonomy of } \\
\text { character }\end{array}$ & \multicolumn{2}{|c|}{ Interpersonal strengths } & \multicolumn{2}{|c|}{ Intrapersonal strengths } & Intellectual strengths \\
\hline \multicolumn{5}{|c|}{ Character $^{\mathrm{a}}$} & \\
\hline $\begin{array}{l}\text { CASEL core } \\
\text { competencies }\end{array}$ & Relationship skills & $\begin{array}{r}\text { Social awareness } \\
\text { Responsible }\end{array}$ & $\begin{array}{l}\text { Self-management } \\
\text { sion-making }{ }^{\mathrm{a}}\end{array}$ & Self-awareness & \\
\hline OECD framework & $\begin{array}{l}\text { Engagement } \\
\text { with others }\end{array}$ & Collaboration & Task performance & Emotion regulation & Open-mindedness \\
\hline $\begin{array}{l}\text { Big Five } \\
\text { personality traits }\end{array}$ & Extraversion & Agreeableness & Conscientiousness & $\begin{array}{l}\text { Emotional Stability } \\
\text { (vs. Neuroticism) }\end{array}$ & $\begin{array}{l}\text { Openness to } \\
\text { Experience }\end{array}$ \\
\hline
\end{tabular}

Note. 21st century competencies (National Research Council, 2012). Tripartite taxonomy of character (Park et al., 2017). Five Cs of positive youth development (Lerner et al., 2005). CASEL core competencies (CASEL, 2020). OECD framework (Chernyshenko, et al., 2018). Big Five personality traits (John et al., 2008). ${ }^{a}$ We provisionally assign character and responsible decision-making to combine aspects of Cooperation and Self-Management Skills. 
Table 2

A Hierarchical Taxonomy of Behavioral, Emotional, and Social Skills (Study 1)

\begin{tabular}{|c|c|c|c|}
\hline Skill facet & $\begin{array}{l}\text { Primary } \\
\text { Big Five } \\
\text { domain } \\
\text { (Study 1) }\end{array}$ & $\begin{array}{c}\text { Primary } \\
\text { BESSI } \\
\text { domain } \\
\text { (Study 3) }\end{array}$ & Capacities used to... \\
\hline Social Engagement Skills & & & Actively engage with other people. \\
\hline Leadership Skill & $\mathrm{E}$ & SE & Assert one's views and speak in a group. \\
\hline Conversational Skill & $\mathrm{E}$ & SE & Initiate and maintain social interactions. \\
\hline Expressive Skill & $\mathrm{E}$ & SE & Communicate one's thoughts and feelings to other people. \\
\hline Persuasive Skill & A- & SE & Present arguments effectively. \\
\hline Energy Regulation & $\mathrm{E}$ & $\mathrm{SE} / \mathrm{SM}$ & Channel energy in a productive way. \\
\hline Cooperation Skills & & & Maintain positive social relationships. \\
\hline Perspective-Taking Skill & A & $\mathrm{C}$ & Understand other people's thoughts and feelings. \\
\hline Capacity for Social Warmth & A & $\mathrm{C}$ & Evoke positive social responses from other people. \\
\hline (Capacity for Friendliness) & $\mathrm{E}$ & - & (Merged with capacity for social warmth.) \\
\hline Capacity for Trust & A & $\mathrm{C}$ & Trust and forgive other people. \\
\hline Teamwork Skill & A & $\mathrm{C}$ & Work with others to achieve shared goals. \\
\hline Ethical Competence & A & $\mathrm{C} / \mathrm{SM}$ & Behave ethically, even in difficult circumstances. \\
\hline Self-Management Skills & & & Effectively pursue goals and complete tasks. \\
\hline Task Management & $\mathrm{C}$ & $\mathrm{SM}$ & Work persistently to complete tasks and achieve goals. \\
\hline Responsibility Management & $\mathrm{C}$ & $\mathrm{SM}$ & Fulfill promises and commitments. \\
\hline Organizational Skill & $\mathrm{C}$ & $\mathrm{SM}$ & Organize personal spaces and objects. \\
\hline [Time Management] & - & $\mathrm{SM}$ & Use time effectively while accomplishing goals. \\
\hline Detail Management & $\mathrm{C}$ & $\mathrm{SM}$ & Do careful and thorough work. \\
\hline Goal Regulation & $\mathrm{C}$ & $\mathrm{SM}$ & Set clear and ambitious personal goals. \\
\hline Rule-Following Skill & $\mathrm{C}$ & SM & Follow instructions, rules, and norms. \\
\hline Decision-Making Skill & $\mathrm{C}$ & $\mathrm{SM}$ & Make well-reasoned decisions. \\
\hline Capacity for Consistency & $\mathrm{O}-$ & SM & Reliably perform routine tasks. \\
\hline
\end{tabular}




\section{Emotional Resilience Skills}

Stress Regulation

Capacity for Optimism

Anger Management

(Emotional Control)

Confidence Regulation

Impulse Regulation

Innovation Skills

Abstract Thinking Skill

Creative Skill

Artistic Skill

Cultural Competence

Information Processing Skill

Compound Skills

Capacity for Independence

Self-Reflection Skill

Adaptability

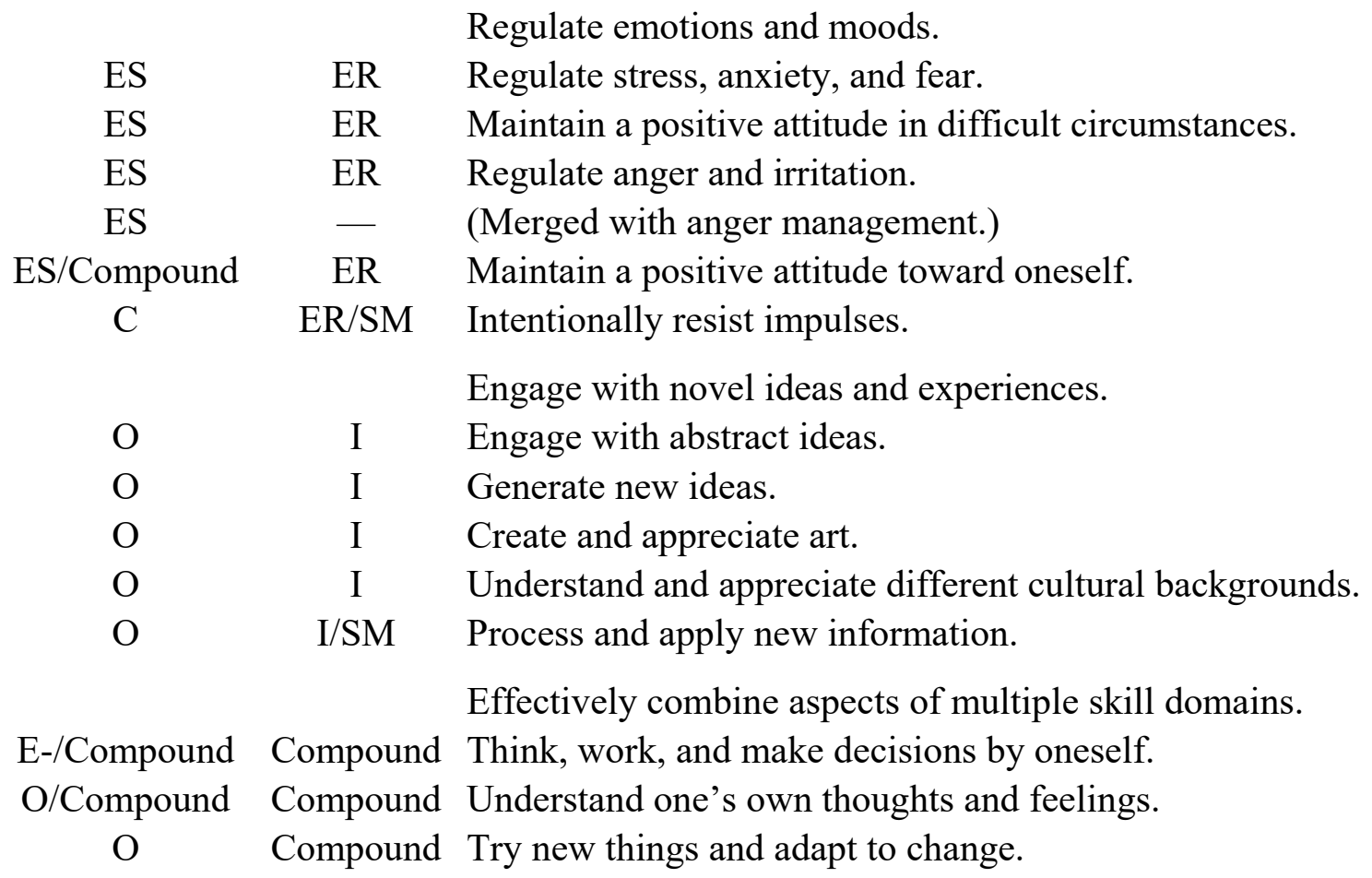

Regulate emotions and moods.

ER Regulate stress, anxiety, and fear.

ER Maintain a positive attitude in difficult circumstances.

ES ER Regulate anger and irritation.

ES _ - (Merged with anger management.)

ES/Compound ER Maintain a positive attitude toward oneself.

C ER/SM Intentionally resist impulses.

Engage with novel ideas and experiences.

$\mathrm{O} \quad \mathrm{I} \quad$ Engage with abstract ideas.

O I Generate new ideas.

O I Create and appreciate art.

O I Understand and appreciate different cultural backgrounds.

O I/SM Process and apply new information.

Effectively combine aspects of multiple skill domains.

E-/Compound Compound Think, work, and make decisions by oneself.

O/Compound Compound Understand one's own thoughts and feelings.

$\mathrm{O} \quad$ Compound Try new things and adapt to change.

Note. For Big Five domain, $\mathrm{E}=$ Extraversion; $\mathrm{A}=$ Agreeableness; $\mathrm{C}=$ Conscientiousness; $\mathrm{ES}=$ Emotional Stability (vs. Negative Emotionality); $\mathrm{O}=$ Openness to Experience. For BESSI domain, $\mathrm{SE}=$ Social Engagement; $\mathrm{C}=$ Cooperation; $\mathrm{SM}=\mathrm{Self}-\mathrm{Management}$; $\mathrm{ER}=$ Emotional Resilience; I = Innovation. - = Skill facet oriented toward the low pole of the skill domain. Skill facets in brackets were added during Study 2. Skill facets in parentheses were eliminated during Study 2. 


\section{Table 3}

Aligning the BESSI Skill Facets with Hierarchical Representations of the Big Five (Study 1)

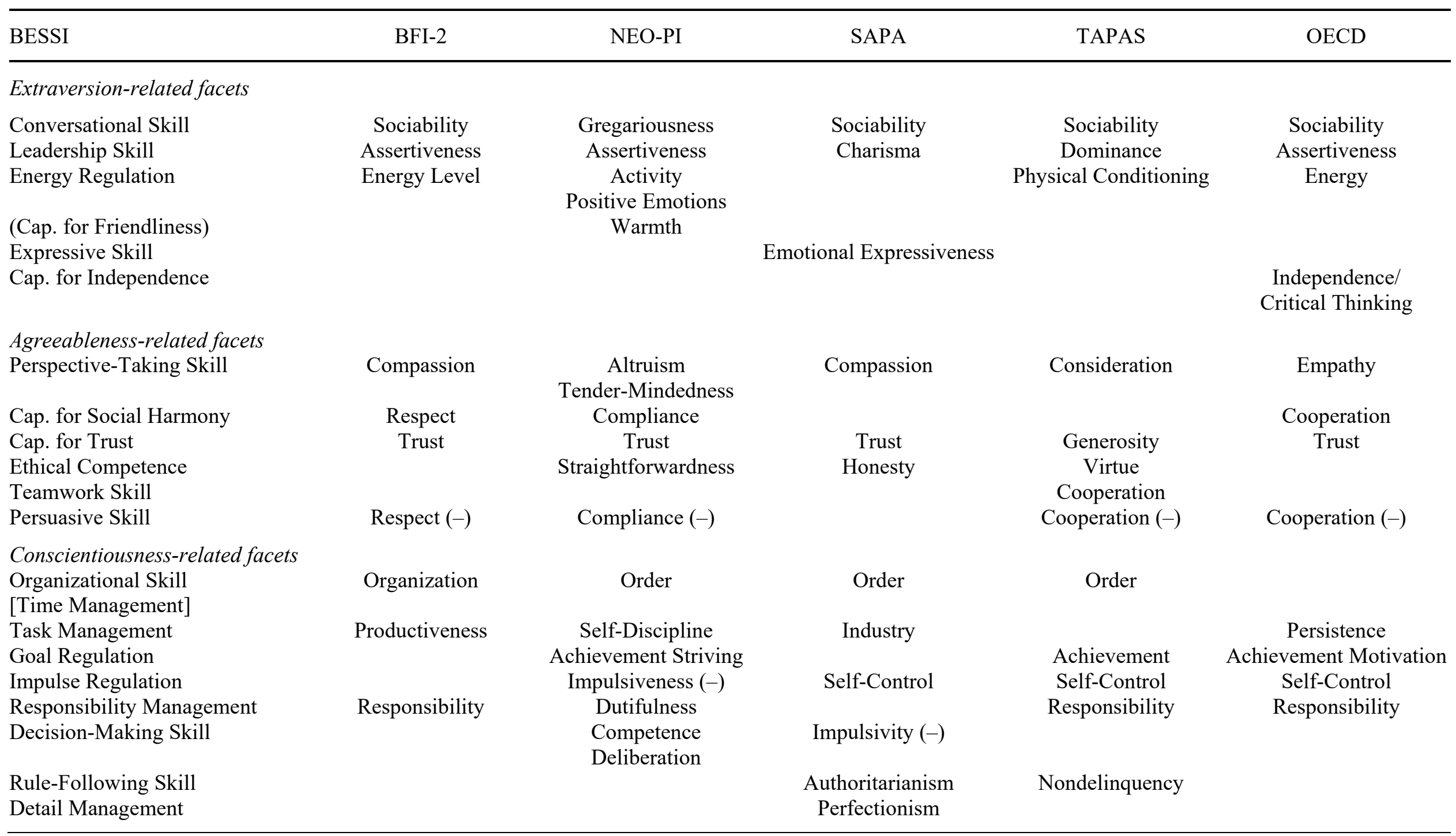


Emotional Stability-related facets

Stress Regulation

Cap. for Optimism

(Emotional Control)

Anger Management

Confidence Regulation

Openness-related facets

Artistic Skill

Abstract Thinking Skill

Creative Skill

Information Processing Skill

Cultural Competence

Self-Reflection Skill

Adaptability

Cap. for Consistency

Additional facets

$\begin{array}{cc}\text { Anxiety (-) } & \text { Anxiety (-) } \\ & \text { Vulnerability (-) } \\ \text { Depression (-) } & \text { Depression (-) } \\ \text { Emotional Volatility (-) } & \\ & \text { Angry Hostility (-) } \\ & \text { Self-Consciousness (-) } \\ \text { Artistic Sensitivity } & \text { Aesthetics } \\ \text { Intellectual Curiosity } & \text { Ideas } \\ \text { Creative Imagination } & \text { Fantasy } \\ & \\ & \text { Feelings } \\ & \text { Actions } \\ & \text { Actions (-) } \\ & \text { Excitement-Seeking } \\ & \text { Modesty } \\ & \text { Values }\end{array}$

$$
\text { Anxiety (-) }
$$

Emal Stability

Irritability (-)

Well-Being
Art Appreciation
Creativity
Intellect

Introspection

Adaptability

Adaptability (-)

Sensation-Seeking

Attention-Seeking

Conformity

Easy-Goingness

Humor

Conservatism

Note. BESSI = Behavioral, Emotional, and Social Skills Inventory. BFI-2 = Big Five Inventory-2 (Soto \& John, 2017). NEO-PI = NEO Personality Inventories (McCrae \& Costa, 2010). SAPA = Synthetic Aperture Personality Assessment Personality Inventory (Condon, 2017). TAPAS = Tailored Adaptive Personality Assessment System (Stark, Chernyshenko, Drasgow, Nye, White, Heffner, \& Farmer, 2014). OECD = OECD framework for social and emotional skills (Chernyshenko, Kankaraš, \& Drasgow, 2018). Cap. = Capacity. Skill facets in brackets were added during Study 2. Skill facets in parentheses were eliminated during Study 2. Additional facets are traits that could not be readily conceptualized as skills. 
Table 4

Length and Internal Consistency of the Iterative BESSI Facets (Study 2)

\begin{tabular}{|c|c|c|c|c|c|c|c|c|c|c|}
\hline \multirow[b]{2}{*}{ Facet } & \multicolumn{2}{|c|}{$\begin{array}{c}\text { BESSI v0.1 } \\
\text { (Internet sample A) }\end{array}$} & \multicolumn{2}{|c|}{$\begin{array}{c}\text { BESSI v0.2 } \\
\text { (Internet sample B) }\end{array}$} & \multicolumn{3}{|c|}{$\begin{array}{c}\text { BESSI v0.3 } \\
\text { (Internet sample C) }\end{array}$} & \multicolumn{3}{|c|}{$\begin{array}{c}\text { BESSI v1.0 } \\
\text { (Internet sample D) }\end{array}$} \\
\hline & Items & $\begin{array}{l}\text { Alpha } \\
\text { reliability }\end{array}$ & Items & $\begin{array}{l}\text { Alpha } \\
\text { reliability }\end{array}$ & Items & $\begin{array}{l}\text { Alpha } \\
\text { reliability }\end{array}$ & $\begin{array}{l}\text { Omega } \\
\text { reliability }\end{array}$ & Items & $\begin{array}{l}\text { Alpha } \\
\text { reliability }\end{array}$ & $\begin{array}{l}\text { Omega } \\
\text { reliability }\end{array}$ \\
\hline \multicolumn{11}{|l|}{ Social Engagement Skills } \\
\hline Leadership Skill & 10 & .91 & 9 & .93 & 6 & .90 & .93 & 6 & .89 & .91 \\
\hline Conversational Skill & 11 & .93 & 9 & .94 & 6 & .91 & .93 & 6 & .92 & .94 \\
\hline Expressive Skill & 9 & .89 & 8 & .92 & 6 & .91 & .94 & 6 & .90 & .93 \\
\hline Persuasive Skill & 10 & .90 & 8 & .89 & 6 & .86 & .93 & 6 & .86 & .92 \\
\hline Energy Regulation & 10 & .85 & 8 & .85 & 6 & .83 & .85 & 6 & .84 & .87 \\
\hline \multicolumn{11}{|l|}{ Cooperation Skills } \\
\hline Perspective-Taking Skill & 10 & .90 & 10 & .93 & 6 & .90 & .92 & 6 & .89 & .92 \\
\hline Capacity for Social Warmth & 10 & .88 & 8 & .88 & 6 & .86 & .89 & 6 & .86 & .88 \\
\hline (Friendliness) & 10 & .89 & 8 & .82 & - & - & - & - & - & - \\
\hline Capacity for Trust & 10 & .86 & 8 & .84 & 8 & .85 & .85 & 6 & .80 & .94 \\
\hline Teamwork Skill & 9 & .90 & 8 & .94 & 6 & .90 & .91 & 6 & .91 & .92 \\
\hline Ethical Competence & 10 & .83 & 8 & .85 & 6 & .83 & .84 & 6 & .82 & .84 \\
\hline \multicolumn{11}{|l|}{ Self-Management Skills } \\
\hline Task Management & 10 & .86 & 9 & .90 & 8 & .89 & .88 & 6 & .85 & .86 \\
\hline Responsibility Management & 8 & .83 & 9 & .88 & 6 & .85 & .89 & 6 & .85 & .88 \\
\hline Organizational Skill & 10 & .88 & 8 & .89 & 8 & .92 & .94 & 6 & .92 & .95 \\
\hline Time Management & - & - & - & - & 8 & .89 & .92 & 6 & .87 & .92 \\
\hline Detail Management & 9 & .83 & 8 & .88 & 6 & .86 & .89 & 6 & .87 & .90 \\
\hline Goal Regulation & 13 & .91 & 9 & .86 & 6 & .87 & .89 & 6 & .87 & .91 \\
\hline Rule-Following Skill & 9 & .90 & 8 & .90 & 6 & .90 & .90 & 6 & .89 & .90 \\
\hline Decision-Making Skill & 10 & .90 & 8 & .88 & 6 & .89 & .91 & 6 & .88 & .90 \\
\hline Capacity for Consistency & 9 & .93 & 8 & .91 & 6 & .89 & .90 & 6 & .86 & .87 \\
\hline
\end{tabular}




\begin{tabular}{|c|c|c|c|c|c|c|c|c|c|c|}
\hline \multicolumn{11}{|l|}{ Emotional Resilience Skills } \\
\hline Stress Regulation & 9 & .87 & 8 & .90 & 6 & .88 & .91 & 6 & .89 & .91 \\
\hline Capacity for Optimism & 10 & .90 & 9 & .93 & 6 & .93 & .94 & 6 & .93 & .95 \\
\hline Anger Management & 8 & .91 & 8 & .94 & 6 & .93 & .95 & 6 & .92 & .94 \\
\hline (Emotional Control) & 9 & .92 & 8 & .94 & - & - & - & - & - & - \\
\hline Confidence Regulation & 9 & .94 & 8 & .93 & 6 & .91 & .93 & 6 & .92 & .94 \\
\hline Impulse Regulation & 10 & .84 & 8 & .85 & 6 & .84 & .86 & 6 & .88 & .91 \\
\hline \multicolumn{11}{|l|}{ Innovation Skills } \\
\hline Abstract Thinking Skill & 10 & .90 & 8 & .84 & 6 & .86 & .89 & 6 & .84 & .87 \\
\hline Creative Skill & 9 & .89 & 9 & .91 & 6 & .86 & .89 & 6 & .86 & .89 \\
\hline Artistic Skill & 8 & .87 & 8 & .89 & 6 & .85 & .87 & 6 & .84 & .87 \\
\hline Cultural Competence & 8 & .86 & 8 & .92 & 6 & .87 & .87 & 6 & .89 & .90 \\
\hline Information Processing Skill & 9 & .88 & 8 & .88 & 6 & .83 & .86 & 6 & .84 & .87 \\
\hline \multicolumn{11}{|l|}{ Compound Skills } \\
\hline Capacity for Independence & 8 & .84 & 8 & .89 & 6 & .85 & .86 & 6 & .86 & .88 \\
\hline Self-Reflection Skill & 8 & .93 & 8 & .91 & 6 & .85 & .88 & 6 & .86 & .88 \\
\hline Adaptability & 10 & .87 & 8 & .83 & 6 & .85 & .87 & 6 & .86 & .87 \\
\hline
\end{tabular}

Note. For Internet samples A, B, and C, $N=400$. For Internet sample D, $N=600$. 
Table 5

Fit Statistics for Confirmatory Factor Analyses of the BESSI's Facet-Level Structure (Studies 2 and 3)

\begin{tabular}{|c|c|c|c|c|c|c|}
\hline Model & $\chi^{2}$ & $\mathrm{df}$ & CFI & TLI & RMSEA & SRMR \\
\hline \multicolumn{7}{|c|}{ Internet sample C (Study 2) } \\
\hline Single-factor model & $30,858.41$ & 4,464 & .343 & .329 & .122 & .153 \\
\hline 32-facet model & $6,192.13$ & 3,968 & .945 & .936 & .037 & .042 \\
\hline \multicolumn{7}{|c|}{ Internet sample D (Study 2) } \\
\hline Single-factor model & $46,996.78$ & 4,464 & .329 & .315 & .126 & .148 \\
\hline 32-facet model & $8,040.70$ & 3,968 & .936 & .926 & .041 & .040 \\
\hline \multicolumn{7}{|c|}{ College student sample (Study 3) } \\
\hline Single-factor model & $23,720.47$ & 4,464 & .543 & .533 & .116 & .139 \\
\hline 32-facet model & 6066.28 & 3,968 & .950 & .943 & .041 & .042 \\
\hline \multicolumn{7}{|c|}{ High school student sample (Study 3) } \\
\hline Single-factor model & $25,199.51$ & 4,464 & .680 & .673 & .096 & .093 \\
\hline 32-facet model & $6,448.39$ & 3,968 & .962 & .956 & .035 & .033 \\
\hline \multicolumn{7}{|c|}{ Observer-report sample (Study 3) } \\
\hline Single-factor model & $27,995.98$ & 4,464 & .788 & .783 & .104 & .086 \\
\hline 32-facet model & $6,925.85$ & 3,968 & .973 & .969 & .039 & .023 \\
\hline
\end{tabular}

Note. $N=400$ for Internet sample C, 600 for Internet sample D, 322 for the college student sample, 499 for the high school student sample, and 488 for the observer-report sample. 
Table 6

Loadings, Intercorrelations, and Congruence for EFAs of the BESSI Facet Scales (Study 3)

\begin{tabular}{|c|c|c|c|c|c|}
\hline & $\begin{array}{c}\text { Self- } \\
\text { Management }\end{array}$ & $\begin{array}{c}\text { Social } \\
\text { Engagement }\end{array}$ & Cooperation & $\begin{array}{l}\text { Emotional } \\
\text { Resilience }\end{array}$ & Innovation \\
\hline \multicolumn{6}{|l|}{ Self-Management Skills } \\
\hline Time Management & .85 & .00 & -.01 & .02 & -.10 \\
\hline Organizational Skill & .72 & -.06 & .02 & .02 & -.03 \\
\hline Capacity for Consistency & .72 & -.09 & .04 & -.01 & .01 \\
\hline Task Management & .85 & .09 & -.08 & .10 & -.03 \\
\hline Detail Management & .72 & -.07 & -.01 & -.02 & .22 \\
\hline Rule-Following Skill & .62 & -.25 & .26 & .04 & -.03 \\
\hline Responsibility Management & .75 & .07 & .21 & -.03 & .03 \\
\hline Goal Regulation & .71 & .22 & .03 & .03 & .08 \\
\hline Decision-Making Skill & .51 & -.18 & .05 & .19 & .28 \\
\hline \multicolumn{6}{|l|}{ Social Engagement Skills } \\
\hline Leadership Skill & .12 & .61 & .12 & .08 & .20 \\
\hline Persuasive Skill & .05 & .65 & -.06 & .03 & .26 \\
\hline Expressive Skill & -.05 & .29 & .33 & .20 & .16 \\
\hline Conversational Skill & -.03 & .50 & .51 & .09 & .00 \\
\hline Energy Regulation & .54 & .34 & .12 & .23 & -.08 \\
\hline \multicolumn{6}{|l|}{ Cooperation Skills } \\
\hline Perspective-Taking Skill & .08 & -.12 & .66 & -.01 & .29 \\
\hline Capacity for Trust & -.02 & -.15 & .57 & .29 & .06 \\
\hline Capacity for Social Warmth & .11 & .22 & .67 & .11 & .05 \\
\hline Teamwork Skill & .32 & .12 & .50 & .06 & .08 \\
\hline Ethical Competence & .40 & -.12 & .31 & .08 & .25 \\
\hline \multicolumn{6}{|l|}{ Emotional Resilience Skills } \\
\hline Stress Regulation & -.01 & .01 & -.10 & .89 & .05 \\
\hline Capacity for Optimism & .01 & .09 & .26 & .70 & -.06 \\
\hline Anger Management & .09 & -.34 & .14 & .64 & .09 \\
\hline Confidence Regulation & .13 & .30 & .01 & .58 & -.02 \\
\hline Impulse Regulation & .45 & -.16 & -.02 & .39 & .07 \\
\hline \multicolumn{6}{|l|}{ Innovation Skills } \\
\hline Abstract Thinking Skill & .02 & .05 & .06 & -.02 & .86 \\
\hline Creative Skill & .03 & .15 & .03 & .07 & .64 \\
\hline Artistic Skill & -.11 & .00 & .04 & .02 & .63 \\
\hline Cultural Competence & .03 & -.05 & .35 & -.01 & .51 \\
\hline Information Processing Skill & .35 & .11 & -.12 & .12 & .52 \\
\hline \multicolumn{6}{|l|}{ Compound Skills } \\
\hline Self-Reflection Skill & .06 & .03 & .15 & .32 & .42 \\
\hline Adaptability & .06 & .28 & .24 & .29 & .25 \\
\hline Capacity for Independence & .46 & .20 & -.14 & .14 & .29 \\
\hline \multicolumn{6}{|l|}{ Intercorrelations } \\
\hline Social Engagement Skills & .14 & & & & \\
\hline Cooperation Skills & .26 & .09 & & & \\
\hline Emotional Resilience Skills & .38 & .17 & .31 & & \\
\hline Innovation Skills & .32 & .18 & .29 & .30 & \\
\hline Mean congruence coefficient & .98 & .88 & .92 & .92 & .95 \\
\hline
\end{tabular}

Note. Values are averaged across Internet sample $\mathrm{C}(N=400)$, Internet sample $\mathrm{D}(N=600)$, the college student sample $(N=322)$, the high school student sample $(N=499)$, and the observer-report sample $(N=$ 488). Absolute values of .40 or greater are bolded. 
Table 7

Correlations between the BESSI Skill Facets and Big Five Personality Traits (Study 3)

\begin{tabular}{|c|c|c|c|c|c|}
\hline & Ext. & Agr. & Con. & ES & Ope. \\
\hline \multicolumn{6}{|l|}{ Social Engagement Skills } \\
\hline Leadership Skill & .73 & .03 & .13 & .18 & .28 \\
\hline Persuasive Skill & .54 & -.22 & .02 & .05 & .23 \\
\hline Expressive Skill & .53 & .22 & .06 & .22 & .30 \\
\hline Conversational Skill & .73 & .28 & .12 & .25 & .24 \\
\hline Energy Regulation & .48 & .25 & .51 & .42 & .12 \\
\hline \multicolumn{6}{|l|}{ Cooperation Skills } \\
\hline Perspective-Taking Skill & .24 & .60 & .18 & .06 & .32 \\
\hline Capacity for Trust & .23 & .67 & .08 & .33 & .17 \\
\hline Capacity for Social Warmth & .58 & .45 & .17 & .34 & .26 \\
\hline Teamwork Skill & .34 & .45 & .28 & .29 & .26 \\
\hline Ethical Competence & .23 & .45 & .37 & .29 & .23 \\
\hline \multicolumn{6}{|l|}{ Self-Management Skills } \\
\hline Time Management & .01 & .19 & .73 & .21 & -.05 \\
\hline Organizational Skill & .04 & .25 & .69 & .23 & .04 \\
\hline Capacity for Consistency & .01 & .16 & .55 & .16 & .05 \\
\hline Task Management & .17 & .24 & .69 & .33 & .01 \\
\hline Detail Management & .10 & .33 & .61 & .19 & .17 \\
\hline Rule-Following Skill & -.08 & .39 & .50 & .19 & -.01 \\
\hline Responsibility Management & .14 & .39 & .60 & .28 & .14 \\
\hline Goal Regulation & .26 & .30 & .55 & .27 & .20 \\
\hline Decision-Making Skill & .07 & .34 & .44 & .21 & .22 \\
\hline \multicolumn{6}{|l|}{ Emotional Resilience Skills } \\
\hline Stress Regulation & .24 & .17 & .14 & .77 & .13 \\
\hline Capacity for Optimism & .46 & .39 & .13 & .67 & .13 \\
\hline Anger Management & .05 & .52 & .21 & .54 & .24 \\
\hline Confidence Regulation & .46 & .13 & .20 & .63 & .16 \\
\hline Impulse Regulation & .07 & .36 & .51 & .40 & .09 \\
\hline \multicolumn{6}{|l|}{ Innovation Skills } \\
\hline Abstract Thinking Skill & .31 & .15 & .05 & .04 & .66 \\
\hline Creative Skill & .38 & .23 & .06 & .16 & .68 \\
\hline Artistic Skill & .18 & .11 & -.02 & .08 & .73 \\
\hline Cultural Competence & .22 & .26 & .10 & .11 & .44 \\
\hline Information Processing Skill & .24 & .18 & .30 & .24 & .29 \\
\hline \multicolumn{6}{|l|}{ Compound Skills } \\
\hline Self-Reflection Skill & .31 & .21 & .08 & .22 & .38 \\
\hline Adaptability & .43 & .26 & .07 & .35 & .37 \\
\hline Capacity for Independence & .22 & .15 & .41 & .32 & .26 \\
\hline
\end{tabular}

Note. $N=313$. Ext. = Extraversion. Agr. = Agreeableness. Con. $=$ Conscientiousness. Emotional Stability (vs. Negative Emotionality). Ope. = Open-Mindedness. Absolute correlations of .40 or stronger are bolded. 
Table 8

Fit Statistics for Confirmatory Factor Analyses and Exploratory Structural Equation Models of the BESSI's Domain-Level Structure

(Study 3)

\begin{tabular}{|c|c|c|c|c|c|c|}
\hline Model & $\chi^{2}$ & df & CFI & TLI & RMSEA & SRMR \\
\hline \multicolumn{7}{|l|}{ Internet sample $C$} \\
\hline Hierarchical five-domain CFA model & $10,801.36$ & 4,406 & .841 & .835 & .060 & .086 \\
\hline Bifactor five-domain ESEM & $6,233.11$ & 3,994 & .944 & .936 & .037 & .038 \\
\hline \multicolumn{7}{|l|}{ Internet sample D } \\
\hline Hierarchical five-domain CFA model & $15,716.61$ & 4,406 & .822 & .815 & .065 & .088 \\
\hline Bifactor five-domain ESEM & $7,873.33$ & 3,994 & .939 & .930 & .040 & .036 \\
\hline \multicolumn{7}{|l|}{ College student sample } \\
\hline Hierarchical five-domain CFA model & $8,858.94$ & 4,406 & .894 & .891 & .056 & .076 \\
\hline Bifactor five-domain ESEM & $5,763.07$ & 3,994 & .958 & .952 & .037 & .037 \\
\hline \multicolumn{7}{|l|}{ High school student sample } \\
\hline Hierarchical five-domain CFA model & $10,256.27$ & 4,406 & .910 & .907 & .052 & .057 \\
\hline Bifactor five-domain ESEM & $6,494.68$ & 3,994 & .961 & .956 & .035 & .030 \\
\hline \multicolumn{7}{|l|}{ Observer-report sample } \\
\hline Hierarchical five-domain CFA model & $12,204.21$ & 4,406 & .930 & .927 & .060 & .049 \\
\hline Bifactor five-domain ESEM & $7,231.62$ & 3,994 & .971 & .967 & .041 & .022 \\
\hline
\end{tabular}

Note. $N=400$ for Internet sample C, 600 for Internet sample D, 322 for the college student sample, 499 for the high school student sample, and 488 for the observer-report sample. 
Table 9

Correlations of the BESSI Skill Domains with Domain-Level Convergent Measures (Study 4)

\begin{tabular}{|c|c|c|c|c|c|c|c|c|c|c|c|c|c|c|c|c|c|c|c|c|c|c|}
\hline & \multicolumn{5}{|c|}{$\mathrm{BFI}-2(N=313)$} & \multicolumn{5}{|c|}{ PYD-SF $(N=312)$} & \multicolumn{3}{|c|}{ TTC $(N=249)$} & \multicolumn{5}{|c|}{$\operatorname{SECA}(N=249)$} & \multicolumn{4}{|c|}{$\operatorname{SELS}(N=249)$} \\
\hline & $\mathrm{C}$ & $\mathrm{E}$ & $\mathrm{A}$ & ES & $\mathrm{OM}$ & Cmp & $\mathrm{Cnf}$ & Cha & Car & $\mathrm{Cnn}$ & Inter & Intel & Intra & $\mathrm{SeA}$ & SoA & $\mathrm{SM}$ & $\mathrm{RS}$ & $\mathrm{RD}$ & SM & GM & SEf & SoA \\
\hline Self-Management & .74 & .14 & .38 & .32 & .13 & .18 & .27 & .45 & .31 & .36 & .56 & .52 & .77 & .40 & .33 & .70 & .39 & .45 & .63 & .35 & .39 & .41 \\
\hline Social Engagement & .16 & .79 & .13 & .26 & .32 & .32 & .40 & .26 & .21 & .30 & .39 & .60 & .28 & .36 & .45 & .22 & .54 & .34 & .17 & .32 & .27 & .49 \\
\hline Cooperation & .25 & .42 & .67 & .32 & .31 & .21 & .28 & .52 & .54 & .36 & .68 & .52 & .39 & .36 & .61 & .27 & .62 & .43 & .23 & .32 & .20 & .62 \\
\hline Emotional Resilience & .26 & .35 & .39 & .79 & .20 & .36 & .56 & .28 & .17 & .34 & .47 & .46 & .39 & .62 & .35 & .44 & .45 & .32 & .31 & .40 & .41 & .44 \\
\hline Innovation & .09 & .34 & .24 & .14 & .76 & .17 & .21 & .39 & .27 & .16 & .46 & .56 & .30 & .31 & .41 & .27 & .36 & .46 & .16 & .44 & .35 & .36 \\
\hline
\end{tabular}

Note. BFI-2 = Big Five Inventory-2. PYD-SF = Positive Youth Development-Short Form. TTC = Tripartite Taxonomy of Character. SECA $=$ Social and Emotional Competency Assessment. SELS $=$ Social-Emotional Learning Surveys. $\mathrm{C}=$ Conscientiousness. $\mathrm{E}=\mathrm{Extraversion} . \mathrm{A}=$ Agreeableness. ES = Emotional Stability (vs. Negative Emotionality). OM = Open-mindedness. Cmp = Competence. Cnf = Confidence. Cha $=$ Character. Car $=$ Caring. Cnn $=$ Connection. Inter $=$ Interpersonal strengths. Intel $=$ Intellectual strengths. Intra $=$ Intrapersonal strengths.

$\mathrm{SeA}=$ Self-awareness. SoA = Social awareness. $\mathrm{SM}=$ Self-management. $\mathrm{RS}=$ Relationship skills. $\mathrm{RD}=\mathrm{Responsible} \mathrm{decision-making}$. GM $=$ Growth mindset. SEf = Self-efficacy. Correlations of .13 or stronger are statistically significant $(p<.05)$, and correlations of .50 or stronger are bolded. 
Table 10

Regressions of Domain-Level Convergent Measures on the BESSI Skill Domains (Study 4)

\begin{tabular}{|c|c|c|c|c|c|c|c|c|c|c|c|c|c|c|c|c|c|c|c|c|c|c|}
\hline & \multicolumn{5}{|c|}{ BFI-2 $(N=313)$} & \multicolumn{5}{|c|}{ PYD-SF $(N=312)$} & \multicolumn{3}{|c|}{ TTC $(N=249)$} & \multicolumn{5}{|c|}{$\operatorname{SECA}(N=249)$} & \multicolumn{4}{|c|}{$\operatorname{SELS}(N=249)$} \\
\hline & $\mathrm{C}$ & $\mathrm{E}$ & A & $\mathrm{NE}$ & $\mathrm{OM}$ & Cmp & $\mathrm{Cnf}$ & Cha & Car & Cnn & Inter & Intel & Intra & $\mathrm{SeA}$ & SoA & SM & $\mathrm{RS}$ & $\mathrm{RD}$ & SM & GM & SEf & SoA \\
\hline Self-Management & .94 & -.23 & .03 & -.04 & -.18 & -.01 & .00 & .26 & .10 & .21 & .24 & .25 & .80 & .12 & -.02 & .73 & .04 & .25 & .73 & .12 & .26 & .08 \\
\hline Social Engagement & -.01 & .89 & -.40 & -.07 & -.08 & .25 & .26 & -.12 & -.12 & .15 & -.04 & .35 & .05 & .08 & .13 & .00 & .29 & .05 & .03 & .04 & .06 & .22 \\
\hline Cooperation & -.12 & .07 & .91 & -.10 & -.06 & -.08 & -.13 & .42 & .69 & .20 & .51 & .02 & -.06 & -.09 & .54 & -.26 & .44 & .12 & -.15 & -.07 & -.29 & .46 \\
\hline Emotional Resilience & -.07 & .03 & .08 & .99 & -.04 & .31 & .55 & -.11 & -.22 & .12 & .05 & .07 & .02 & .55 & -.03 & .22 & .08 & -.01 & .07 & .23 & .32 & .06 \\
\hline Innovation & -.20 & -.12 & -.12 & -.17 & .93 & -.05 & -.11 & .14 & -.01 & -.19 & .07 & .22 & -.06 & .04 & .06 & .01 & -.08 & .26 & -.12 & .30 & .24 & -.07 \\
\hline$R^{2}$ & .63 & .67 & .58 & .69 & .64 & .16 & .35 & .33 & .34 & .21 & .52 & .51 & .60 & .40 & .39 & .54 & .45 & .30 & .43 & .26 & .27 & .42 \\
\hline
\end{tabular}

Note. BFI-2 = Big Five Inventory-2. PYD-SF = Positive Youth Development-Short Form. TTC = Tripartite Taxonomy of Character. SECA $=$ Social and Emotional Competency Assessment. SELS $=$ Social-Emotional Learning Surveys. $\mathrm{C}=$ Conscientiousness. $\mathrm{E}=$ Extraversion. $\mathrm{A}=$ Agreeableness. ES = Emotional Stability (vs. Negative Emotionality). OM = Open-mindedness. Cmp = Competence. Cnf = Confidence. Cha $=$ Character. Car $=$ Caring. Cnn $=$ Connection. Inter $=$ Interpersonal strengths. Intel = Intellectual strengths. Intra $=$ Intrapersonal strengths. $\mathrm{SeA}=$ Self-awareness. SoA = Social awareness. $\mathrm{SM}=$ Self-management. $\mathrm{RS}=$ Relationship skills. $\mathrm{RD}=\mathrm{Responsible} \mathrm{decision-making}$. GM $=$ Growth mindset. SEf = Self-efficacy. Values are standardized regression coefficients $(\beta \mathrm{s})$. Coefficients of .13 or stronger are statistically significant $(p<.05)$, and coefficients of .30 or stronger are bolded. 
Table 11

Correlations of the BESSI Skill Facets with Facet-Level Convergent Measures (Study 4)

$$
\text { BFI-2 }(N=313)
$$

PYD-SF $(N=312)$

COr CPr CRe ESo EAs EEL ACo ARe ATr SAn SDe SEV OIC OAS OCI Cmp Cnf Cha Car Cnn

Self-Management Skills Time Management

Organizational Skill

Capacity for Consistency

Task Management

Detail Management

Rule-Following Skill

Responsibility Management

Goal Regulation

Decision-Making Skill

Social Engagement Skills

Leadership Skill

Persuasive Skill

Expressive Skill

Conversational Skill

Energy Regulation

Cooperation Skills

Perspective-Taking Skill

Capacity for Trust

Capacity for Social Warmth

Teamwork Skill

Ethical Competence

Emotional Resilience Skills

Stress Regulation

Capacity for Optimism

Anger Management

Confidence Regulation

Impulse Regulation

Innovation Skills

Abstract Thinking Skill

Creative Skill

Artistic Skill

Cultural Competence

Information Processing Skill

Compound Skills

Self-Reflection Skill

Adaptability

Capacity for Independence

\begin{tabular}{|c|c|c|c|c|c|c|c|c|c|c|c|c|c|c|c|c|c|c|c|}
\hline .58 & .63 & .59 & -.09 & .00 & .15 & .13 & .30 & .06 & .06 & .19 & .28 & .03 & -.14 & .02 & .17 & .15 & .29 & .21 & .30 \\
\hline .80 & .40 & .47 & -.04 & .03 & .15 & .15 & .38 & .12 & .09 & .22 & .27 & .06 & -.01 & .07 & .04 & .13 & .29 & .21 & .26 \\
\hline .41 & .48 & .49 & -.09 & .02 & .12 & .16 & .27 & .01 & .05 & .13 & .23 & .09 & -.01 & .06 & .09 & .13 & .35 & .21 & .25 \\
\hline .41 & .77 & .54 & .05 & .15 & .26 & .18 & .27 & .16 & .16 & .32 & .36 & .10 & -.12 & .10 & .21 & .25 & .29 & .19 & .31 \\
\hline .46 & .52 & .55 & -.02 & .08 & .23 & .31 & .41 & .12 & -.01 & .24 & .25 & .22 & .07 & .17 & .16 & .21 & .33 & .23 & .30 \\
\hline .38 & .33 & .55 & -.15 & -.11 & .09 & .31 & .49 & .20 & .02 & .20 & .26 & .06 & -.07 & .00 & .00 & .13 & .33 & .28 & .27 \\
\hline .38 & .54 & .60 & .03 & .07 & .27 & .34 & .44 & .20 & .14 & .26 & .31 & .21 & .01 & .15 & .17 & .26 & .43 & .31 & .33 \\
\hline .32 & .58 & .49 & .12 & .23 & .33 & .28 & .33 & .14 & .12 & .30 & .27 & .26 & .05 & .22 & .22 & .28 & .42 & .33 & .30 \\
\hline .27 & .35 & .51 & -.05 & .11 & .15 & .31 & .38 & .17 & .05 & .20 & .29 & .26 & .14 & .17 & .06 & .21 & .36 & .24 & .27 \\
\hline .03 & .21 & .11 & .58 & .80 & .43 & .08 & -.02 & .00 & .16 & .27 & .04 & .29 & .11 & .32 & .25 & .28 & .21 & .13 & .20 \\
\hline .06 & .10 & .02 & .39 & .67 & .27 & -.10 & -.24 & -.19 & .04 & .16 & -.07 & .28 & .10 & .23 & .24 & .21 & .17 & .03 & 10 \\
\hline-.01 & .11 & .05 & .49 & .41 & .41 & .25 & .08 & .18 & .16 & .32 & .09 & .26 & .22 & .26 & .19 & .34 & .16 & .20 & .29 \\
\hline .00 & .23 & .09 & .73 & .49 & .58 & .26 & .16 & .24 & .18 & .36 & .09 & .25 & .10 & .29 & .30 & .38 & .25 & .25 & .30 \\
\hline .27 & .65 & .37 & .34 & .31 & .60 & .21 & .22 & .19 & .26 & .48 & .33 & .16 & -.06 & .24 & .36 & .39 & .28 & .23 & .34 \\
\hline .05 & .15 & .29 & .22 & .12 & .29 & .59 & .48 & .40 & -.02 & .09 & .08 & .29 & .26 & .27 & .09 & .11 & .47 & .52 & .20 \\
\hline .00 & .11 & .10 & .22 & .04 & .33 & .43 & .41 & .74 & .26 & .32 & .27 & .11 & .12 & .19 & .09 & .16 & .36 & .40 & .25 \\
\hline .05 & .19 & .21 & .51 & .37 & .57 & .37 & .40 & .33 & .24 & .41 & .21 & .27 & .14 & .27 & .31 & .36 & .36 & .44 & .41 \\
\hline .16 & .23 & .33 & .26 & .19 & .42 & .36 & .42 & .31 & .17 & .32 & .25 & .28 & .10 & .29 & .23 & .29 & .41 & .42 & .32 \\
\hline .19 & .32 & .44 & .13 & .20 & .28 & .38 & .40 & .31 & .15 & .29 & .30 & .24 & .11 & .24 & .09 & .20 & .50 & .31 & .24 \\
\hline
\end{tabular}

$\begin{array}{lllllllllllllllllllll}.06 & .15 & .13 & .14 & .24 & .22 & .11 & .12 & .18 & .77 & .62 & .59 & .10 & .04 & .19 & .33 & .43 & .13 & .01 & .21\end{array}$

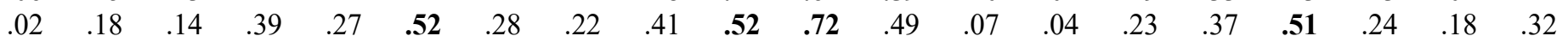

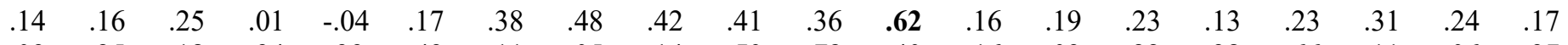

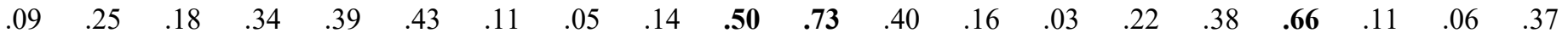

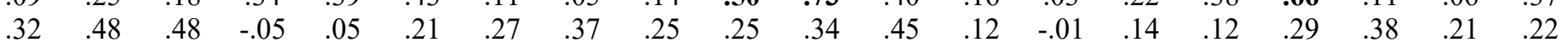

\begin{tabular}{lllllllllllllllllllll}
-.02 & .07 & .08 & .21 & .35 & .22 & .19 & .10 & .08 & .03 & .05 & .02 & .71 & .44 & .52 & .13 & .16 & .34 & .23 & .12 \\
-.05 & .15 & .06 & .29 & .36 & .31 & .20 & .17 & .19 & .14 & .21 & .07 & .46 & .46 & .77 & .19 & .22 & .25 & .19 & .16 \\
-.01 & -.02 & -.01 & .11 & .22 & .13 & .12 & .08 & .07 & .07 & .08 & .05 & .44 & .70 & .63 & .10 & .15 & .20 & .14 & .11 \\
.02 & .07 & .18 & .16 & .17 & .23 & .25 & .26 & .15 & .07 & .13 & .10 & .40 & .36 & .33 & .09 & .12 & .46 & .36 & .10 \\
.18 & .29 & .29 & .13 & .31 & .17 & .18 & .18 & .10 & .18 & .20 & .22 & .30 & .13 & .31 & .23 & .17 & .29 & .12 & .13 \\
& & & & & & & & & & & & & & & & & & & \\
.00 & .11 & .10 & .24 & .30 & .25 & .21 & .18 & .13 & .17 & .25 & .15 & .38 & .26 & .31 & .14 & .33 & .16 & .20 & .18 \\
.00 & .11 & .08 & .40 & .31 & .37 & .19 & .18 & .25 & .32 & .35 & .22 & .31 & .24 & .38 & .25 & .27 & .24 & .21 & .14 \\
.27 & .43 & .33 & .08 & .32 & .18 & .14 & .18 & .06 & .24 & .31 & .28 & .27 & .11 & .30 & .20 & .27 & .35 & .12 & .20 \\
\hline
\end{tabular}


Table 11 (Continued)

TTC $(N=249)$

$\operatorname{SECA}(N=249)$

$\operatorname{SELS}(N=249)$

ISC SInt Grat Zest Cur ASC Grit SSC SEK SoA SER SGM SSW RS RDM SM GM SEf SoA

Self-Management Skills

Time Management

Organizational Skill

Capacity for Consistency

Task Management

Detail Management

Rule-Following Skill

Responsibility Management

Goal Regulation

Decision-Making Skill

Social Engagement Skills

Leadership Skill

Persuasive Skill

Expressive Skill

Conversational Skill

Energy Regulation

Cooperation Skills

Perspective-Taking Skill

Capacity for Trust

Capacity for Social Warmth

Teamwork Skill

Ethical Competence

Emotional Resilience Skills

Stress Regulation

Capacity for Optimism

Anger Management

Confidence Regulation

Impulse Regulation

\begin{tabular}{|c|c|c|c|c|c|c|c|c|c|c|c|c|c|c|c|c|c|c|}
\hline .38 & .27 & .25 & .23 & .28 & .72 & .52 & .22 & .17 & .10 & .25 & .56 & .63 & .18 & .21 & .66 & .15 & .24 & .24 \\
\hline 39 & .34 & .30 & .30 & .27 & .52 & .41 & .23 & .18 & .20 & .25 & .39 & .42 & .28 & .24 & .49 & .23 & .16 & .31 \\
\hline 39 & .25 & .29 & .26 & .40 & .57 & .54 & .23 & .30 & .19 & .39 & .58 & .58 & .24 & .29 & .50 & .22 & .30 & .25 \\
\hline 37 & .31 & .33 & .39 & .45 & .73 & .61 & .33 & .28 & .20 & .41 & .70 & .75 & .29 & .29 & .69 & .32 & .39 & .26 \\
\hline 39 & .38 & .40 & .36 & .49 & .51 & .52 & .33 & .30 & .33 & .30 & .54 & .51 & .36 & .42 & .44 & .29 & .35 & .35 \\
\hline 41 & .35 & .30 & .20 & .29 & .50 & .49 & .23 & .19 & .22 & .26 & .39 & .43 & .25 & .31 & .45 & .20 & .22 & .29 \\
\hline .46 & .40 & .35 & .35 & .43 & .61 & .65 & .28 & .24 & .28 & .26 & .54 & .52 & .31 & .34 & .52 & .26 & .25 & .29 \\
\hline .39 & .43 & .43 & .46 & .55 & .52 & .67 & .35 & .32 & .35 & .31 & .71 & .53 & .39 & .43 & .46 & .38 & .37 & .38 \\
\hline .40 & .40 & .43 & .32 & .47 & .45 & .56 & .29 & .37 & .34 & .31 & .50 & .39 & .31 & .51 & .35 & .29 & .34 & .37 \\
\hline .07 & .31 & .32 & .48 & .45 & .11 & .28 & .17 & .19 & .35 & .07 & .26 & .07 & .34 & .30 & .09 & .35 & .25 & .33 \\
\hline-.02 & .18 & .25 & .33 & .36 & .06 & .18 & .20 & .14 & .24 & .03 & .27 & .02 & .19 & .25 & .03 & .22 & .16 & .22 \\
\hline .16 & .36 & .33 & .44 & .34 & .09 & .21 & .31 & .42 & .38 & .09 & .23 & .06 & .57 & .24 & .11 & .22 & .23 & .51 \\
\hline .20 & .43 & .42 & .55 & .43 & .14 & .27 & .25 & .26 & .42 & .06 & .27 & .10 & .56 & .26 & .16 & .17 & .16 & .46 \\
\hline .31 & .37 & .40 & .56 & .47 & .48 & .59 & .31 & .23 & .31 & .26 & .60 & .47 & .42 & .30 & .44 & .33 & .32 & .38 \\
\hline
\end{tabular}

Innovation Skills

Abstract Thinking Skill

Creative Skill

Artistic Skill

Cultural Competence

Information Processing Skill

Compound Skills

Self-Reflection Skill

$\begin{array}{lllllllll}.38 & . \mathbf{5 6} & .47 & .29 & .37 & .13 & .35 & .21 & .29 \\ .35 & .41 & .35 & .25 & .24 & .10 & .21 & .12 & .18 \\ .36 & . \mathbf{5 4} & \mathbf{. 6 0} & \mathbf{. 5 4} & .43 & .18 & .36 & .30 & .36 \\ .43 & .49 & .46 & .43 & .43 & .33 & .44 & .24 & .25 \\ .40 & .47 & .40 & .36 & .44 & .31 & . \mathbf{5 4} & .29 & .25\end{array}$

$$
.31 \quad .26
$$

Adaptability

$\begin{array}{lllllll}.33 & .16 & .19 & .29 & .17 & .20 & .25 \\ .28 & .31 & .37 & .52 & .36 & .14 & .30 \\ .59 & .37 & .29 & .28 & .29 & .25 & .34 \\ .21 & .25 & .31 & .47 & .30 & .26 & .32 \\ .40 & .30 & .28 & .30 & .33 & .46 & .49\end{array}$

\section{$\begin{array}{lll}.25 & .38 \quad .50\end{array}$}

Capacity for Independence

$\begin{array}{lllllllllllllllllll}.26 & .35 & .35 & .36 & . \mathbf{5 8} & .14 & .33 & .26 & .25 & .36 & .11 & .36 & .13 & .33 & .39 & .12 & .30 & .25 & .35 \\ .28 & .37 & .36 & .44 & .55 & .17 & .34 & .25 & .15 & .31 & .16 & .33 & .12 & .30 & .44 & .13 & .40 & .35 & .27 \\ .27 & .25 & .22 & .28 & .37 & .05 & .18 & .15 & .17 & .21 & .14 & .20 & .03 & .22 & .30 & .06 & .34 & .20 & .18 \\ .34 & .34 & .36 & .29 & .42 & .15 & .29 & .27 & .26 & .46 & .14 & .30 & .10 & .35 & .34 & .14 & .27 & .22 & .36 \\ .29 & .23 & .23 & .25 & .46 & .34 & .38 & .25 & .23 & .22 & .39 & .52 & .41 & .19 & .33 & .29 & .44 & .50 & .24 \\ & & & & & & & & & & & & & & & & & \\ .23 & .28 & .33 & .31 & .37 & .12 & .27 & .40 & .57 & .35 & .16 & .31 & .12 & .41 & .26 & .11 & .20 & .21 & .36 \\ .29 & .38 & .38 & .47 & .48 & .11 & .24 & .28 & .24 & .36 & .25 & .33 & .12 & .40 & .28 & .14 & .25 & .27 & .32 \\ .33 & .31 & .34 & .38 & .47 & .42 & .51 & .38 & .39 & .29 & .37 & .55 & .45 & .34 & .41 & .39 & .40 & .38 & .34\end{array}$


Note. BFI-2 = Big Five Inventory-2. PYD-SF = Positive Youth Development-Short Form. TTC = Tripartite Taxonomy of Character. SECA $=$ Social and Emotional Competency Assessment. SELS = Social-Emotional Learning Surveys. COr = Conscientiousness: Organization. CPr $=$ Conscientiousness: Productiveness. $\mathrm{CRe}=$ Conscientiousness: Responsibility. ESo $=$ Extraversion: Sociability. EAs $=$ Extraversion: Assertiveness. EEL $=$ Extraversion: Energy Level. ACo $=$ Agreeableness: Compassion. ARe $=$ Agreeableness: Respectfulness. ATr $=$ Agreeableness: Trust. SAn = Emotional Stability: Anxiety (reversed). SDe = Emotional Stability: Depression (reversed). SEV = Emotional Stability: Emotional Volatility (reversed). OIC = Open-Mindedness: Intellectual Curiosity. OAS = Open-Mindedness: Aesthetic Sensitivity. $\mathrm{OCI}=$ Open-Mindedness: Creative Imagination. $\mathrm{Cmp}=$ Competence. $\mathrm{Cnf}=$ Confidence. Cha $=$ Character. Car $=\mathrm{Caring} . \mathrm{Cnn}=\mathrm{Connection}$. ISC $=$ Interpersonal Self-Control. Sint $=$ Social Intelligence. Grat $=$ Gratitude. Cur $=$ Curiosity. ASC $=$ Academic Self-Control. SM $=$ SelfManagement. GM = Growth Mindset. Sef = Self-Efficacy. Soa = Social Awareness. SSC = Self-Awareness: Self-Concept. SEK = SelfAwareness: Emotional Knowledge. SER = Self-Management: Emotion Regulation. SGM = Self-Management: Goal Management. SSW = Self-Management: School Work. RS = Relationship Skills. RD = Responsible Decision-Making. Correlations of .13 or stronger are statistically significant $(p<.05)$, and correlations of .50 or stronger are bolded. 
Table 12

Regressions of Domain-Level Convergent Measures on the BESSI Skill Facets (Study 4)

\begin{tabular}{|c|c|c|c|c|c|c|}
\hline & $\beta$ Predictor 1 & $\beta$ Predictor 2 & $\beta$ Predictor 3 & $\beta$ Predictor 4 & $\beta$ Predictor 5 & $R^{2}$ \\
\hline BFI-2 C & .20 Time Management & .41 Organizational Skill & .38 Task Management & -.14 Adaptability & & .69 \\
\hline BFI-2 E & .49 Leadership Skill & .39 Conversational Skill & -.22 Decision-Making Skill & .17 Capacity for Optimism & & .71 \\
\hline BFI-2 A & .49 Capacity for Trust & .32 Perspective-Taking Skill & -.33 Persuasive Skill & .17 Detail Management & & .65 \\
\hline BFI-2 ES & .47 Stress Regulation & .22 Capacity for Optimism & -.23 Abstract Thinking Skill & .17 Anger Management & .19 Confidence Regulation & .71 \\
\hline BFI-2 OM & .43 Artistic Skill & .38 Abstract Thinking Skill & .24 Creative Skill & -.18 Information Processing & & .68 \\
\hline PYD Cmp & .27 Confidence Regulation & .22 Energy Regulation & & & & .18 \\
\hline PYD Cnf & .66 Confidence Regulation & & & & & .43 \\
\hline PYD Cha & .38 Ethical Competence & .31 Cultural Competence & & & & .34 \\
\hline PYD Car & .41 Perspective-Taking Skill & .19 Teamwork Skill & & & & .29 \\
\hline PYD Cnn & .28 Cap. for Social Warmth & .20 Time Management & .20 Confidence Regulation & & & .25 \\
\hline TTC Inter & .42 Cap. for Social Warmth & .26 Anger Management & .25 Decision-Making Skill & & & .50 \\
\hline TTC Intel & .23 Energy Regulation & .28 Creative Skill & .28 Conversational Skill & .23 Detail Management & & .53 \\
\hline TTC Intra & .49 Task Management & .39 Responsibility Man. & & & & .62 \\
\hline SECA SeA & .45 Confidence Regulation & .35 Cap. for Self-Reflection & & & & .47 \\
\hline SECA SoA & .40 Perspective-Taking Skill & .32 Cap. For Social Warmth & & & & .41 \\
\hline SECA SM & .60 Task Management & .22 Cap. for Consistency & & & & .58 \\
\hline SECA RS & .28 Cap. for Social Warmth & .36 Expressive Skill & .22 Teamwork Skill & & & .49 \\
\hline SECA RD & .41 Decision-Making Skill & .29 Creative Skill & & & & .34 \\
\hline SELS SM & .44 Task Management & .34 Time Management & & & & .53 \\
\hline SELS GM & .33 Information Processing & .22 Artistic Skill & .21 Confidence Regulation & & & .29 \\
\hline SELS SEf & .43 Information Processing & .26 Confidence Regulation & & & & .31 \\
\hline SELS SoA & .34 Cap. for Social Warmth & .28 Expressive Skill & .22 Anger Management & & & .42 \\
\hline
\end{tabular}

Note. $N=313$ for BFI-2. $N=312$ for PYD. $N=249$ for TTC, SELS, and SECA. BFI-2 = Big Five Inventory-2. PYD = Positive Youth Development-Short Form. $\mathrm{TTC}=$ Tripartite Taxonomy of Character. SECA $=$ Social and Emotional Competency Assessment. SELS $=$ Social-Emotional Learning Surveys. C $=$

Conscientiousness. $\mathrm{E}=$ Extraversion. $\mathrm{A}=$ Agreeableness. $\mathrm{ES}=$ Emotional Stability (vs. Negative Emotionality). OM= Open-Mindedness. Cmp $=$ Competence.

$\mathrm{Cnf}=$ Confidence. $\mathrm{Cha}=$ Character. $\mathrm{Car}=$ Caring. $\mathrm{Cnn}=$ Connection. Inter $=$ Interpersonal Strengths. Intel $=$ Intellectual Strengths. Intra $=$ Intrapersonal Strengths. SeA = Self-Awareness. SoA = Social Awareness. SM = Self-Management. RS = Relationship Skills. RD = Responsible Decision-Making. GM= Growth Mindset. SEf = Self-Efficacy. Cap. $=$ Capacity. Man. = Management. Values are standardized regression coefficients $(\beta \mathrm{s})$ from the final regression equation for each convergent measure. Predictors are listed in their order of entry. 
Table 13

Testing the Incremental Validity of SEB Skill Domains and Big Five Personality Traits (Study 4)

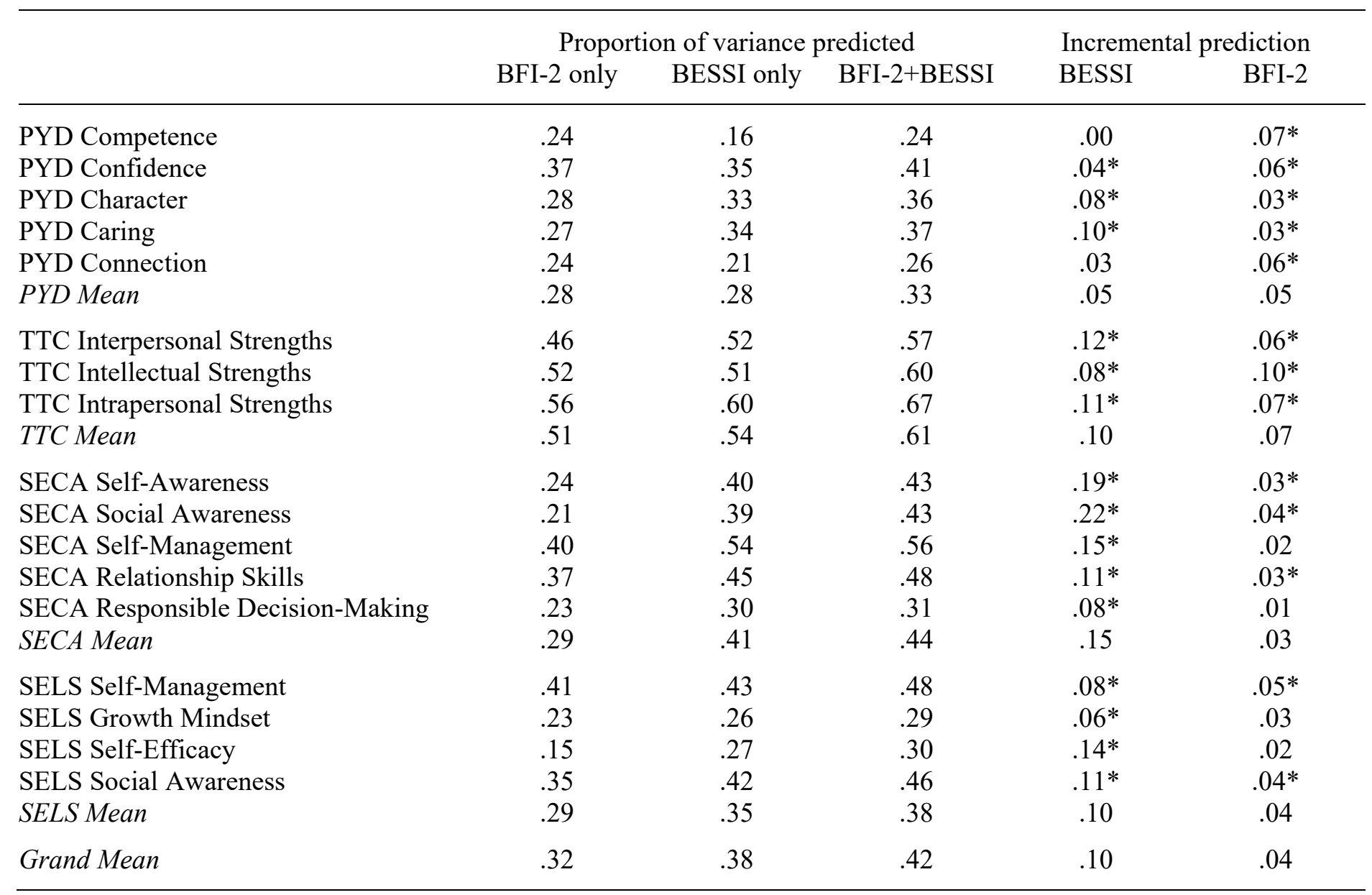

Note. $N=312$ for PYD. $N=249$ for TTC, SECA, and SELS. $* p<.05$. BESSI = Behavioral, Emotional, and Social Skills Inventory. BFI-2 = Big Five Inventory-2. PYD = Positive Youth Development-Short Form. TTC = Tripartite Taxonomy of Character. SECA = Social and Emotional Competency Assessment. SELS = Social-Emotional Learning Surveys. 
Table 14

Correlations of the BESSI Skill Domains with Student Outcomes (Study 5)

\begin{tabular}{|c|c|c|c|c|c|c|c|c|c|c|c|c|c|c|c|c|c|}
\hline & $\begin{array}{l}\text { Winter } \\
\text { GPA }\end{array}$ & $\begin{array}{c}\text { Spring } \\
\text { GPA }\end{array}$ & $\begin{array}{c}\text { Acad. } \\
\text { engage. }\end{array}$ & $\begin{array}{c}\text { Real. } \\
\text { interests }\end{array}$ & $\begin{array}{l}\text { Invest. } \\
\text { interests }\end{array}$ & $\begin{array}{l}\text { Artistic } \\
\text { interests }\end{array}$ & $\begin{array}{c}\text { Social } \\
\text { interests }\end{array}$ & $\begin{array}{c}\text { Enter. } \\
\text { interests }\end{array}$ & $\begin{array}{l}\text { Conven. } \\
\text { interests }\end{array}$ & $\begin{array}{c}\text { Peer } \\
\text { accept. }\end{array}$ & $\begin{array}{l}\text { Friend. } \\
\text { quality }\end{array}$ & $\begin{array}{l}\text { Roman. } \\
\text { quality }\end{array}$ & $\begin{array}{l}\text { Mother } \\
\text { quality }\end{array}$ & $\begin{array}{l}\text { Father } \\
\text { quality }\end{array}$ & $\begin{array}{l}\text { Volun- } \\
\text { teerism }\end{array}$ & Exercise & $\begin{array}{c}\text { Life } \\
\text { satisfac. }\end{array}$ \\
\hline Self-Management & $.23 / .22$ & $.15 / .14$ & $.61 / .61$ & $.19 / .19$ & $.17 / .17$ & $.16 / .16$ & $.30 / .32$ & $.32 / .32$ & $.21 / .20$ & $.28 / .29$ & $.30 / .31$ & $.06 / .04$ & $.25 / .24$ & $.22 / .22$ & $.27 / .27$ & $.17 / .19$ & $.36 / .36$ \\
\hline Social Engagement & $.07 / .06$ & $.05 / .05$ & $.38 / .37$ & $.15 / .15$ & $.11 / .11$ & $.09 / .10$ & $.28 / .31$ & $.34 / .34$ & $.15 / .14$ & $.50 / .50$ & $.33 / .35$ & $.03 / .02$ & $.13 / .12$ & $.09 / .08$ & $.25 / .25$ & $.33 / .34$ & $.35 / .35$ \\
\hline Cooperation & $.09 / .08$ & $.06 / .05$ & $.39 / .39$ & $.15 / .16$ & $.12 / .12$ & $.20 / .20$ & $.35 / .36$ & $.26 / .26$ & $.15 / .15$ & $.35 / .35$ & $.41 / .42$ & $.11 / .11$ & $.16 / .17$ & $.11 / .11$ & $.29 / .29$ & $.15 / .17$ & $.31 / .31$ \\
\hline \multicolumn{18}{|l|}{ Emotional } \\
\hline Resilience & $.01 / .03$ & $-.03 /-.01$ & $.50 / .52$ & $.27 / .22$ & $.11 / .13$ & $.09 / .15$ & $.13 / .23$ & $.28 / .31$ & $.22 / .19$ & $.40 / .39$ & $.20 / .29$ & $.04 / .02$ & $.23 / .19$ & $.23 / .19$ & $.13 / .18$ & $.18 / .16$ & $.45 / .44$ \\
\hline Gender & .08 & .09 & -.01 & -.20 & .06 & .19 & .32 & .08 & -.11 & -.08 & .25 & -.06 & -.16 & -.17 & .17 & -.12 & -.11 \\
\hline Grade level & .17 & .09 & .15 & -.01 & .01 & .00 & .03 & .05 & .06 & .02 & .09 & .11 & .02 & -.02 & .11 & -.12 & .06 \\
\hline$N$ & 469 & 458 & 380 & 380 & 380 & 380 & 380 & 380 & 380 & 379 & 378 & 95 & 373 & 371 & 379 & 248 & 379 \\
\hline
\end{tabular}

Note. Values left of the forward slash are zero-order correlations. Values right of the forward slash are partial correlations controlling for gender $($ coded $-1=$ male, $1=$ female $)$ and grade level. Acad. engage. $=$ Academic engagement. Real. $=$ Realistic. Invest. $=$ Investigative. Enter. $=$ Enterprising. Accept. $=$ Acceptance. Satisfac. $=$ Satisfaction. Statistically significant $(p<.05)$ correlations are bolded. 
Table 15

Regressions of Student Outcomes on the BESSI Skill Domains (Study 5)

\begin{tabular}{|c|c|c|c|c|c|c|c|c|c|c|c|c|c|c|c|c|c|}
\hline & $\begin{array}{c}\text { Winter } \\
\text { GPA }\end{array}$ & $\begin{array}{c}\text { Spring } \\
\text { GPA }\end{array}$ & $\begin{array}{c}\text { Acad. } \\
\text { engage. }\end{array}$ & $\begin{array}{c}\text { Real. } \\
\text { interests i }\end{array}$ & $\begin{array}{l}\text { Invest. } \\
\text { interests }\end{array}$ & $\begin{array}{l}\text { Artistic } \\
\text { interests }\end{array}$ & $\begin{array}{c}\text { Social } \\
\text { interests }\end{array}$ & $\begin{array}{c}\text { Enter. } \\
\text { interests }\end{array}$ & $\begin{array}{l}\text { Conven. } \\
\text { interests }\end{array}$ & $\begin{array}{c}\text { Peer } \\
\text { accept. }\end{array}$ & $\begin{array}{l}\text { Friend. } \\
\text { quality }\end{array}$ & $\begin{array}{l}\text { Roman. } \\
\text { quality }\end{array}$ & $\begin{array}{l}\text { Mother } \\
\text { quality }\end{array}$ & $\begin{array}{l}\text { Father } \\
\text { quality }\end{array}$ & $\begin{array}{l}\text { Volun- } \\
\text { teerism }\end{array}$ & Exercise & $\begin{array}{c}\text { Life } \\
\text { satisfac. }\end{array}$ \\
\hline Self-Management & $.53 / .50$ & $.41 / .39$ & $.64 / .62$ & $-.03 /-.01$ & $.06 / .06$ & $-.21 /-.24$ & $.19 / .13$ & $.17 / .15$ & $.10 / .10$ & $-.11 /-.12$ & $.13 / .08$ & $.00 /-.03$ & $.32 / .33$ & $.35 / .37$ & $.21 / .17$ & $.05 / .08$ & $.17 / .18$ \\
\hline Social Engagement & $.00 / .00$ & $.05 / .05$ & $.04 / .04$ & $-.02 /-.02$ & $.01 / .00$ & $-.13 /-.14$ & $.15 / .13$ & $.25 / .23$ & $.00 /-.01$ & $.44 / .44$ & $.16 / .15$ & $-.07 /-.05$ & $-.03 /-.02$ & $-.05 /-.05$ & $.13 / .12$ & $.45 / .43$ & $.15 / .16$ \\
\hline Cooperation & $-.04 /-.04$ & $.01 / .00$ & $-.11 /-.11$ & $-.07 /-.04-$ & $-.10 /-.10$ & $-.01 /-.03$ & $.24 / .21$ & $-.08 /-.09$ & $-.05 /-.03$ & $3.08 / .08$ & $.38 / .34$ & $.21 / .21$ & $.05 / .08$ & $.02 / .04$ & $.16 / .15$ & $-.19 /-.15$ & $.05 / .04$ \\
\hline Emotional Resilience & $-.29 /-.27$ & $-.29 /-.26$ & $.13 / .14$ & $.30 / .20$ & $.02 / .04$ & $.04 / .10$ & $-.30 /-.16$ & $.02 / .08$ & $.15 / .09$ & $.20 / .18$ & $-.20 /-.07$ & $7-.01 /-.10$ & $.09 / .00$ & $.14 / .06$ & $-.24 /-.18$ & $8-.02 /-.12$ & $.31 / .30$ \\
\hline Innovation & $-.09 /-.10$ & $-.14 /-.14$ & $-.10 /-.10$ & $.10 / .13$ & $.24 / .25$ & $.64 / .63$ & $.09 / .06$ & $.06 / .05$ & $.07 / .09$ & $-.09 /-.08$ & $-.07 /-.11$ & $1-.07 / .00$ & $-.24 /-.22$ & $-.33 /-.30$ & $.07 / .06$ & $-.01 / .03$ & $-.23 /-.23$ \\
\hline Gender & .03 & .04 & .05 & -.17 & .04 & .13 & .26 & .11 & -.09 & -.02 & .24 & -.12 & -.14 & -.11 & .11 & -.15 & .00 \\
\hline Grade level & .14 & .06 & .06 & -.04 & -.02 & -.02 & -.01 & .01 & .03 & -.01 & .06 & .10 & -.01 & -.05 & .08 & -.13 & .00 \\
\hline$R^{2}$ & $.11 / .13$ & $.07 / .07$ & $.40 / .39$ & $.08 / .10$ & $.06 / .06$ & $.24 / .26$ & $.17 / .23$ & $.14 / .14$ & $.06 / .06$ & $.27 / .27$ & $.19 / .23$ & $.02 / .04$ & $.10 / .10$ & $.12 / .12$ & $.12 / .14$ & $.12 / .14$ & $.24 / .25$ \\
\hline$N$ & 469 & 467 & 380 & 380 & 380 & 380 & 380 & 380 & 380 & 379 & 378 & 95 & 373 & 371 & 379 & 248 & 379 \\
\hline
\end{tabular}

Note. Values left of the forward slash are standardized regression coefficients, without gender and grade level included as covariates. Values right of the forward slash are standardized regression coefficients, with gender (coded $-1=$ male, $1=$ female) and grade level included as covariates. Acad. engage. $=$ Academic engagement. Real. $=$ Realistic. Invest. $=$ Investigative. Enter. $=$ Enterprising. Accept. $=$ Acceptance. Satisfac. $=$ Satisfaction. Statistically significant $(p<.05)$ coefficients are bolded. 
Table 16

Correlations of the BESSI Skill Facets with Student Outcomes (Study 5)

Winter Spring Acad. Real. Invest. Artistic Social Enter. Conven. Peer Friend. Roman. Mother Father Volun-

GPA GPA engage. interests interests interests interests interests interests accept. quality quality quality quality teerism Exercise satisfac.

Self-Management Skills

Time Management

Organizational Skill

Capacity for Consistency

Task Management

Detail Management

Rule-Following Skill

Responsibility Management

Goal Regulation

Decision-Making Skill

Social Engagement Skills

Leadership Skill

Persuasive Skill

Expressive Skill

Conversational Skill

Energy Regulation

Cooperation Skills

Perspective-Taking Skill

Capacity for Trust

Capacity for Social Warmth

Teamwork Skill

Ethical Competence

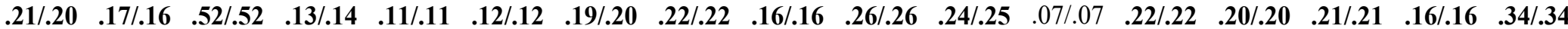
$\begin{array}{lllllllllllllllll}.12 / .11 & .08 / .07 & .44 / .44 & .13 / .15 & .07 / .06 & .12 / .11 & .24 / .22 & .27 / .27 & .14 / .14 & .24 / .24 & .26 / .24 & .10 / .10 & .19 / .21 & .12 / .13 & .15 / .14 & .10 / .12 & .25 / .26\end{array}$ $\begin{array}{lllllllllllllllll}.22 / .20 & .13 / .12 & .46 / .45 & .18 / .19 & .09 / .09 & .13 / .14 & .22 / .23 & .24 / .24 & .22 / .21 & .12 / .12 & .18 / .18 & .12 / .10 & .15 / .14 & .22 / .22 & .24 / .24 & .09 / .10 & .25 / .25\end{array}$

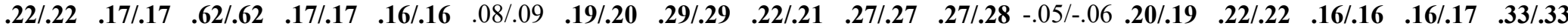
$\begin{array}{lllllllllllllllll}.21 / .19 & .12 / .10 & .54 / .53 & .15 / .16 & .20 / .20 & .20 / .20 & .32 / .32 & .27 / .27 & .19 / .19 & .22 / .22 & .29 / .28 & .08 / .07 & .21 / .21 & .19 / .20 & .26 / .25 & .13 / .15 & .26 / .26\end{array}$

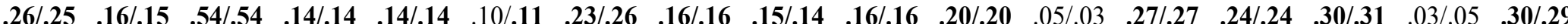
$\begin{array}{llllllllllllllllll}.21 / .19 & .14 / .12 & .50 / .49 & .15 / .17 & .11 / .11 & .11 / .10 & .32 / .31 & . .32 / .32 & .17 / .17 & . .31 / .32 & .39 / .38 & .10 / .09 & .20 / .21 & .17 / .19 & .28 / .26 & .18 / .21 & .33 / .33\end{array}$ $\begin{array}{lllllllllllllllll}.20 / .19 & .13 / .12 & .55 / .55 & .14 / .15 & .14 / .14 & .13 / .13 & .28 / .28 & .34 / .33 & .16 / .16 & .30 / .31 & .27 / .27 & -.03 /-.03 & .25 / .26 & .17 / .18 & .21 / .21 & .21 / .23 & .36 / .37\end{array}$ $\begin{array}{llllllllllllllllll}.15 / .14 & .08 / .08 & .43 / .42 & .13 / .12 & .16 / .16 & .16 / .18 & .27 / .30 & .24 / .25 & .12 / .11 & .19 / .19 & .19 / .21 & .04 / .02 & .16 / .16 & .16 / .16 & .24 / .25 & .06 / .07 & .27 / .26\end{array}$

$\begin{array}{llllllllllllllllllll}.16 / .15 & .13 / .12 & .39 / .39 & .13 / .14 & .13 / .13 & .14 / .14 & .30 / .31 & .38 / .37 & .17 / .17 & .42 / .43 & .26 / .25 & .01 / .00 & .15 / .16 & .06 / .07 & .30 / .29 & .34 / .36 & .30 / .30\end{array}$

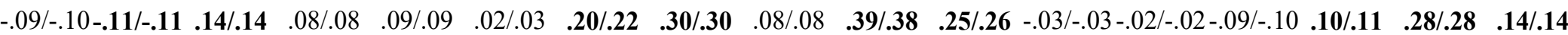
$\begin{array}{lllllllllllllllll}.07 / .07 & .04 / .04 & \mathbf{2 9} / .29 & .09 / .08 & .04 / .05 & .09 / .10 & \mathbf{. 1 9} / .22 & \mathbf{. 1 2} / .13 & .09 / .09 & \mathbf{. 3 0} / .30 & \mathbf{. 2 3} / .25 & .07 / .06 & \mathbf{. 1 1} / .10 & \mathbf{. 1 7} / .16 & \mathbf{. 1 1} / .12 & \mathbf{. 1 8} / . \mathbf{1 8} & \mathbf{. 3 6} / . \mathbf{3 5}\end{array}$ $\begin{array}{lllllllllllllllll}.03 / .03 & .05 / .05 & .22 / .21 & .13 / .13 & .09 / .09 & .03 / .04 & \mathbf{. 1 9} / .22 & \mathbf{. 2 6} / .27 & .08 / .07 & \mathbf{. 4 4} / .43 & \mathbf{. 2 8} / .30 & .04 / .03 & .08 / .07 & .03 / .02 & . \mathbf{2 2} / .23 & \mathbf{. 2 3} / .23 & \mathbf{. 2 3} / .23\end{array}$

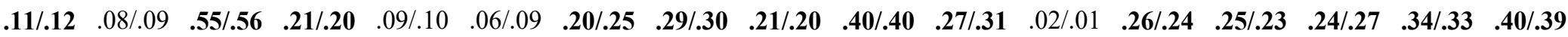

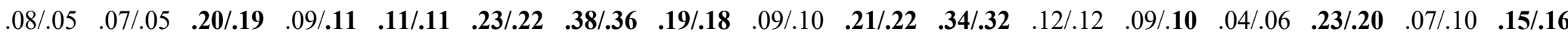
$\begin{array}{llllllllllllllllll}.06 / .06 & .02 / .03 & \mathbf{2 4} / .23 & .06 / .04 & .02 / .02 & .06 / .08 & \mathbf{. 1 5} / .20 & .05 / .06 & .06 / .05 & \mathbf{. 2 2} / .21 & \mathbf{. 2 9} / .33 & \mathbf{. 2 1} / .21 & .10 / .08 & \mathbf{. 1 5} / .13 & \mathbf{. 2 4} / .26 & .09 / .09 & \mathbf{. 2 7} / .26\end{array}$

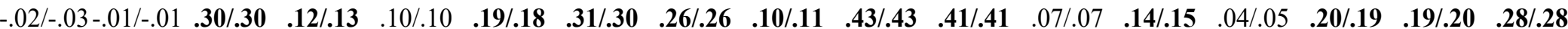
$\begin{array}{lllllllllllllllllll}.17 / .16 & .09 / .09 & .49 / .48 & .19 / .19 & .12 / .12 & .14 / .15 & .29 / .31 & .33 / .33 & .21 / .20 & .36 / .35 & .29 / .30 & .01 / .00 & .17 / .17 & .12 / .12 & .28 / .28 & .18 / .19 & .31 / .31\end{array}$ $\begin{array}{llllllllllllllllll}.14 / .11 & .06 / .05 & .46 / .45 & .19 / .19 & .18 / .18 & .20 / .21 & .31 / .34 & .25 / .25 & .20 / .19 & .17 / .17 & .31 / .31 & .05 / .03 & .22 / .22 & .10 / .10 & .25 / .24 & .07 / .09 & .27 / .26\end{array}$

Emotional Resilience Skills

Stress Regulation

Capacity for Optimism

Anger Management

Confidence Regulation

Impulse Regulation

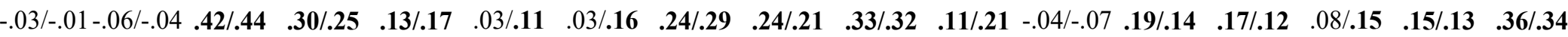
$\begin{array}{lllllllllllllllll}.01 / .02 & -.02 / .00 & \mathbf{. 4 4} / .45 & \mathbf{. 2 3} / .20 & .08 / .09 & .08 / .12 & \mathbf{. 1 7} / .24 & \mathbf{. 2 4} / .27 & \mathbf{. 1 8} / .17 & \mathbf{. 3 8} / .37 & \mathbf{. 2 2} / .28 & .07 / .06 & . \mathbf{2 5} / .23 & \mathbf{. 1 8} / .15 & \mathbf{. 1 6} / .20 & \mathbf{. 1 7} / .15 & \mathbf{. 4 4} / .43\end{array}$ $\begin{array}{llllllllllllllllll}.08 / .09 & .01 / .03 & \mathbf{. 3 0} / .30 & \mathbf{. 1 7} / .13 & \mathbf{. 1 0} / .12 & \mathbf{. 1 1} / .16 & .10 / .19 & \mathbf{. 1 3} / .15 & \mathbf{. 1 2} / .09 & \mathbf{. 2 2} / .20 & \mathbf{. 1 1} / .17 & .12 / .10 & \mathbf{. 1 3} / .09 & \mathbf{. 1 5} / .12 & \mathbf{. 1 7} / .22 & .05 / .04 & \mathbf{. 2 8} / .26\end{array}$ $\begin{array}{lllllllllllllllll}-.04 /-.03 & -.04 /-.03 & \mathbf{4 8} / .49 & \mathbf{. 1 8} / .16 & .05 / .06 & .06 / .09 & .09 / .15 & \mathbf{. 2 9} / .30 & \mathbf{. 1 8} / .17 & \mathbf{. 4 4} / .44 & \mathbf{. 2 5} / .30 & -.01 /-.02 & \mathbf{. 2 1} / .19 & \mathbf{. 2 5} / .23 & .00 / .03 & \mathbf{. 1 9} / .18 & \mathbf{. 4 6} / .45\end{array}$ $\begin{array}{lllllllllllllllllll}.09 / .10 & .04 / .05 & .43 / .43 & .21 / .19 & .12 / .13 & .10 / .13 & .18 / .24 & .24 / .26 & .16 / .15 & .17 / .16 & .10 / .14 & .07 / .06 & .13 / .11 & .16 / .15 & .12 / .14 & .17 / .17 & .23 / .22\end{array}$

Innovation Skills

Abstract Thinking Skill

Creative Skill

Artistic Skill

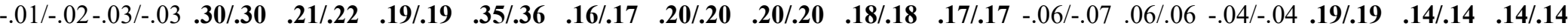
$\begin{array}{lllllllllllllllll}.02 / .00 & -.02 /-.04 & \mathbf{1 8} / .18 & .04 / .08 & .10 / .09 & \mathbf{. 5 6} / .54 & \mathbf{. 2 2} / .17 & \mathbf{. 1 7} / .15 & .09 / .11 & .08 / .10 & .09 / .05 & -.02 /-.01 & -.06 /-.03 & -.06 /-.03 & .016 / .13 & .07 / .10 & .02 / .04\end{array}$ $\begin{array}{llllllllllllllllll}.08 / .06 & .04 / .02 & \mathbf{. 2 1} / .21 & \mathbf{. 1 2} / .17 & \mathbf{. 1 9} / .18 & \mathbf{. 2 8} / .25 & \mathbf{. 3 7 / . 3 3} & \mathbf{. 2 4} / .22 & .10 / .12 & \mathbf{. 1 4} / .16 & \mathbf{. 3 0} / .26 & .16 / .17 & .01 / .05 & -.07 /-.04 & .23 / .19 & .05 / .08 & .07 / .09\end{array}$

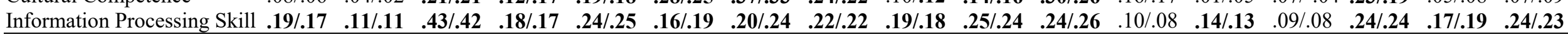


Table 16 (Continued)

Winter Spring Acad. Real. Invest. Artistic Social Enter. Conven. Peer Friend. Roman. Mother Father Volun-

GPA GPA engage. interests interests interests interests interests interests accept. quality quality quality quality teerism Exercise satisfac.

Compound Skills

Self-Reflection Skill

Adaptability

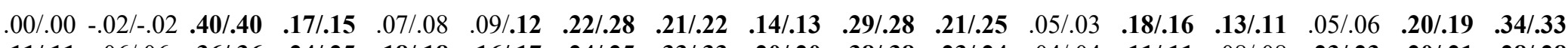

Capacity for Independence

$\begin{array}{llllllllllllllllll}.11 / .11 & .06 / .06 & .36 / .36 & .24 / .25 & .18 / .18 & .16 / .17 & .24 / .25 & .33 / .33 & .20 / .20 & .38 / .38 & .23 / .24 & .04 / .04 & .11 / .11 & .08 / .08 & .23 / .23 & .20 / .21 & .28 / .28\end{array}$

Demographic predictors

\begin{tabular}{|c|c|c|c|c|c|c|c|c|c|c|c|c|c|c|c|c|c|}
\hline Gender & .08 & .09 & -.01 & -.20 & .06 & .19 & .32 & .08 & -.11 & -.08 & .25 & -.07 & -.16 & -.16 & .17 & -.12 & -.11 \\
\hline Grade level & .17 & .09 & .15 & -.01 & .01 & .00 & .03 & .05 & .06 & .02 & .09 & .11 & .02 & -.02 & .11 & -.12 & .06 \\
\hline$N$ & 469 & 458 & 380 & 380 & 380 & 380 & 380 & 380 & 380 & 379 & 378 & 95 & 373 & 371 & 379 & 248 & 379 \\
\hline
\end{tabular}

Note. Values left of the forward slash are zero-order correlations. Values right of the forward slash are partial correlations controlling for gender (coded $-1=$ male, $1=$ female $)$ and grade level. Acad. engage. $=$ Academic engagement. Real. $=$ Realistic. Invest. $=$ Investigative. Enter. $=$ Enterprising. Accept. $=$ Acceptance.

Satisfac. $=$ Satisfaction. Statistically significant $(p<.05)$ correlations are bolded. 
Table 17

Regressions of Student Outcomes on the BESSI Skill Facets (Study 5)

\begin{tabular}{|c|c|c|c|c|c|}
\hline & $\beta$ Predictor 1 & $\beta$ Predictor 2 & $\beta$ Predictor 3 & $\beta$ Predictor 4 & $R^{2}$ \\
\hline Winter GPA & .26 Rule-Following Skill & -.22 Cap. for Social Warmth & .33 Leadership Skill & -.21 Persuasive Skill & .15 \\
\hline Spring GPA & .24 Task Management & -.32 Persuasive Skill & .30 Leadership Skill & -.20 Stress Regulation & .13 \\
\hline Academic engagement & .46 Task Management & .26 Rule-Following Skill & & & .43 \\
\hline Realistic interests & .30 Stress Regulation & & & & .09 \\
\hline Investigative interests & .24 Information Processing & & & & .06 \\
\hline Artistic interests & .56 Artistic Skill & & & & .31 \\
\hline Social interests & .23 Perspective-Taking Skill & .23 Cultural Competence & & & .17 \\
\hline Enterprising interests & .27 Leadership Skill & .19 Goal Regulation & & & .17 \\
\hline Conventional interests & .24 Stress Regulation & & & & .06 \\
\hline Peer acceptance & .31 Confidence Regulation & .30 Conversational Skill & & & .27 \\
\hline Friendship quality & .29 Cap. for Social Warmth & .34 Responsibility Man. & -.21 Impulse Regulation & & .23 \\
\hline Romantic quality & No predictors & & & & - \\
\hline Mother quality & .27 Rule-Following Skill & & & & .07 \\
\hline Father quality & .35 Confidence Regulation & -.24 Persuasive Skill & & & .11 \\
\hline Volunteerism & .31 Rule-Following Skill & .32 Leadership Skill & -.28 Confidence Regulation & & .19 \\
\hline Exercise & .34 Energy Regulation & & & & .11 \\
\hline Life satisfaction & .30 Confidence Regulation & .23 Capacity For Optimism & & & .24 \\
\hline
\end{tabular}

Note. $N=469$ for winter GPA. $N=458$ for spring GPA. $N=380$ for academic engagement and occupational interests. $N=379$ for peer acceptance, volunteerism, and life satisfaction. $N=378$ for friendship quality. $N=373$ for Mother relationship quality. $N=371$ for father relationship quality. $N$ $=248$ for exercise. $N=95$ for romantic relationship quality. Cap. $=$ Capacity. Man. $=$ Management. Values are standardized regression coefficients $(\beta \mathrm{s})$ from the final regression equation for each outcome measure. Predictors are listed in their order of entry. 
Figure 1

Proposed Domain-Level Structure of the Behavioral, Emotional, and Social Skills Inventory (BESSI)

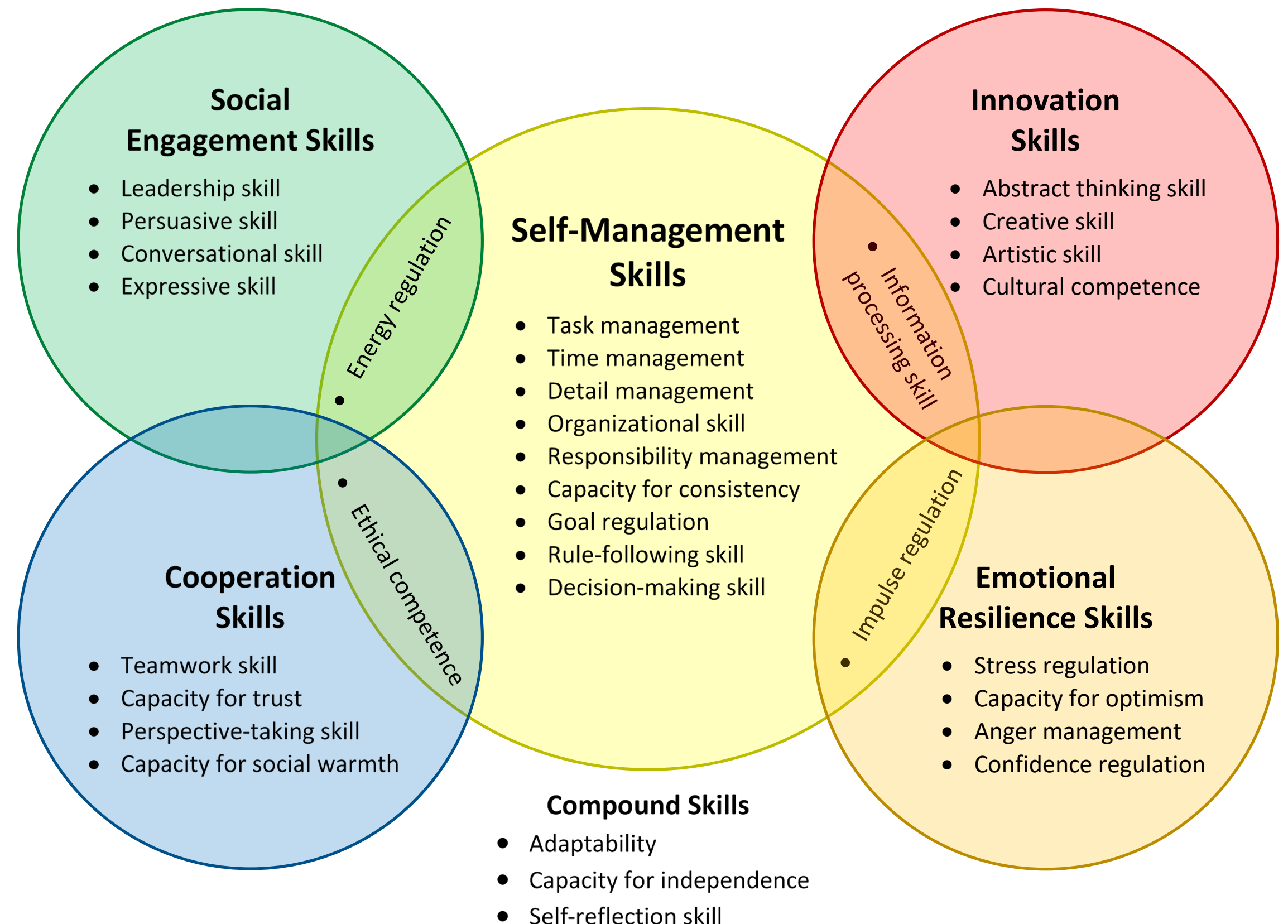

